\title{
International Union of Basic and Clinical Pharmacology. XC. Multisite Pharmacology: Recommendations for the Nomenclature of Receptor Allosterism and Allosteric Ligands
}

Arthur Christopoulos, Jean-Pierre Changeux, William A Catterall, Doriano Fabbro, Thomas P. Burris, John A Cidlowski, Richard W. Olsen, John A. Peters, Richard R. Neubig, Jean-Philippe Pin, Patrick M. Sexton, Terry P. Kenakin, Frederick J. Ehlert, Michael Spedding, and Christopher J. Langmead

Drug Discovery Biology and Department of Pharmacology, Monash Institute of Pharmaceutical Sciences, Monash University, Parkville, Victoria, Australia (A.C., P.M.S., C.J.L.); Collège de France and CNRS URA 2182, Institut Pasteur, Paris, France (J.-P.C.); Department of Pharmacology, School of Medicine, University of Washington, Seattle, Washington (W.A.C.); PIQUR Therapeutics AG, Basel, Switzerland (D.F.); Department of Pharmacological \& Physiological Science, Saint Louis University School of Medicine, St. Louis, Louisiana (T.P.B.); Signal Transduction Laboratory, Molecular Endocrinology Group, National Institute of Environmental Health Sciences, Research Triangle Park, North Carolina (J.A.C.); Department of Molecular and Medical Pharmacology, University of California, Los Angeles, California (R.W.O.); Division of Neuroscience, School of Medicine, University of Dundee, Scotland, United Kingdom (J.A.P.); Department of Pharmacology and Toxicology, Michigan State University, East Lansing, Michigan (R.R.N.); Institut de Genomique Fonctionelle, CNRS, Montpellier, France (J.-P.P.); Department of Pharmacology, University of North Carolina, Chapel Hill, North Carolina (T.P.K.); Department of Pharmacology, University of California, Irvine, California (F.J.E.); and Research Solutions SARL, Paris, France (M.S.)

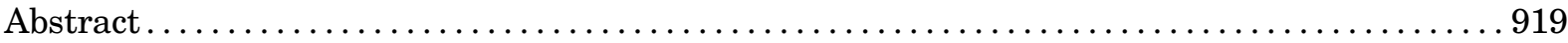

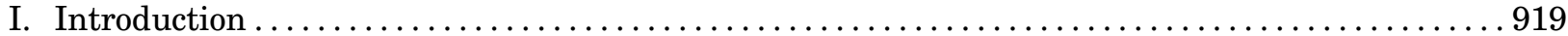

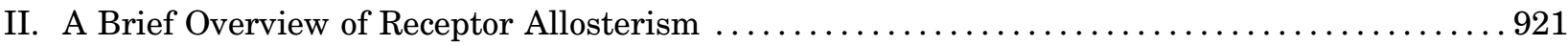

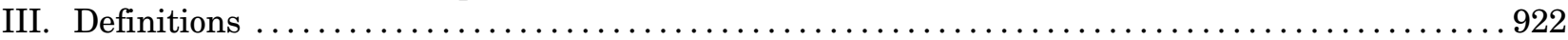

IV. Some Representative Examples of Allosteric Receptor Modulation .................... 924

A. Ion Channels .......................................................... 924

1. Ligand-Gated Ion Channels. ......................................... 924

a. Pentameric ligand-gated ion channel allosteric sites on extracellular nonagonist

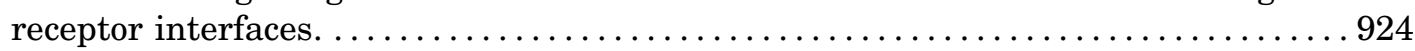

b. Pentameric ligand-gated ion channel allosteric sites in the transmembrane domains.925

c. Pentameric ligand-gated ion channel allosteric sites in intracellular domains...... .926

d. Allosteric sites on nonpentameric ligand-gated ion channels. . . . . . . . . . . . . . . . 926

2. Voltage-Gated Ion Channels............................................. 926

a. Voltage-gated ion channel architecture .............................. 926

b. Allosteric sites on voltage-gated ion channels....................... 927

c. Role of regulatory domains in voltage-gated ion channel allostery. . . . . . . . . . 928

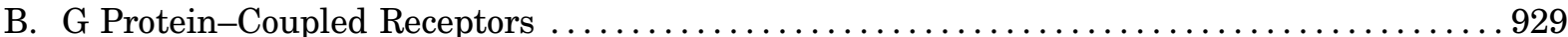

1. Allostery at Class A G Protein-Coupled Receptors. . . . . . . . . . . . . . . . . . . . . . 929

2. Allostery at Class B (Peptide) G Protein-Coupled Receptors.. . . . . . . . . . . . . . . . . . 930

3. Allostery at Class C G Protein-Coupled Receptors. ........................... 930

4. Structural Biology of G Protein-Coupled Receptor Allosteric Sites................. 930

C. Nuclear Hormone Receptors..................................... 931

1. Structural Insights into Nuclear Hormone Receptor Allosteric Coupling. ............ 932

2. Synthetic Nuclear Hormone Receptor Modulators.............................. 932

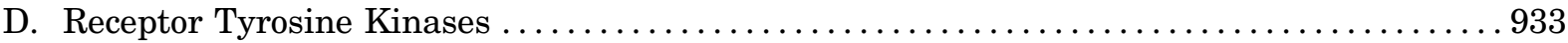

1. The Tyrosine Kinase Domain.................................... 933

2. Structural Regulation of the Tyrosine Kinase Domain..................... 933

A.C. and P.M.S. are Primary Research Fellows of the National Health and Medical Research Council of Australia.

Address correspondence to: Prof. Arthur Christopoulos, Drug Discovery Biology, Monash Institute of Pharmaceutical Sciences, Monash University, 399 Royal Parade, Parkville, VIC 3052, Australia. E-mail: arthur.christopoulos@monash.edu dx.doi.org/10.1124/pr.114.008862. 
3. Small Molecule Kinase Inhibitors................................ 934

4. Extracellular Allosteric Modulation of Receptor Tyrosine Kinases. . . . . . . . . . . . 935

5. Antibody Modulation of Receptor Tyrosine Kinase Activity. . . . . . . . . . . . . . 936

V. Recommendations for Allosteric Ligand Classification . . . . . . . . . . . . . . . . . . 936

VI. Classification of Endogenous Allosteric Ligands . . . . . . . . . . . . . . . . . . . . . . 937

VII. Experimental Approaches for Validating an Allosteric Interaction. . . . . . . . . . . . . . . . 938

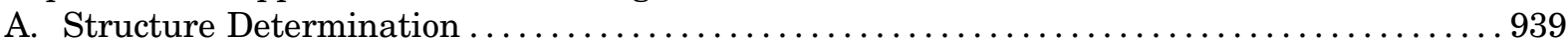

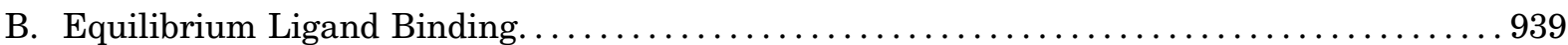

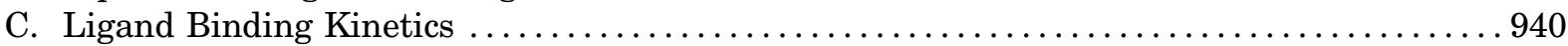

D. Functional Assays ................................................. 941

E. Allosteric Agonists . . . . . . . . . . . . . . . . . . . . . . . . . . . . . . . . . . . . . . 942

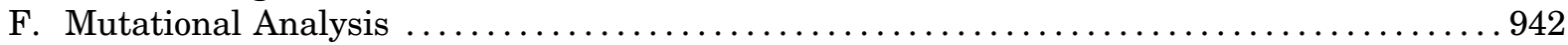

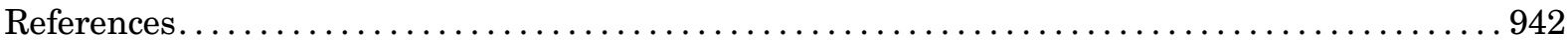

\begin{abstract}
Allosteric interactions play vital roles in metabolic processes and signal transduction and, more recently, have become the focus of numerous pharmacological studies because of the potential for discovering more target-selective chemical probes and therapeutic agents. In addition to classic early studies on enzymes, there are now examples of small molecule allosteric modulators for all superfamilies of receptors encoded by the genome, including ligand- and voltage-gated ion channels,
\end{abstract}

G protein-coupled receptors, nuclear hormone receptors, and receptor tyrosine kinases. As a consequence, a vast array of pharmacologic behaviors has been ascribed to allosteric ligands that can vary in a target-, ligand-, and cell-/tissue-dependent manner. The current article presents an overview of allostery as applied to receptor families and approaches for detecting and validating allosteric interactions and gives recommendations for the nomenclature of allosteric ligands and their properties.

\section{Introduction}

The classification of drugs and receptors has traditionally been informed by the study of interactions between receptor macromolecules and ligands that recognize the endogenous agonist binding site(s) on these macromolecules. This endogenous agonist-binding site is referred to as the orthosteric site (Neubig et al., 2003; see also section III, Table 1 below). Although the pursuit of compounds that either mimic or antagonize the actions of endogenous orthosteric agonists represents a logical approach to drug discovery and has yielded a number of hugely successful pharmacologic tools and drugs (e.g., Black, 1989), there has also been a marked increase in the discovery of compounds that mediate their effects by interacting with topographically distinct allosteric sites on receptors (Christopoulos, 2002; Olsen et al., 2004; Hogg et al., 2005; Bertrand and Gopalakrishnan, 2007; May et al.,
2007; Conn et al., 2009; Changeux, 2012; Melancon et al., 2012; Wootten et al., 2013). This finding has substantial implications for drug discovery and pharmacology. For instance, the structural features that govern the binding of allosteric ligands can be different from those that determine the interaction of orthosteric ligands with a receptor. Allosteric ligands also offer the potential for greater receptor subtype-selectivity because of higher sequence divergence in allosteric sites across receptor subtypes relative to the conserved orthosteric domain or because of selective modulation of orthosteric ligand actions at a given subtype to the exclusion of others (Christopoulos, 2002; Lazareno et al., 2004). Importantly, ligands that bind to allosteric sites will modify the conformation of a receptor such that its interactive properties toward orthosteric ligands or coupling proteins may change. This latter phenomenon introduces substantial diversity

ABBREVIATIONS: BZ, benzodiazepine; $\mathrm{Ca}_{\mathrm{V}}$, voltage-gated $\mathrm{Ca}^{2+}$ channel; $\mathrm{CBS}$, coregulator binding site; CNG, cyclic nucleotide-gated; CP-376395, $N$-(1-ethylpropyl)-3,6-dimethyl-2-(2,4,6-trimethylphenoxy)-4-pyridinamine hydrochloride; CP55940, 2-[(1R,2R,5R)-5-hydroxy-2-(3-hydroxypropyl) cyclohexyl]-5-(2-methyloctan-2-yl)phenol; CX614, 2H,3H,6aH-pyrrolidino(2,1-3',2')1,3-oxazino $\left(6^{\prime}, 5^{\prime}-5,4\right)$ benzo(e)1,4-dioxan-10-one; DBD, DNA binding domain; DQP-1105, 5-(4-bromophenyl)-3-(1,2-dihydro-6-methyl-2-oxo-4-phenyl-3-quinolinyl)-4,5-dihydro-g-oxo-1H-pyrazole-1-butanoic acid; FGF, fibroblast growth factor; GLIC, Gloeobacter ligand-gated ion channel; GPCR, G protein-coupled receptor; HCN, hyperpolarization and cyclic nucleotide-activated; hERG, human ether-à-go-go; IL, interleukin; KNF, Koshland-Nemethy-Filmer; KI, kinase inhibitor; $\mathrm{K}_{\mathrm{V}}$, voltage-gated $\mathrm{K}^{+}$channel; LBD, ligand binding domain; LGIC, ligand-gated ion channel; LY02119620, 3-amino-5-chloro- $N$-cyclopropyl-4-methyl-6-[2-(4-methylpiperazin-1-yl)-2-oxoethoxy] thieno[2,3-b] pyridine-2-carboxamide; LY2033298, 3-amino-5-chloro- $N$-cyclopropyl-6-methoxy-4-methyl-thieno[2,3-b]pyridine-2-carboxamide; LY 2087101, [2-[(4fluorophenyl)amino]-4-methyl-5-thiazolyl]-3-thienylmethanone; MWC, Monod-Wyman-Changeux; mAChR, muscarinic acetylcholine receptor; McN-A343, 4-[[[(3-chlorophenyl)amino]carbonyl]oxy]- $N, N, N$-trimethyl-2-butyn-1-aminium chloride; nAChR, nicotinic acetylcholine receptor; NAM, negative allosteric modulator; $\mathrm{Na}_{\mathrm{V}}$, voltage-gated $\mathrm{Na}^{+}$channel; $\mathrm{NHR}$, nuclear hormone receptor; NMDA, $N$-methyl-D-aspartate; NR box, NHR interacting domain; Org27569, 5-chloro-3-ethyl- $N$-(4-(piperidin-1-yl)phenethyl)- $1 H$-indole-2-carboxamide; PAM, positive allosteric modulator; pLGIC, pentameric ligandgated ion channel; PNU-120596, $N$-(5-chloro-2,4-dimethoxyphenyl)- $N$ '-(5-methyl-3-isoxazolyl)-urea; PPAR, peroxisome proliferator-activated receptor; QNZ46, 4-[6-methoxy-2-[(1E)-2-(3-nitrophenyl)ethenyl]-4-oxo-3(4H)quinazolinyl]benzoic acid; SSR128129E, sodium 2-amino-5-(1-methoxy-2-methylindolizine-3-carbonyl)benzoate; RTK, receptor tyrosine kinase; RXR, retinoid X receptor; TCN-201, 3-chloro-4-fluoro- $N$-[4-[[2-(phenylcarbonyl)hydrazino] carbonyl]benzyl]benzenesulfonamide; THRX160209, 4-\{N-[7-(3-(S)-(1-carbamoyl-1,1-diphenylmethyl)pyrrolidin-1-yl)hept-1-yl]- $N$-( $n$-propyl)amino\}-1-(2,6dimethoxybenzyl)piperidine; TKI, tyrosine kinase inhibitor; TM, transmembrane; TRP, transient receptor potential; VGIC, voltage-gated ion channel. 
TABLE 1

Terms used to describe receptor allosterism and allosteric ligand actions (see also Note 1)

\begin{tabular}{|c|c|}
\hline Term & Suggested Use \\
\hline Orthosteric site & $\begin{array}{l}\text { The binding site/s on a receptor macromolecule that } \\
\text { is/are recognized by the endogenous agonist/s for that } \\
\text { receptor. }\end{array}$ \\
\hline Allosteric site & $\begin{array}{l}\text { A binding site on a receptor macromolecule that is } \\
\text { nonoverlapping and spatially distinct from, but } \\
\text { conformationally linked to, the orthosteric binding } \\
\text { site. }\end{array}$ \\
\hline Orthosteric agonist & $\begin{array}{l}\text { A ligand that binds to the orthosteric site of a receptor } \\
\text { and alters the receptor state, resulting in a biologic } \\
\text { response. Conventional orthosteric agonists increase } \\
\text { receptor activity, whereas orthosteric inverse } \\
\text { agonists reduce it (see also Notes } 2 \text { and } 3 \text { ). }\end{array}$ \\
\hline Allosteric agonist & $\begin{array}{l}\text { A ligand that binds to an allosteric site on a receptor } \\
\text { macromolecule and alters the receptor state, } \\
\text { resulting in a biologic response. Conventional } \\
\text { allosteric agonists increase receptor activity, whereas } \\
\text { allosteric inverse agonists reduce it (see also } \\
\text { Notes } 4 \text { and 5). }\end{array}$ \\
\hline Allosteric modulator & $\begin{array}{l}\text { A ligand that modifies the action of an orthosteric } \\
\text { agonist, endogenous activator, or antagonist by } \\
\text { combining with an allosteric site on the receptor } \\
\text { macromolecule. A positive allosteric modulator } \\
\text { (PAM) increases the action (affinity and/or efficacy) } \\
\text { of an orthosteric agonist, activator, or antagonist, } \\
\text { whereas a negative allosteric modulator (NAM) } \\
\text { decreases the action (affinity and/or efficacy) } \\
\text { of an orthosteric agonist, activator, or antagonist. } \\
\text { Note that the term "modulator" is preferred to the } \\
\text { terms "effector" or "regulator." }\end{array}$ \\
\hline Neutral allosteric ligand & $\begin{array}{l}\text { A ligand that combines with an allosteric site on } \\
\text { a receptor macromolecule but does not alter the } \\
\text { action of a (given) orthosteric agonist, activator, or } \\
\text { antagonist. The neutral allosteric ligand (NAL) can, } \\
\text { however, prevent the binding of other allosteric } \\
\text { ligands to the same allosteric site via a steric } \\
\text { interaction and may be a positive or negative } \\
\text { allosteric modulator of other orthosteric ligands, } \\
\text { activators, or antagonists or allosteric ligands that } \\
\text { bind to a different (second) allosteric site on the } \\
\text { receptor macromolecule (see also Note 6). Neutral } \\
\text { allosteric ligands have also been referred to as "silent } \\
\text { allosteric modulators" (SAMs). Note, however, that } \\
\text { the terms "neutral" and "ligand" are preferred to the } \\
\text { terms "silent" and "modulator" for ligands with } \\
\text { neutral cooperativity. This ensures conformity with } \\
\text { prior terms, such as "neutral antagonist" and also } \\
\text { reflects the fact that if a ligand is neutral, it is not " } \\
\text { modulating." }\end{array}$ \\
\hline Bitopic ligand & $\begin{array}{l}\text { A hybrid molecule that concomitantly engages an } \\
\text { orthosteric and an allosteric site on a receptor } \\
\text { macromolecule via two pharmacologically active } \\
\text { pharmacophores (one constituting an orthosteric } \\
\text { ligand and the other an allosteric ligand; see also } \\
\text { Note 7). }\end{array}$ \\
\hline Allosteric interaction & $\begin{array}{l}\text { An indirect interaction between ligands that bind to } \\
\text { spatially distinct, nonoverlapping recognition sites on } \\
\text { the receptor macromolecule mediated by } \\
\text { a conformational change. }\end{array}$ \\
\hline Allosteric transition & $\begin{array}{l}\text { The isomerization of a receptor macromolecule between } \\
\text { different conformational states. }\end{array}$ \\
\hline Competitive interaction & $\begin{array}{l}\text { An interaction between ligands that bind to the same } \\
\text { recognition site or to recognition sites that overlap on } \\
\text { the receptor macromolecule. A competitive } \\
\text { interaction can occur between different orthosteric } \\
\text { ligands or between different allosteric ligands } \\
\text { provided that each class shares a similar recognition } \\
\text { domain on the receptor macromolecule (see also } \\
\text { Note 3). }\end{array}$ \\
\hline Homotropic interaction & $\begin{array}{l}\text { An allosteric interaction between structurally identical } \\
\text { ligands. }\end{array}$ \\
\hline Heterotropic interaction & $\begin{array}{l}\text { An allosteric interaction between structurally different } \\
\text { ligands. }\end{array}$ \\
\hline
\end{tabular}


to the pharmacology of cobound orthosteric ligands that can vary in a ligand-, receptor-, species-, and cell-dependent manner (Leach et al., 2007; Kenakin, 2009) and thus poses substantial challenges for the detection, quantification, and validation of allosteric drug effects. Given these issues and the increasing prevalence of allosteric ligands being discovered for all superfamilies of receptors, the aim of the current article is to provide guidelines by the International Union of Basic and Clinical Pharmacology Committee on Receptor Nomenclature and Drug Classification for the classification of allosteric ligands and their pharmacological properties to facilitate uniformity in terminology across different receptor families.

\section{A Brief Overview of Receptor Allosterism}

It is not the intent of this article to provide a comprehensive review of the phenomenon of allostery as it pertains to receptors; this has already been covered in a number of prior reviews (e.g., Changeux and Edelstein, 1998, 2005; Christopoulos, 2002; Christopoulos and Kenakin, 2002; May et al., 2007; Conn et al., 2009; Changeux, 2010, 2012, 2013a; Wootten et al., 2013). Nonetheless, it is appropriate to consider briefly the historical development of the concept and how this has shaped key ideas associated with receptor pharmacology.

The term "allosteric" was first coined by Monod and Jacob (1961) to describe the newly identified phenomenon (Changeux, 1961; Gerhart and Pardee, 1962) of an interaction between two topographically distinct sites on a protein (an enzyme in this instance) that was mediated indirectly by a conformational change transmitted between the sites. The use of the term was formalized by Monod et al. (1963), and the mechanism underlying the conformational change [commonly referred to as the Monod-Wyman-Changeux (MWC) model] was subsequently proposed to be one of conformational selection, whereby the macromolecule was envisaged to exist in a thermal equilibrium between active and inactive states that were preferentially stabilized by the binding of orthosteric or allosteric ligands to their respective (nonoverlapping) binding sites (Monod et al., 1965). More contemporary restatings of the MWC model, based predominantly on NMR studies, are often referred to as "population shift" models to explicitly highlight the dynamic nature of proteins as ensembles of pre-existing conformations that are differentially stabilized by the binding of ligands or other substances, such as nucleic acids or other proteins (Cui and Karplus, 2008).

There are a number of properties arising from the MWC model and its variants that have substantial bearing on our current understanding of drug-receptor interactions. These include the expectation that regulatory proteins are oligomeric, with the subunits arranged around an axis of symmetry (or pseudosymmetry); that the isomerization between discrete conformational states occurs in a concerted (all-or-none) fashion for all subunits- referred to as the allosteric transition; that the proteins should display some level of basal (ligand-independent) activity corresponding to the spontaneous equilibrium between states in the absence of ligand; and that the role of either orthosteric or allosteric ligands is to shift the equilibrium between receptor states. Given the subsequent discovery of phenomena such as constitutive receptor activation (Jackson, 1984; Costa and Herz, 1989; Kjelsberg et al., 1992) and inverse agonists (Costa and Herz, 1989; Revah et al., 1991), and the demonstration that all classes of receptor can form dimers, or higher order oligomers (Changeux and Edelstein, 1998; Pin et al., 2007), the heuristic nature of the MWC model cannot be overstated.

Although originally developed to explain mechanisms underlying the function of regulatory enzymes, the MWC model (an example of a "two-state" model) was soon applied to the study of membrane receptors (Changeux et al., 1967; Karlin, 1967; Colquhoun, 1973; Thron, 1973) and ion channels, in particular ligand-gated ion channels (LGICs) (Changeux, 2010, 2013a,b), and provided a parsimonious mechanism to account for signal transduction mediated by open channel states, which preferentially bind agonist ligands, and closed channel states, which preferentially bind inverse agonists. ${ }^{1}$ The oligomeric nature of the model also accommodates the phenomenon of cooperativity in ligand binding, because multiple equivalents of the same ligand may bind to different protomers within the complex. Importantly, there is now a large body of structural and molecular data that provides substantial support for the relevance of this model as a mechanism for LGIC behavior, although it is evident that there are likely to be more than two discrete states required to account for the functional and interactive properties of these receptors (Taly et al., 2009). Indeed, early work on voltage-gated ion channels (VGICs) showed that there were at least three states (open, closed, inactivated) and the presence of drugs favored certain states depending on the allosteric site the drugs bound to, thereby switching the channel between different modes or families of open/ closed/inactivated states (Hess et al., 1984; Nowycky et al., 1985; Spedding and Paoletti, 1992).

Soon after the development of the MWC model, Koshland, Nemethy and Filmer proposed an alternative mechanism (the KNF model), building on prior work of Pauling, to account for cooperative behavior of proteins (Koshland et al., 1966). The key postulates of the KNF model are that the binding of a ligand to a protein complex induces a conformational change in the complex

\footnotetext{
${ }^{1}$ It should also be noted that receptor models dealing with receptor isomerization between different conformational states were published as early as the 1950s to describe the mechanism of action of the nicotinic acetylcholine receptor [del Castillo J and Katz B (1957) Interaction at end-plate receptors between different choline derivatives. Proc Roy Soc (Lond) 146:369-381; and Katz B and Thesleff S (1957) A study of the 'desensitization' produced by acetylcholine at the motor end-plate. J Physiol (Lond) 138:63-80].
} 
(conformational induction mechanism) and, if the complex is composed of multiple subunits, each subunit can change its tertiary structure sequentially with the binding of successive molecules, rather than in a concerted all-ornone quaternary fashion. A particularly attractive feature of the KNF model is that it can readily account for negative homotropic cooperativity, whereas the MWC model (in its simplest sense) only predicts positive homotropic cooperativity. In the ensuing years, much has been learned regarding the manifestations of allostery across different protein families. It is now known, for instance, that proteins need not be oligomeric to display allosteric behavior, nor do they need to undergo global changes in quaternary structure around an axis of symmetry (Canals et al., 2011). The concerted conformational selection nature of the MWC model and the induced-fit nature of the KNF model are likely to be two extremes of a common mechanism driven by protein ensemble behavior (Kenakin and Miller, 2010). Interestingly, there are now examples of allostery driven almost exclusively by changes in the frequency of protein motions, rather than overt structural effects, such that cooperativity arises not from changes in one binding site upon occupancy of another, but rather by a change in the timing of fluctuations of different regions within a protein, even if distinct from the actual ligand binding pockets (Popovych et al., 2009). Such purely entropically-based changes have been referred to as "dynamically driven allostery" (Kern and Zuiderweg, 2003; Popovych et al., 2009).

In parallel to the application of multistate allosteric theory to LGICs, the development of "ternary complex" mechanisms to explain the binding and signaling of $\mathrm{G}$ protein-coupled receptors (GPCRs) also invoked allosteric interactions (De Lean et al., 1980; Ehlert, 1985). This is because GPCRs respond to extracellular agonist binding by translocating within the plane of the membrane and interacting with intracellular proteins to transduce signals (Cuatrecasas, 1974; Gilman, 1987; Hamm, 1998) and thus possess topographically distinct binding sites that are conformationally linked (Christopoulos and Kenakin, 2002). Indeed, it is well established that agonists and $G$ proteins promote reciprocal effects on the binding of each other to GPCRs (Ehlert, 1985). At around the same time, provocative experimental data emerged to suggest that GPCRs were able to form complexes concomitantly with more than one (different) type of ligand (Clark and Mitchelson, 1976; Stockton et al., 1983), which could quantitatively be accommodated by a ternary complex model assuming cross-interactions between spatially distinct sites (Stockton et al., 1983; Ehlert, 1988). The subsequent incorporation of the ability of GPCRs to undergo allosteric transitions between different states into these models (Hall, 2000) has resulted in contemporary versions of GPCR mass-action schemes with different levels of complexity but all broadly consistent with the predicted behavior of the MWC model and its variants (Canals et al., 2011, 2012).
Finally, it should be appreciated that there are numerous instances of naturally occurring mutations that can affect the allosteric transition of a receptor between states (Taly et al., 2006; Tao, 2008); often, these are clinically relevant. In addition, such naturally occurring mutations may change the properties of allosteric modulators, either by perturbing the modulator binding pocket or the degree of cooperativity between sites (Leach et al., 2013).

\section{Definitions}

Different authors have used the term "allosteric" in different ways (Colquhoun, 1998; Fenton, 2008), including the description of events beyond protein structural changes elicited by the transmission of conformational changes between spatially distinct ligand-binding sites on a receptor macromolecule. Some examples of these other uses of the term include the description of the coupling of an amino acid side chain mutation and a ligand binding event or the stabilization of a distinct conformational state of a protein by a single ligand in the absence of any cobound ligands (for further discussion, see Fenton, 2008; Colquhoun and Lape, 2012). It is recommended that the term "allosteric" not be used to describe such phenomena but be reserved for instances where the properties of one ligand (small molecule or protein) are altered upon binding of a second ligand at a nonoverlapping, topographically distinct site and where, ideally, reciprocity in this interaction can be demonstrated. Table 1 summarizes terms that are recommended for use in describing allosteric receptor phenomena and drug actions.

Note 1: Where possible, the terminology used in Table 1 is consistent with terms outlined in the prior International Union of Basic and Clinical Pharmacology Committee on Receptor Nomenclature and Drug Classification documents: "Recommendations on terms and symbols in quantitative pharmacology" (Jenkinson et al., 1995) and "Update on terms and symbols in quantitative pharmacology" (Neubig et al., 2003). Where differences exist, the terms and suggested uses in the current document supersede previous recommendations.

Note 2: For the purposes of these guidelines, physical activators for nonligand-gated channels, such as voltage or heat, are considered akin to the "orthosteric agonist" of chemically-liganded receptors.

Note 3: Different chemical structures can interact with different residues within a receptor macromolecule. Thus, it is to be expected that ligands may adopt different poses within a "common" binding cavity (illustrated schematically in Fig. 1). In this regard, "orthosteric" ligands are defined as those that display mutually exclusive binding with the endogenous agonist of the receptor by virtue of 


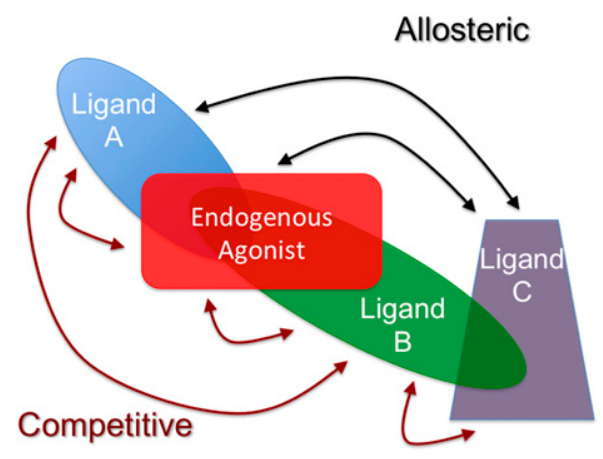

Fig. 1. Simple schematic illustrating the potential for different ligands to display either competitive or allosteric interactions depending on their binding sites relative to one another.

steric overlap, i.e., their binding pose may overlap with some, or most, of the regions used by the endogenous orthosteric agonist. Steric overlap will manifest as a competitive interaction, and this can occur between two orthosteric ligands or two allosteric ligands. The occurrence of substantially different binding poses is also one mechanism whereby a ligand may appear competitive with both an orthosteric and an allosteric ligand (e.g., ligand B in Fig. 1).

Note 4: The term "coagonist" has been used to describe the requirement of both glutamate and glycine to bind as orthosteric agonists to gate $N$-methyl-D-aspartate (NMDA) receptors comprised of GluN1 and GluN2A-D subunits. Coagonists are best defined as endogenous ligands that, individually, do not activate the receptor macromolecule (under defined conditions) but combine with a receptor macromolecule concomitantly to activate it.

Note 5: As is the case with orthosteric drugs, the ability of allosteric ligands to preferentially stabilize active, or inactive, receptor states as part of their mechanism of action suggests that it is likely some of these ligands will display some degree of positive, or negative, efficacy in their own right, and thus behave as either conventional agonists or inverse agonists (Hall, 2000). However, this will vary with the experimental conditions used to detect allosteric ligand behavior, i.e., if there are low levels of constitutive receptor activity, receptor expression, and/or stimulus-response coupling, then allosteric agonism/inverse agonism may not be detected, whereas allosteric modulation of orthosteric ligand function may still be noted. This is the most likely reason for the observation that many allosteric modulators do not appear to possess positive, or negative, efficacy and is akin to the situation where orthosteric partial, or inverse agonists, may appear as neutral antagonists under certain experimental conditions (Keov et al., 2011). See also section VII.E below.
Note 6: A truly "neutral" allosteric (or orthosteric) ligand would be one that binds to a receptor macromolecule but retains similar affinities for the various states of that receptor (i.e., does not select one set of states over another set). Thermodynamically, however, this is highly unlikely, and thus the definition proposed herein explicitly incorporates the orthosteric ligand, or other endogenous activator against which the allosteric ligand is tested. It should be noted that many ligands (orthosteric or allosteric) can possess appreciable, but still intrinsically different, affinities for the two conformational states, such that the shift of the equilibrium in the direction of the preferred state is incomplete. This has previously been referred to as "nonexclusive binding" and is the simplest mechanistic basis for the phenomenon of partial agonism (Rubin and Changeux, 1966).

Note 7: The term "bitopic" is used to explicitly define bifunctional ligands that are comprised of pharmacophores known to (independently) interact with orthosteric and allosteric sites, respectively. A bitopic mode of engagement involves the (single) ligand occupying both sites at the same time and thus would still exhibit competitive behavior because one of the pharmacophores occupies the orthosteric site. The term "dualsteric" has also been applied to such ligands (Antony et al., 2009; Mohr et al., 2013). Bitopic ligands should be viewed as a special case of the "bivalent" or "multivalent" ligand, which is comprised of two distinct pharmacophores but whose sites of interaction (orthosteric or allosteric) are not defined (Valant et al., 2012b; Lane et al., 2013).

Note 8: The term "noncompetitive" has traditionally been attributed to observed behaviors in functional assays whereby the maximal agonist response is reduced in the presence of an antagonist. This term should be regarded as phenomenological as it can arise through different mechanisms, of which one is allosteric. For instance, depression in a maximal agonist response can also be caused by an irreversible, or very slowly dissociating, orthosteric antagonist or by a compound acting downstream of the receptor in another part of the signal transduction chain. However, it is likely that some "noncompetitive" antagonists are actually negative allosteric modulators of agonist efficacy but neutral ligands with respect to agonist affinity (e.g., CPCCOEt at mGluR1; Litschig et al., 1999), such that they depress the maximal agonist response in functional assays but have no observable effect on agonist binding.

Note 9: The term "probe dependence" is frequently used to describe a phenomenon whereby the direction and magnitude of the effect mediated by a given allosteric ligand on an orthosteric ligand 
that is used to probe receptor activity (either in a functional sense or at the level of ligand binding) varies with the orthosteric ligand that is used. Thus, different allosteric effects may be observed for the same modulator, acting at the same receptor but with different orthosteric ligands (Kenakin, 2005). The simplest mechanism underlying probe dependence within a MWC two-state receptor system is one where the direction and magnitude of the observed allosteric modulation correlates with the intrinsic efficacy of the interacting ligands, i.e., a given positive allosteric modulator will potentiate higher efficacy agonists to a greater extent than lower efficacy agonists while acting as a negative allosteric modulator of inverse agonists and vice versa (Canals et al., 2011; Keov et al., 2011). For instance, diazepam significantly increases the potency of the full agonist, GABA, at the $\alpha_{1} \beta_{3} \gamma_{2^{-}}$ containing $\mathrm{GABA}_{\mathrm{A}}$ pentameric LGIC (pLGIC) while having minimal effect on the potency of the partial agonist, kojic amine (although it does increase the maximal effect of the partial agonist; Downing et al., 2005). At the $\mathrm{M}_{1}$ muscarinic GPCR, benzyl quinolone carboxylic acid potentiates the actions of the full agonists acetylcholine or carbachol to a much greater extent than the partial agonists pilocarpine or xanomeline, while simultaneously inhibiting the actions of inverse agonists (Canals et al., 2012). However, there are even more striking examples of probe dependence that suggest differential stabilization of multiple functionally relevant states. For example, TCN-201 (3-chloro-4-fluoro- $N$-[4-[[2(phenylcarbonyl)hydrazino] carbonyl]benzyl] benzenesulfonamide) is a negative allosteric modulator of glycine but a neutral allosteric ligand with respect to glutamate at the GluN1/GluN2A NMDA receptor (Hansen et al., 2012); LY2033298 (3-amino-5-chloro- $N$-cyclopropyl-6-methoxy-4-methylthieno[2,3-b]pyridine-2-carboxamide) allosterically potentiates the signaling of the orthosteric agonist oxotremorine-M but inhibits the signaling of xanomeline at the $\mathrm{M}_{2}$ muscarinic receptor (Valant et al., 2012a).

\section{Some Representative Examples of Allosteric Receptor Modulation}

\section{A. Ion Channels}

Much of the original research on membrane protein allostery was performed on LGICs and VGICs, because many of the early drugs acting on the therapeutic targets acted at allosteric sites. It is instructive to revisit this research in light of new findings in molecular modeling and crystal structure where the sites have been more precisely defined.

1. Ligand-Gated Ion Channels. Allosteric interactions in LGICs are of great importance because many experimental agents and therapeutic compounds act at these receptors by allosteric mechanisms. The nicotinic acetylcholine receptor ( $\mathrm{nAChR})$ is perhaps the beststudied model system for understanding allosteric interactions at neurotransmitter receptors. The $\mathrm{nAChR}$ is an integral pentameric membrane protein of the "Cys-loop" family, with the five units arranged around the C5 axis of symmetry of the central ion channel pore (Taly et al., 2009). This classic structural paradigm is also shared by other key pLGICs, such as the GABA $\mathrm{A}_{\mathrm{A}}$, glycine, and $5-\mathrm{HT}_{3}$ receptors. Numerous studies have established that the orthosteric sites on these receptors are located in the extracellular regions of subunit interfaces, at about $60 \AA$ from the pore-forming transmembrane 2 (TM2) regions of each protomer (Changeux, 2013b); importantly, this has been directly confirmed through X-ray structural studies on related prokaryotic pentameric LGICs (Hibbs and Gouaux, 2011; Corringer et al., 2012; Pan et al., 2012).

Given the rich history associated with the study of signal transduction and allosterism at LGICs, in particular the pLGICs, three broad categories of allosteric sites have been identified (Fig. 2), two of which have already been associated with pharmacological targeting and highresolution structural insights (Fig. 3).

a. Pentameric ligand-gated ion channel allosteric sites on extracellular nonagonist receptor interfaces. The classic model for this type of site is the $\mathrm{GABA}_{\mathrm{A}}$ receptor (Smith and Olsen, 1995; Galzi and Changeux, 1994; Nguyen et al., 2002), which harbors an interfacial site between distinct loops within the extracellular domain of its $\alpha(+)$ and $\gamma(-)$ subunits that binds clinically used benzodiazepines and other chemical classes (Olsen and Sieghart, 2009). The possible binding of $\mathrm{GABA}_{\mathrm{A}}$ allosteric modulators at this nonagonist binding interface was initially suggested on the basis of identification of a similar site in heteropentameric nAChRs (Galzi and Changeux, 1994).

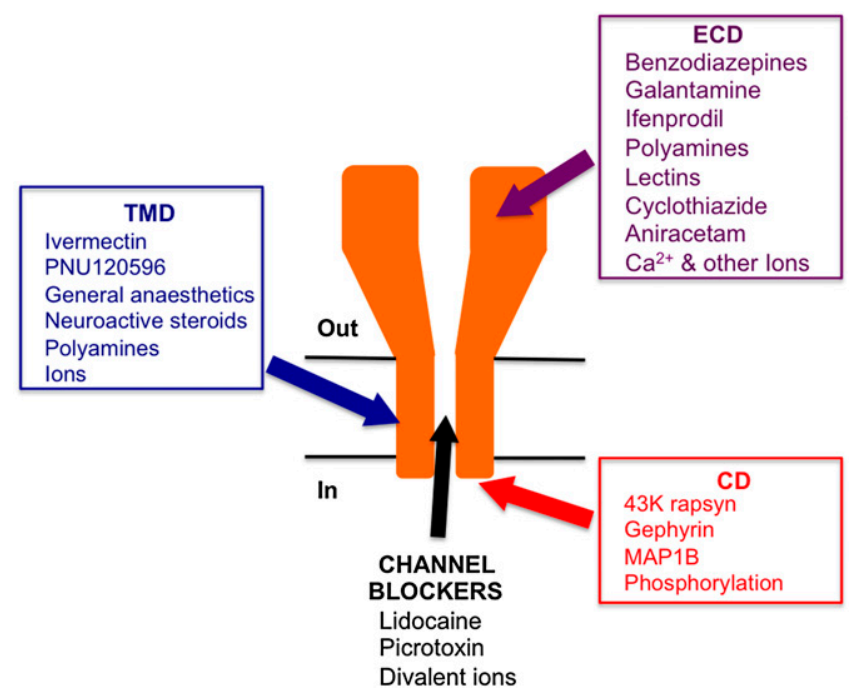

Fig. 2. Diagrammatic representation of different classes of allosteric sites and exemplar ligands of LGICs. ECD, extracellular domain; TMD, transmembrane domain; CD, cytoplasmic domain. 

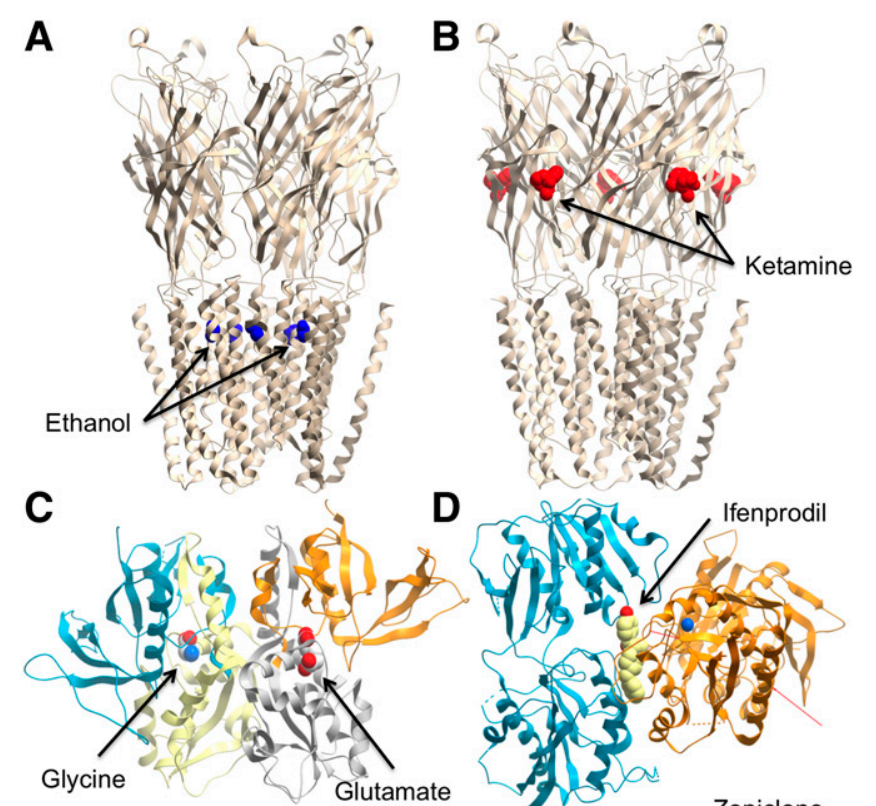

D
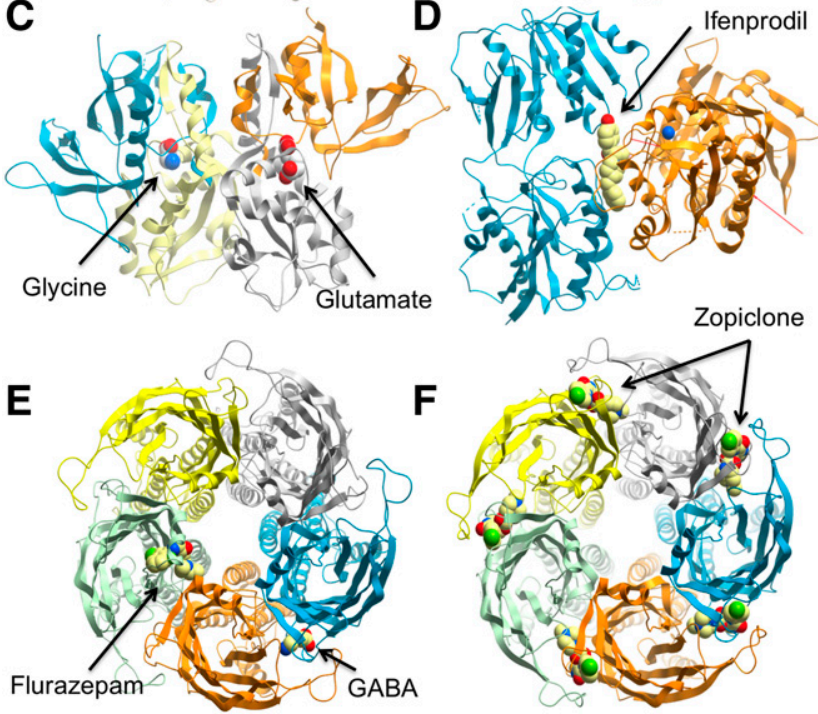

Fig. 3. Crystal structures of ligand-gated ion channels, showing the range of allosteric (or coagonist) binding sites. (A) Ethanol binding sites on the ethanol-sensitive mutant GLIC pentameric ligand gated ion channel (PDB ID 4HFE). (B) Ketamine bound to the GLIC pentameric ligand gated ion channel (PDB ID 4F8H). (C) GluN1/GluN2A ligand-binding domain in complex with GluN receptor coagonists glycine and glutamate (PDB ID 4NF8). (D) Crystal structure of amino terminal domains of the GluN receptor subunit GluN1 and GluN2B in complex with ifenprodil (PDB ID 3 QEL). Crystal structure of a pentameric ligand gated ion channel Erminia ligand-gated ion channel in complex with GABA and flurazepam (E; PDB ID 2YOE) or zopiclone (F; PDB ID 4A97).

Considerable biochemical, pharmacological, and modeling evidence has since demonstrated that benzodiazepine ligands do indeed bind to intersubunit sites in the extracellular domain of the $\mathrm{GABA}_{\mathrm{A}}$ receptor that are homologous to the GABA site but do not bind GABA (Smith and Olsen, 2000; Sawyer et al., 2002). This site illustrates a range of allosteric phenomena and highlights the utility of targeting allosteric sites in the development of drugs that are selective for $\mathrm{GABA}_{\mathrm{A}}$ receptor isoforms that differ in the identity of the $\alpha$-subunit that they incorporate. Thus, by acting at $\mathrm{GABA}_{\mathrm{A}}$ receptors with a subunit composition that confers benzodiazepine sensitivity (see Olsen and Sieghart, 2009), the anxiolytic, sedative-hypnotic and anticonvulsant 1,4 benzodiazepine, diazepam, is a positive allosteric modulator [originally termed a "benzodiazepine (BZ) site agonist"] of GABA that increases the frequency of channel openings and bursts elicited by GABA in electrophysiological studies (Study and Barker, 1981; Rogers et al.,
1994). Conversely, the convulsant and anxiogenic $\beta$-carboline, methyl-6,7-dimethoxy-4-ethyl- $\beta$-carboline-3-carboxylate, is a negative allosteric modulator of GABA (originally termed a "BZ site inverse agonist") that exerts opposite effects to those of diazepam upon the kinetics of channels gated by GABA (Rogers et al., 1994). The actions of both diazepam and DMCN are blocked by flumazenil, which has no influence upon the currents evoked by GABA at most $\mathrm{GABA}_{\mathrm{A}}$ receptors and is thus defined as a neutral allosteric ligand with respect to GABA (originally termed a "BZ site antagonist"). Between the extremes outlined above are compounds that have previously been described as "BZ site partial agonists" or "BZ site partial inverse agonists" (see Barnard et al., 1998) that, in the present scheme (Table 1), would be termed as weaker positive or negative allosteric modulators (PAM or NAM) of GABA affinity (i.e., with more limited cooperativity), respectively. Similarly, ions such as $\mathrm{Zn}^{2+}$, or substances such as galantamine, strychnine, cocaine, and morphine have also been suggested to bind extracellularly at nonagonist interfaces of heteropentameric $\mathrm{nAChRs}$ to mediate allosteric interactions at this receptor, thus highlighting the generality of this paradigm for allosteric targeting of LGICs (Hansen and Taylor, 2007; Taly et al., 2009; Nemecz and Taylor, 2011; Hamouda et al., 2013).

The second major category of allosteric site in the ECD of pLGICs is found in the vicinity of the transmembrane spanning domains. A particularly important divalent cation that can modulate LGICs is $\mathrm{Ca}^{2+}$. Indeed, for the $\alpha_{7} \mathrm{nAChR}$, the receptor is virtually quiescent in the absence of this ion (Mulle et al., 1992; Vernino et al., 1992). The binding sites for this ion are at subunit boundaries but at a level lower than that of the orthosteric site and near the extracellular transmembrane interface (Galzi et al., 1996; Le Novere et al., 2002). Homologs of the $\mathrm{Ca}^{2+}$ sites have been recognized in the structure of the prokaryotic Erminia ligand-gated ion channel, where they bind divalent cations such as $\mathrm{Ba}^{2+}$ that behave as negative modulators (Zimmermann et al., 2012), and in the prokaryotic Gloeobacter ligand-gated ion channel (GLIC), where they form a well delimited pocket for still unidentified ligands (Sauguet et al., 2014).

b. Pentameric ligand-gated ion channel allosteric sites in the transmembrane domains. Further down, local anesthetics, such as lidocaine, and toxins, such as picrotoxin, block nAChR activity by targeting the channel-forming pore itself. Such compounds constitute the traditional "channel blocker" category ascribed to noncompetitive antagonists acting within the pore. In contrast, the antihelminthic ivermectin acts elsewhere within the transmembrane-spanning region as a positive allosteric modulator of the $\alpha_{7} \mathrm{nAChR}$ (Krause et al., 1998) as do modulators such as PNU-120596 [N-(5-chloro-2,4-dimethoxyphenyl)- $N$ '-(5-methyl-3-isoxazolyl)-urea] and LY 2087101 ([2-[(4-fluorophenyl)amino]-4-methyl-5-thiazolyl]-3-thienylmethanone) (Bertrand and Gopalakrishnan, 2007; Changeux, 2013b). 
Interestingly, general anesthetics, such as propofol and desflurane, which behave as negative modulators of the prokaryotic GLIC (Weng et al., 2010), possess a common binding site identified in the GLIC structure within the upper part of the transmembrane domain of each subunit inside a cavity delimited by TM1, TM2, and TM3 (Nury et al., 2011). This intrasubunit cavity is accessible from the lipid bilayer, and its entrance is obstructed by a lipid alkyl chain that clashes with propofol binding. Thus, lipids might be the endogenous ligands of this membrane allosteric site (Nury et al., 2011). These general anesthetic sites also appear to be related to the ethanol sites identified in the crystal structures of an ethanol-sensitized GLIC variant in a transmembrane cavity located between channel subunits (Sauguet et al., 2013) and may stabilize the open form of the channel. Structural and mutagenesis studies have further defined overlapping mechanisms of potentiation by alcohols and general anesthetics via such intersubunit cavities (Chiara et al., 2014). Furthermore, homology modeling suggested that this cavity is conserved in human ethanol-sensitive glycine and $\mathrm{GABA}_{\mathrm{A}}$ receptors and involves residues previously shown to influence alcohol and anesthetic action on these proteins (Hanchar et al., 2006; Li et al., 2006; Perkins et al., 2009). Numerous classes of general anesthetics inhibit etomidate binding to $\mathrm{GABA}_{\mathrm{A}}$ receptors. Anticonvulsants, anesthetics, and diuretics acting on the glycine or $\mathrm{GABA}_{\mathrm{A}}$ receptor or on the $\mathrm{nAChR}$, also act in the transmembrane domain both within and between subunits (Li et al., 2010; Chiara et al., 2013; Olsen et al., 2014).

c. Pentameric ligand-gated ion channel allosteric sites in intracellular domains. The third category of allosteric site on pentameric LGICs is the least explored pharmacologically and represents the intracellular cytoplasmic domain of the receptors. This region is known to influence single channel conductance, ion selectivity (Peters et al., 2010) and also to regulate receptor activity through mechanisms such as differential phosphorylation of intracellular residues and serves as the target for a variety of scaffolding proteins, such as 14-3-3, 43K rapsyn, tubulin, dynamin, clathrin, gephyrin, PSD95, and MAP1B (Changeux, 2013b). Given that many of these interactions occur in a receptorand subtype-selective manner, there remains scope for targeting these pharmacologically.

d. Allosteric sites on nonpentameric ligand-gated ion channels. The ionotropic glutamate receptors are also an important model of allostery for LGICs (Fig. 3C), although they differ from the $\mathrm{nAChRs}$ and $\mathrm{GABA}_{\mathrm{A}}$ receptors in that they are tetrameric rather than pentameric. AMPA and kainate receptors possess at least one, if not more, allosteric binding sites located at the extracellular interface between the dimers that form the orthosteric binding site and are recognized by modulators such as cyclothiazide, aniracetam, CX614 $[2 \mathrm{H}, 3 \mathrm{H}, 6 \mathrm{a} H$-pyrrolidino (2,1-3' $\left.2^{\prime}\right) 1,3$-oxazino $\left(6^{\prime}, 5^{\prime}-5,4\right)$ benzo(e)1,4-dioxan-10-one] and the monovalent ions $\mathrm{Cl}^{-}$and $\mathrm{K}^{+}$(Traynelis et al., 2010). The N-terminal domain of these receptors also presents an allosteric site for lectins, and the corresponding domain in the NMDA receptor family can interact with modulators such as ifenprodil (Figs. 2 and 3D), various polyamines, and zinc ions. As with the pLGICs, the glutamate family of ion channels possesses allosteric sites in the transmembrane regions, recognized by substances such as polyamines, divalent cations, and pregnenalone sulfate (Traynelis et al., 2010). The unique nature of NMDA receptors, in terms of the requirement for two coagonists to activate the receptors, also presents interesting examples of differential allosteric modulation. For example, the novel GluN2C/D NMDA receptor allosteric modulators, DQP-1105 [5-(4-bromophenyl)-3(1,2-dihydro-6-methyl-2-oxo-4-phenyl-3-quinolinyl)-4,5dihydro-g-oxo- $1 H$-pyrazole-1-butanoic acid] or QNZ46 (4-[6-methoxy-2-[(1E)-2-(3-nitrophenyl)ethenyl]-4-oxo$3(4 H)$ quinazolinyl]benzoic acid), inhibit receptor function more potently when glutamate (but not glycine) is present (Acker et al., 2011; Hansen and Traynelis, 2011), whereas the small molecule TCN-201 is a potent negative allosteric modulator of glycine but not glutamate at Glun2A NMDA receptors (Hansen et al., 2012).

Collectively these findings have important clinical implications. Specifically, several orthosteric ligands of these receptors are central nervous system excitotoxins because of mechanisms that involve changes in receptor desensitization, activation, and deactivation rates. Because allosteric ligands can modulate these processes in a different manner, they may prove more amenable to achieving therapeutic targeting of the receptors in the absence of excitotoxicity (Collingridge et al., 2009).

2. Voltage-Gated Ion Channels. The earliest conceptual models of voltage-gated $\mathrm{Na}^{+}$channels posited that they are composed of two functionally distinct components, a pore and a voltage-sensitive gating apparatus that opens and closes the pore (Armstrong, 1981; Hille, 2001). Structural studies of voltage-gated $\mathrm{K}^{+}$ channels $\left(\mathrm{K}_{\mathrm{V}}\right)$ and $\mathrm{Na}^{+}$channels $\left(\mathrm{Na}_{\mathrm{V}}\right)$ provide direct evidence for this concept (Long et al., 2007; Payandeh et al., 2011, 2012; Zhang et al., 2012).

a. Voltage-gated ion channel architecture. A central pore module composed of the pore-forming S5, P, and S6 transmembrane segments from four homologous subunits or domains (Fig. 4A, left, blue) is surrounded by four symmetrically arranged voltage-sensing modules containing the S1-S4 transmembrane segments (Fig. 4A, left, green) connected by the S4-S5 linkers (Fig. 4A, left, red). Current structure-function models indicate that positive gating charges at intervals of three amino acid residues in the $\mathrm{S} 4$ transmembrane segment in each voltage-sensing module move outward under the influence of the electric field and initiate opening of the activation gate at the intracellular end of the pore by exerting a torque on the inner end of the pore-lining S6 segments (Catterall, 2010; Vargas et al., 2012; Yarov-Yarovoy et al., 2012). The structure of $\mathrm{Na}_{\mathrm{V}} \mathrm{Ab}$ captures the preopen state-all voltage sensors are activated while 
A

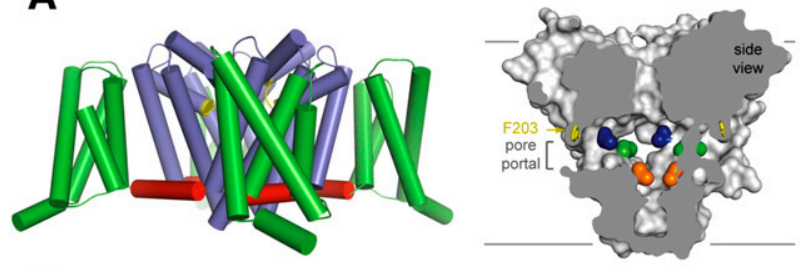

B

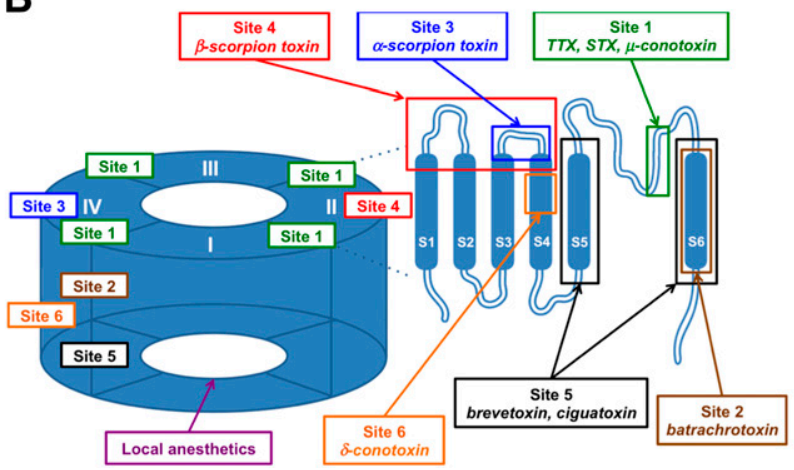

Fig. 4. (A) Side view of the crystal structure of the bacterial $\mathrm{Na}_{\mathrm{V}} \mathrm{Ab}$ VGIC (Payandeh et al., 2011). (Left) $\mathrm{Na}_{\mathrm{V}} \mathrm{Ab}$ crystal structure illustrating the voltage-sensing module (green), pore module (blue), and connecting S4-S5 linker (red) in the preopen state. (Right) The $\mathrm{Na}_{\mathrm{v}} \mathrm{Ab}$ pore module in the preopen state, indicating amino acids implicated in the binding of channel pore blockers. The tight closure in the intracellular regions provides a structural explanation for use-dependent blockade by large or hydrophilic drugs, because they would bind more rapidly upon channel opening. The amino acid Phe203 plays a key role in governing drug access to this site. The other highlighted residues, Thr206 (blue), Met209 (green), and Val213 (orange) have been implicated as key contributors to the drugbinding pocket in mammalian Nav channels. (B) Diagrammatic representation of multiple distinct allosteric sites for neurotoxins and local anesthetics at voltage-gated sodium channels, with exemplar molecules listed. The channels comprise four homologous voltage-sensing domains (I-IV), each composed of six (S1-S6) segments, which surround a central pore. The locations of the different allosteric sites (Site 1-6 and the local anesthetic site) are indicated both with regards to their domain location (left) and their localization within a given intradomain module (right). TTX, tetrodotoxin; STX, saxitoxin.

the pore remains closed but poised to open (Payandeh et al., 2011).

The functional division between the voltage-sensing module and pore module of VGICs is analogous to the functional division between the ligand-binding domain and pore domain of LGICs. Thus, for the purposes of these guidelines, the activator voltage is considered to be the "orthosteric agonist" for activation of VGICs (despite being a physical activator rather than a chemical ligand), and the gating charges in the S4 segment can be considered the "orthosteric site" for the activating action of voltage; the ion is considered the effector of the signal because it carries the signal into the cytosol or propagates it along the membrane. In this conceptual framework, many drugs and neurotoxins serve as allosteric ligands that alter the voltage dependence of channel activation and the ion conductance activity of the pore by binding to sites that are distinct from the gating charges that are responsible for voltage-dependent activation.

$b$. Allosteric sites on voltage-gated ion channels. Detailed studies of voltage-gated sodium channels have revealed six distinct sites of neurotoxin action and an additional site for local anesthetics and related drugs (Catterall, 1980; Cestele and Catterall, 2000; Fig. 4B). Tetrodotoxin, saxitoxin, and $\mu$-conotoxins block the pore by binding to its outer opening (Hille, 2001; Tikhonov and Zhorov, 2012). Local anesthetics and related drugs bind within the central cavity of the pore and block it (Ragsdale et al., 1994; Hille, 2001; Payandeh et al., 2011) (Fig. 4A, right). In contrast to these pore blockers, the binding sites at which scorpion toxins modify voltagedependent gating are located on the extracellular ends of the S3-S4 segments (Catterall et al., 2007). Toxins bound in this position lock the voltage sensor in its resting or activated states and thereby modify channel function (Catterall et al., 2007). Multiple classes of lipophilic neurotoxins modify voltage-dependent gating by binding to incompletely characterized sites in the S5 and S6 transmembrane segments (Cestele and Catterall, 2000). Binding of ligands at these different neurotoxin receptor sites is allosterically coupled, and these interactions follow the MWC model for heterotropic allosteric interactions (Catterall, 1980; Cestele and Catterall, 2000).

Similar ligand-binding studies of L-type voltage-gated $\mathrm{Ca}^{2+}\left(\mathrm{Ca}_{\mathrm{V}}\right)$ channels revealed three allosterically coupled sites of drug action, specific for pore-blocking phenylalkylamines, like verapamil, and benzothiazepines, like diltiazem, and gating modifier dihydropyridines, like amlodipine (Spedding, 1985a; Spedding et al., 1995; Hockerman et al., 1997a; Striessnig, 1999). Allosteric interactions are observed between drugs bound at these three sites. Like $\mathrm{Na}_{\mathrm{V}}, \mathrm{Ca}_{\mathrm{V}}$ channels are targets for multiple classes of neurotoxins that can be divided into pore blockers (e.g., $\omega$-conotoxin GVIA) and gating modifiers (e.g., $\omega$-agatoxin IVA) (Olivera et al., 1994; Bourinet et al., 1999; Winterfield and Swartz, 2000). All of these agents are allosteric modulators with respect to the effects of voltage on the gating charges in the $\mathrm{S} 4$ segments in the voltage-sensing module.

$\mathrm{K}_{\mathrm{V}}$ channels also are allosteric proteins. Tetraethylammonium and other tertiary and quaternary amines bind in the central cavity and block the pore (Armstrong, 1974). Polypeptide toxins, like charybdotoxin, bind at the extracellular end of the pore (MacKinnon and Miller, 1989). Gating modifier toxins, like hanatoxin, bind to the extracellular S3-S4 loop at the extracellular end of the S4 segment that bears the gating charges, and they oppose activation in an allosteric manner by increasing the conformational force against which the voltage-driven outward movement of the gating charges must work (Li-Smerin and Swartz, 1998). Thus, all three classes of $\mathrm{K}_{\mathrm{V}}$ channel modulators are allosteric in the sense that they act at sites distinct from the gating charges where voltage exerts its force to induce channel activation. Moreover (although it is not often considered in the same context), the $\mathrm{K}^{+}$channel encoded by the human ether-àgo-go (hERG) gene is also associated with multiple allosteric sites. Indeed, recent studies using radiolabeled versions of the hERG channel inhibitors, astemizole and 
dofetilide, demonstrated the existence of at least three distinct binding sites occupied by $\mathrm{K}^{+}$ions, LUF6200, and dofetilide/astemizole (Yu et al., 2014). The study also showed that the binding of $\mathrm{K}^{+}$ions and dofetilide/ astemizole are positively cooperative with respect to each other as is the interaction between LUF6200 and $\mathrm{K}^{+}$ions. These insights are important, because the hERG channel is an important antitarget in drug discovery; inhibition of this channel is associated with increased risk of arrhythmia.

Consistent with the conformational selection mechanism of the MWC model, allosteric modulation of the activity of voltage-gated sodium, calcium, and potassium channels is bidirectional. Batrachotoxin and other lipophilic toxins are positive allosteric modulators and enhance sodium channel activation (Catterall, 1980). The polypeptide $\beta$-scorpion toxins are also positive allosteric modulators that trap the voltage sensor in its activated state (Catterall et al., 2007). In contrast, protoxins block outward movement of the voltage sensors and prevent activation (Schmalhofer et al., 2008; Sokolov et al., 2008), and $\alpha$-scorpion toxins trap the voltage sensor in domain IV of sodium channels in a partially activated state and thereby prevent voltage-dependent fast inactivation (Catterall et al., 2007). Dihydropyridines can be either positive or negative allosteric modulators of calcium channels, acting at a single receptor site, depending on the experimental conditions (Hockerman et al., 1997b; Ito et al., 1997; Sinnegger et al., 1997; Spedding, 1985a; Spedding et al., 1995; Striessnig, 1999). Negative allosteric modulators can oppose channel activation, as in the cases of hanatoxin acting on $\mathrm{K}_{\mathrm{V}}$ channels and both dihydropyridines and agatoxin IVA acting on $\mathrm{Ca}_{\mathrm{V}}$ channels. Pore blockers prevent ion conductance of all three classes of voltage-gated ion channels. Thus, although the VGICs are a completely distinct family of proteins from GPCRs and LGICs, the principles of allostery also apply to them when membrane voltage is considered as the agonist that activates this unique set of proteins.

c. Role of regulatory domains in voltage-gated ion channel allostery. The VGIC superfamily also includes calcium-activated potassium $\left(\mathrm{K}_{\mathrm{Ca}}\right)$ channels, cyclic nucleotide-gated (CNG) channels, hyperpolarization and cyclic nucleotide-activated (HCN) channels, and transient receptor potential (TRP) channels (Yu and Catterall, 2004). These channel types have the same 6TM architecture as $\mathrm{Na}_{\mathrm{V}}$ and $\mathrm{K}_{\mathrm{V}}$ channels, with a structurally analogous voltage-sensing domain and pore domain (Yu and Catterall, 2004). However, they all have an additional regulatory domain that binds ligands and modulates channel gating and/or function by an allosteric mechanism. $\mathrm{K}_{\mathrm{Ca}}$ channels have an intracellular "regulate-the-conductance-of- $\mathrm{K}^{+"}$ domain in the $\mathrm{C}$-terminal segment of each of their four subunits, which interacts allosterically with the voltage sensor domains to regulate channel opening (Yuan et al., 2010; Pantazis and
Olcese, 2012). $\mathrm{Ca}^{2+}$ and voltage work synergistically to control channel gating. CNG and HCN channels have cyclic nucleotide-binding domains in the C-terminal segments. These ligand-binding domains are the primary regulators of CNG and HCN channels (Matulef and Zagotta, 2003; Flynn et al., 2007). Binding of ligands induces a local conformation change, which is thought to work in an allosteric manner by transmitting a torque to the pore-lining S6 segments and enhancing the opening conformational change of these channels. Cyclic nucleotide binding and voltage changes work synergistically to control opening and closing of HCN channels, just as $\mathrm{Ca}^{2+}$ and voltage work together to control $\mathrm{K}_{\mathrm{Ca}}$ channels.

Members of the TRP family of channels are regulated by diverse physiologic stimuli, including lipid second messengers such as phosphatidylinositol phosphates, heat, cold, and noxious chemicals (Bautista et al., 2007; Wu et al., 2010a; Grimm et al., 2011). Recent high-resolution structures show that the temperature-sensitive TRPV channels have a transmembrane core with a fold like $\mathrm{K}_{\mathrm{V}}$ or $\mathrm{Na}_{\mathrm{V}}$ channels plus a large intracellular TRP domain that interacts with the transmembrane core of the channel through the S4-S5 linker and is well positioned for allosteric interactions with the voltage-sensing domains (Liao et al., 2013). The heat-activated TRPV1 channel and cold-activated TRPM8 channel are both voltage-sensitive, and their voltage sensitivity is modulated by temperature and by activators and inhibitors (Nilius et al., 2005). Vanniloid activators bind to the S3 and S4 segments in the voltage-sensing domain and toxins that act as allosteric modulators bind to the pore turret (Cao et al., 2013; Liao et al., 2013). Thus, it is possible that TRP channels can be thought of in the same structural terms as the VGICs, with voltage sensitivity as the "orthosteric" activator. However, in TRP channels, voltage changes are not sufficient to open the channel by themselves, and modulation by temperature, noxious chemicals, toxins, and/or physiologic ligands, like lipid second messengers, is also required for robust pore opening. Recent crystal structures reveal apparently open and closed channel states in which the voltagesensing domain conformation is unchanged, suggesting that opening the pore at the extracellular end is the primary gating process and may be regulated by conformational changes independent of the voltage sensor (Cao et al., 2013; Liao et al., 2013). Further studies are currently required to assess whether the voltage-sensing domain, the outer pore, or the unique intracellular TRP domains should be considered akin to the primary, orthosteric site at TRP channels. However, in any case, allosteric interactions among voltage, temperature, and diverse allosteric ligands are all central regulators of opening and closing of TRP channels.

There are 143 members of the VGIC protein superfamily in the human genome (Yu and Catterall, 2004). Remarkably, channel families that include 113 members of this superfamily also depend on allosteric interactions 
for their normal gating and for modulation of gating by temperature, noxious chemicals, drugs, and toxins. Thus, the VGICs are one of the largest superfamilies of allosteric proteins.

\section{B. G Protein-Coupled Receptors}

Much of the current interest in small molecule allosteric receptor modulators has been driven by the surge in the discovery of such ligands for all major $G$ proteincoupled receptor subfamilies by both academic and, notably, industry groups. Moreover, the biologic requirement of GPCRs to interact with other proteins to transfer information from the extra- to intracellular environments highlights that all aspects of the function of these proteins are essentially driven by allostery. That is, the highly dynamic protein can be viewed as a "conduit" involved in transmitting energy from one ligand or protein (the "modulator") to another (the "guest") through topographically distinct domains. If both "modulator" and "guest" represent different small molecules, then this describes the classic view of allosteric receptor interactions. If the "modulator" and "guest" represent a ligand and an intracellular signaling protein, then this describes the general phenomenon of agonism, as well as the case of "biased" agonism (Kenakin and Miller, 2010; Kenakin and Christopoulos, 2013; Lane et al., 2013). This refers to the ability of different ligands to preferentially stabilize a subset of functionally relevant receptor conformations such that different signaling proteins (and associated pathways) are recruited to the relative exclusion of others. Increasing examples are also being identified where bias can be imposed on the signaling of orthosteric agonists by cobound allosteric modulators, leading to situations where positive, negative, or neutral modulation can be observed for the same orthosteric-allosteric ligand pair at the same receptor depending on the pathway that is being measured (Leach et al., 2007; Keov et al., 2011; Kenakin and Christopoulos, 2013; Langmead and Christopoulos, 2014).

The characteristic structural features of GPCRs are the presence of seven transmembrane-spanning domains (hence the alternative designation of "7TMR") connected by three intra- and three extracellular loops, an extracellular N-terminal domain, and intracellular C-terminal domain. On the basis of structural characteristics, the nonolfactory GPCRs are minimally divided into three broad classes (A, B, or C). In all cases, the activation mechanism of the receptors is intrinsically allosteric, because it involves the long-range transmission of an activating extracellular signal imparted by the orthosteric agonist to a spatially distinct intracellular domain that is recognized by $G$ proteins and other transducers, such as the $\beta$-arrestins (Christopoulos and Kenakin, 2002; Kenakin and Miller, 2010; Kenakin and Christopoulos, 2013; Lane et al., 2013). The recent highresolution crystal structure of an activated $\beta_{2}$-adrenergic GPCR bound to both an agonist and its cognate $G_{s}$ heterotrimeric $\mathrm{G}$ protein highlighted key molecular mechanisms by which a monomeric GPCR can participate in allosteric communication that mediates signal transduction (Rasmussen et al., 2011). Moreover, it is known that GPCRs can also form dimers or higher-order oligomers, thus increasing the likelihood of allosteric interactions between receptor protomers (Pin et al., 2007).

1. Allostery at Class A G Protein-Coupled Receptors. In terms of allosteric binding sites for small molecules, the muscarinic acetylcholine receptors $(\mathrm{mAChRs})$ are arguably some of the most well characterized class A GPCRs. Indeed the earliest example of a GPCR (negative) allosteric modulator was identified at this family (Lullmann et al., 1969), and since that time a number of seminal studies have validated and extended this observation such that the entire spectrum of allosteric ligand types has been described for the mAChRs, including prototypical allosteric inhibitors and enhancers, such as gallamine and alcuronium; allosteric agonist/ modulators, such as LY2033298; and even bitopic ligands, such as McN-A-343 (4-[[[(3-chlorophenyl)amino]carbonyl] oxy]- $N, N, N$-trimethyl-2-butyn-1-aminium chloride) and THRX160209 (4-\{N-[7-(3-(S)-(1-carbamoyl-1,1-diphenylmethyl)pyrrolidin-1-yl)hept-1-yl]- $N$-( $n$-propyl)amino\}-1(2,6-dimethoxybenzyl)piperidine) (Clark and Mitchelson, 1976; Stockton et al., 1983; Proska and Tucek, 1994; Steinfeld et al., 2007; Chan et al., 2008; Valant et al., 2008; Leach et al., 2010). Most of these molecules are believed to interact at an extracellular vestibule that sits above the orthosteric binding site, which is located deeper in the transmembrane domain bundle; this is likely to be a common motif for other Class A GPCRs but by no means all of them (Conn et al., 2009). The adenosine family of GPCRs is also an important example for the study of Class A GPCR allosterism, because the $A_{1}$ adenosine receptor subtype was one of the first GPCRs for which positive allosteric modulators were reported (Bruns and Fergus, 1990), and the development of $A_{1}$ allosteric enhancers may prove a promising avenue for drug development in treating neurologic, cardiac, sleep, immune, and inflammatory disorders (Jacobson and Gao 2006; Fredholm et al., 2011). Throughout the last two decades, the number of GPCR allosteric modulators reported has increased dramatically, with over 40 different Class A GPCRs having been associated with one or more allosteric modulators (Conn et al., 2009). With regards to current therapeutic utility, the chemokine CCR5 receptor represents the first Class A GPCR for which an allosteric modulator, the antagonist maraviroc, has been approved for clinical use (Dorr et al., 2005), and substantial efforts are underway exploring allosteric modulators of other chemokine receptor subtypes (Allegretti et al., 2008). More recently, the immunostimulant CXCR4 antagonist plerixafor (Scholten et al., 2012) and the antithrombotic purine P2Y12 antagonist ticagrelor (van Giezen et al., 2009) have also been suggested to 
potentially mediate their antagonistic effects via an allosteric mechanism.

2. Allostery at Class B (Peptide) G Protein-Coupled Receptors. Class B peptide hormone GPCRs have been particularly difficult to target therapeutically because of the diffuse pharmacophore associated with the peptide orthosteric site, which is extracellular and involves multiple points of interaction with the $\mathrm{N}$ terminus and top of the transmembrane bundle. However, a number of small molecules have recently emerged that act allosterically, examples of which are found with molecules targeting the corticotrophin releasing factor-1 receptor (Hoare et al., 2008), the calcitonin receptor (Dong et al., 2009), and the glucagon-like peptide-1 receptor (Knudsen et al., 2007; Wootten et al., 2011). These findings suggest that the allosteric approach represents a viable path forward for discovering small molecules directed against these peptide-hormone receptors. Interestingly, and in contrast to many of the Class A receptors, the binding site in Class B receptors for most allosteric small molecules identified to date is most likely located further in the transmembrane domain bundle than the orthosteric ligands.

3. Allostery at Class C G Protein-Coupled Receptors. The Class C GPCRs have traditionally proven most amenable to allosteric modulation and are the subfamily of GPCRs that have largely led the renaissance in small molecule allosteric drug discovery within the pharmaceutical industry. This likely reflects the fact that these receptors have the most clearly delineated distinction between the location of the orthosteric binding pocket, which is found in the large "Venus flytrap-like" N-terminal domain, and at least one, if not more, allosteric sites, which are located with the transmembrane-spanning bundles. They are also the first family of GPCR for which an allosteric modulator was approved and marketed as a novel therapeutic; cinacalcet is a positive allosteric modulator of the calcium-sensing receptor and is indicated for the treatment of secondary hyperparathyroidism in patients with chronic kidney disease (Lindberg et al., 2005; Poon, 2005). Allosteric modulators of the metabotropic glutamate (e.g., CPCCOEt, MPEP, ADX-47273) and GABA $_{\mathrm{B}}$ Class C GPCRs (e.g., CGP7930; CGP13501; GS39783; see Conn et al., 2009) are also the subject of substantial research because of their emerging therapeutic potential for a range of psychiatric and neurologic disorders such as pain, anxiety, cognition, Parkinson's disease, drug addiction, and schizophrenia (Pin and Prezeau, 2007; Conn et al., 2009).

4. Structural Biology of G Protein-Coupled Receptor Allosteric Sites. Arguably one of the biggest breakthroughs in GPCR biology in recent years has been the solution of a number of receptor crystal structures cobound with ligands and/or interacting proteins (Venkatakrishnan et al., 2013). These structural studies are finally shedding new light on the molecular basis of allostery at this large receptor family. For example, the "classic" ternary complex of activated GPCR, orthosteric agonist, and G protein was recently solved for the $\beta_{2}$-adrenergic receptor/ $G_{\mathrm{s}}$ complex, providing the first snapshot of how orthosteric ligand binding can be allosterically coupled to G protein activation (Rasmussen et al., 2011). Recent 1.8- $\AA$ structures of the adenosine $\mathrm{A}_{2 \mathrm{~A}}$ receptor (Liu et al., 2012 ) or the $\delta$-opioid receptor (Fenalti et al., 2014) have also revealed a molecular mechanism by which sodium ions can act as an allosteric modulator that can bias GPCR state transitions and orthosteric ligand activity. From the point of view of small molecule allosteric ligands, the crystal structures of the Class A chemokine CCR5 receptor bound to maraviroc (Tan et al., 2013), the transmembrane-spanning region of the Class B CRF1 receptor bound to CP-376395 [ $N$-(1-ethylpropyl)-3, 6-dimethyl-2-(2,4,6-trimethylphenoxy)-4-pyridinamine hydrochloride] (Hollenstein et al., 2013), and the transmembrane-spanning region of the Class $\mathrm{C}$ metabotropic glutamate mGluR1 receptor bound to FITM (Wu et al., 2014) have yielded the first insights into pockets used by allosteric molecules (Fig. 5A). However, these latter structures still represent binary complexes, because, in all instances, the small molecules are negative allosteric modulators that do not favor the cobinding of orthosteric ligand. The challenge of identifying ternary complexes with cobound orthosteric and allosteric ligands has recently been overcome by the solution of the first structure of an activated GPCR in complex with both an agonist and a positive allosteric modulator, namely, the $\mathrm{M}_{2} \mathrm{mAChR}$ bound to an activating nanobody, a highefficacy orthosteric agonist (iperoxo) and a positive modulator of agonist affinity (LY02119620; 3-amino-5chloro- $N$-cyclopropyl-4-methyl-6-[2-(4-methylpiperazin1-yl)-2-oxoethoxy] thieno[2,3-b]pyridine-2-carboxamide)

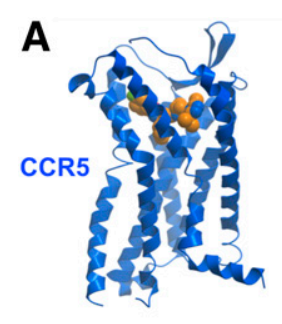

B
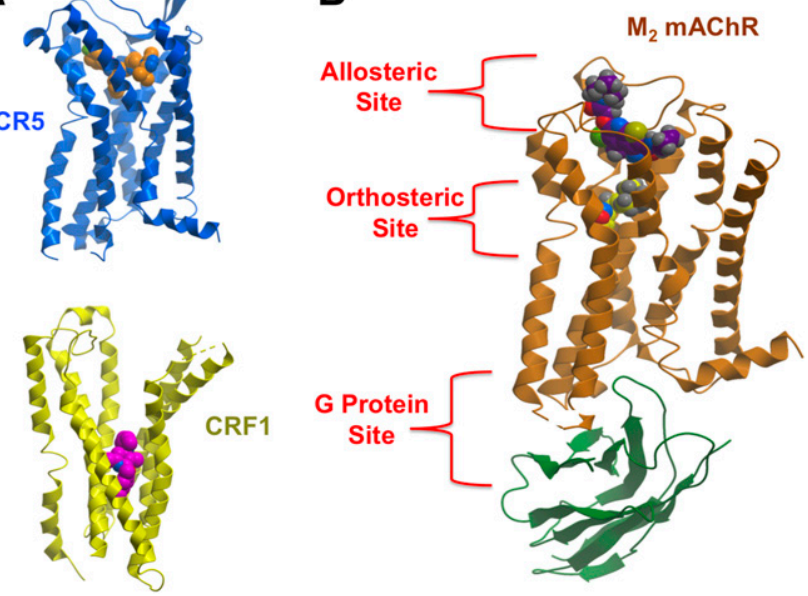

Fig. 5. Topographically distinct but conformationally linked domains within GPCRs. (A) Structures of the chemokine CCR5 receptor bound to maraviroc (PDB ID 4MBS) and the corticotrophin releasing factor receptor (CRF1) bound to CP-376395 (PDB ID 4K5Y). (B) Structure of the $\mathrm{M}_{2} \mathrm{mAChR}$ (PDB ID 4MQT) in complex with a positive allosteric modulator (LY02119620, purple), an agonist (iperoxo, yellow), and a nanobody (Nb9-8, green) that stabilizes an active state of the receptor. 
(Kruse et al., 2013). This structure (Fig. 5B) has provided striking insight into some of the dramatic changes that occur at the level of the intracellular G protein site, the orthosteric pocket, and an extracellular allosteric site, highlighting the high degree of conformational linkage between these topographically distinct domains within a single GPCR. In parallel with these crystallographic breakthroughs, there have been significant computational advances that have also impacted our understanding of GPCR allostery. Using the inactivestate crystal structure of the $\mathrm{M}_{2} \mathrm{mAChR}$, Dror et al. (2013) performed long time-scale molecular dynamic simulations using multiple, structurally diverse, allosteric modulators of antagonist binding to reveal a common allosteric pocket and mode of interaction that were subsequently validated experimentally. Importantly, this study also uncovered mechanisms contributing to the observed cooperativity, including electrostatic interactions between ligands and induced changes in conformational coupling between binding pockets that are not readily discernible through the study of crystal structures alone.

Collectively, most GPCRs possess a minimum of two allosteric sites: an intracellular region recognized by signal transducing proteins and another binding pocket for small molecules that is spatially distinct from the orthosteric site, but can vary dramatically between subfamilies, for instance, within the transmembrane domains (e.g., CCK1 receptor; Gao et al., 2008), extracellular loops (e.g., $\mathrm{M}_{2}$ mACh; Kruse et al., 2013), or intracellular regions (e.g., chemokine CXCR2; Nicholls et al., 2008). Interestingly, there are also examples of multiple allosteric sites on the same GPCR (Lazareno et al., 2002; de Kruijf et al., 2011; Noetzel et al., 2013; Zweemer et al., 2013), further highlighting the rich potential for allosteric targeting of this receptor family.

\section{Nuclear Hormone Receptors}

Nuclear hormone receptors (NHRs) are ligand-regulated transcription factors that serve as receptors for steroid hormones and other sterols, lipophilic vitamins, and fatty acids as well as other hydrophobic compounds. Unlike ligands for most of the receptors and ion channels discussed in this review, ligands for NHRs must traverse the plasma membrane to bind to these intracellular receptors. Because of the hydrophobic nature of NHR ligands, most are believed to passively transfer across the plasma membrane, although there have been reports of at least some ligands being actively transported. Depending on the NHR in question, the receptor may be primarily cytoplasmic or nuclear in localization before ligand binding. Forty-eight members of this superfamily of receptors are found in humans, and they display a conserved modular structure (Fig. 6A) composed of a variable $\mathrm{N}$-terminal $\mathrm{A} / \mathrm{B}$ region that also contains a ligandindependent transactivation domain ("AF1"), a central highly conserved DNA binding domain (DBD; C region),

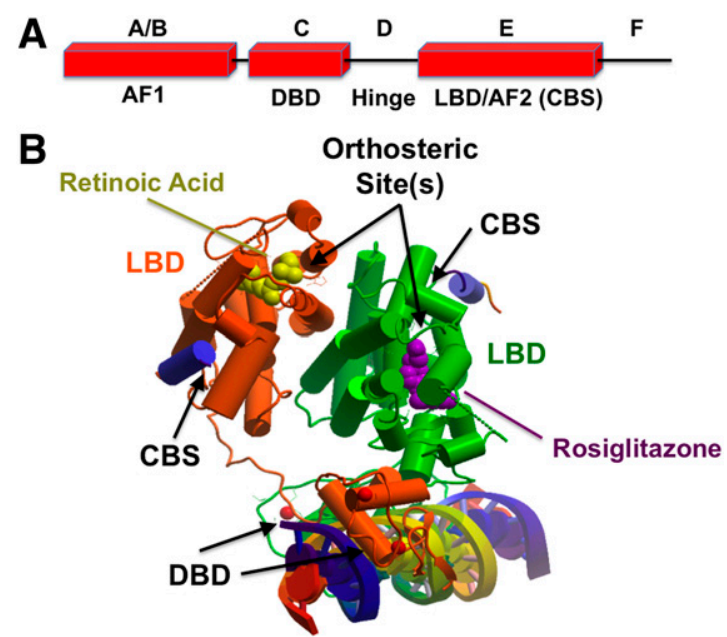

Fig. 6. (A) Modular domain structure of NHRs. (B) Crystal structure of the PPAR $\gamma /$ RXR heterodimeric NHR (PDB ID 3DZY) bound to the orthosteric ligands retinoic acid and rosiglitazone, highlighting potential sites for allosteric modulation. AF, activation function.

and a C-terminal ligand binding domain (LBD; E region) that also contains the ligand-dependent "AF2" transactivation domain. NHRs also contain a "hinge" region (D) that is quite variable and links the $\mathrm{C}$ and $\mathrm{E}$ regions. Some receptors also contain an $\mathrm{F}$ region located in the C-terminal region of the LBD; however, the function of this region of the receptor is unclear.

NHRs function as homodimers, heterodimers, or monomers depending on the specific receptor as well as the physiologic conditions and respond to agonist binding by recruiting specific transcriptional cofactor proteins, coactivators, that allow the receptor to activate transcription of target genes to which the receptor has been directed to bind via its DBD (Burris et al., 2013). In addition to coactivators, corepressor proteins can interact with some NHRs depending on the physiologic conditions and direct repression of transcription. The dimeric NHRs are subdivided into two general classes. The class I receptors are phylogenetically older and form homodimers. Exemplars of this class are the steroid receptors. Class II receptors form heterodimers with the retinoid $\mathrm{X}$ receptor (RXR)/ultraspiracle protein, such as the peroxisome proliferator-activated receptor (PPAR) $\gamma / \mathrm{RXR} \alpha$ NHR. Another subgrouping of NHRs includes many orphan NHRs such as receptors for heme (REV-ERB) and oxysterols (retinoic acid receptor related orphan receptors) (Kojetin and Burris 2014).

The LBD is a globular domain composed of a threelayered $\alpha$-helical "sandwich" (Brzozowski et al., 1997; Moras and Gronemeyer, 1998; Savkur and Burris, 2004). The orthosteric ligand binding site is located within the LBD, and in many cases the ligand is typically encased within a hydrophobic pocket with little solvent exposure. A "mouse-trap" model for ligand binding has been proposed where the ligand accesses the orthosteric site via a channel to the interior of the LBD (Renaud et al., 1995), and 
the resulting conformational change induced by ligand binding causes a specific alpha helix (helix 12) to shift position, enclosing the ligand and also creating a surface on the LBD amenable to recognition of transcriptional coregulator proteins (defined herein as the coregulator binding site [CBS]) necessary for the receptor to modulate transcription of target genes.

There are hundreds of transcriptional coregulator proteins recognized by NHRs, and there are likely multiple mechanisms of interaction of these proteins with the receptors; however, one mechanism that is widely used and relatively well characterized is recognition of the NHR interacting domain (NR box) contained in many coactivator proteins by agonist-bound NHRs. The NR box is composed of an LxxLL motif $(\mathrm{L}=$ leucine and $\mathrm{x}=$ any amino acid) that forms an amphipathic $\alpha$-helix that recognizes a specific groove on the surface of the NHR LBD formed by the conformational change induced by agonist binding (Heery et al., 1997; Torchia et al., 1997; Voegel et al., 1998; Savkur and Burris, 2004). Recognition of the NR box by agonist-bound NHR is mediated by two key interactions-hydrophobic interactions between the hydrophobic surface of the LxxLL helix and the hydrophobic cleft in the LBD surface and hydrogen bonding between specific charged amino acid side chains from the LBD [a glutamic acid (from helix 12 of the LBD) and a lysine residue (from helix 3 of the LBD)] and the peptide backbone of the NR box. Effective recruitment of the coactivator protein via NR box recognition by the NHR requires key positioning of helix 12 , which is regulated by orthosteric ligand binding, leading to formation of the "charge clamp" that is composed of the two charged residues in helices 3 and 12 that position the LxxLL helix to allow the leucine side chains to pack into the hydrophobic cleft of the LBD, the so-called coactivator binding groove.

1. Structural Insights into Nuclear Hormone Receptor Allosteric Coupling. Given the modular nature and functionality of the NHR superfamily, the majority of studies on mechanisms of allostery at these receptors have focused on the coupling between the orthosteric $\mathrm{LBD}$, the cofactor binding regions, and the DBD. Numerous structures of LBDs and DBDs have been solved by NMR and crystallography. More recently, the solution of the crystal structure of the PPAR $\gamma / \mathrm{RXR} \alpha$ heterodimer (Fig. 6B), the LXR $\beta / \mathrm{RXR} \alpha$ heterodimer and the hepatocyte nuclear factor $4 \alpha$ homodimer, each bound to DNA (Chandra et al., 2008, 2013; Lou et al., 2014), and the cryo-EM structure of the vitamin D receptor/RXR (Orlov et al., 2012) have yielded further new knowledge about the quaternary structure of the complex and the allosteric interplay between the different binding domains. The binding of cofactors to the CBS in the LBD of NHRs can be associated with different degrees of asymmetry in the relative ability of each LBD to bind a cofactor, even for homodimeric NHRs. This asymmetry can be quite extreme for large cofactors, characterized by negative cooperativity that ensures only one cofactor binds per
LBD homodimer. The binding of DNA, via its relevant response elements, also exerts additional allosteric control over the resulting structure and receptor function. In some instances, crystallographic studies have revealed different binding poses for orthosteric ligands within a dimeric LBD complex (e.g., estrogen receptors in complex with bisphenol A) but not others (e.g., estrogen receptors bound to $17 \beta$-estradiol), suggesting that additional (as yet largely undefined) allosteric mechanisms exist for some NHRs that can modify the interaction between orthosteric ligands across protomers.

Although the complete repertoire of allosteric mechanisms at NHRs is still being unraveled, insights gained from structural analysis of the lac repressor, a well studied transcriptional regulator in bacteria, suggest that classic allosteric behaviors associated with the MWC model are likely to be operative in such systems. The minimal structure of the lac repressor is one of a homodimer containing a disordered hinge region that, upon binding DNA, loses the disorder and becomes a fully symmetrical molecule (Lewis et al., 1996). Two distinct conformations of the repressor have been observed corresponding to induced and repressed states, with the allosteric transition between the two states involving communication via the dimer interface while preserving the axial symmetry of the dimer (Lewis, 2005).

2. Synthetic Nuclear Hormone Receptor Modulators. Design of synthetic NHR ligands have almost exclusively focused on the orthosteric site until relatively recently. This includes well studied molecules, referred to collectively as "selective nuclear hormone receptor modulators," such as tamoxifen, andarine, GW0072, and many others (Burris et al., 2013). Although a commonly applied term, such ligands nonetheless bind in the orthosteric pocket of the NHRs. The key distinguishing characteristic of selective nuclear hormone receptor modulators is their ability to display divergent pharmacological actions (e.g., agonist or antagonist) via the same receptor in a cell/tissue context-dependent manner (Burris et al., 2013). Thus, these molecules are akin to biased (orthosteric) agonists that have been described for GPCRs (Kenakin and Christopoulos, 2013). In each instance, the ligand promotes a distinct conformation in the receptor that changes its interactive properties toward its cellular partners in a nonuniform manner, which will thus manifest differently depending on the cellular complement of receptor interactants (e.g., corepressors, coactivators, etc.). Excitingly, recent work combining structural and chemical biology approaches has yielded new insights into possible molecular determinants underlying this cell/tissue-specific signaling of the NHRs. Specifically, studies of the LBD of the ER $\alpha$ receptor in complex with a variety of compounds that exhibit graded and phenotypically diverse activities have unmasked a novel phenomenon, termed "dynamic binding," whereby the same molecule can adopt different orientations within the orthosteric pocket (Bruning et al., 2010; Srinivasan 
et al., 2013). The distribution of different orientations of the same ligand across receptor confomers may thus be the mechanism by which ligand activity can be titrated in a cell background-specific manner.

The discovery that binding of ligands to the orthosteric site of the LBD regulated the conformation of the CBS and that this allowed recruitment of coactivator proteins and "agonistic" effects, also led to the potential to directly target the CBS formed upon agonist binding with small molecules. A range of peptides, peptidomimetics, and nonpeptide small molecules that inhibit the activity of a variety of NHRs even when agonists are present has been designed over the past decade (Chang et al., 1999, 2005; Norris et al., 1999; Hall et al., 2000; Nguyen et al., 2002; Kern and Zuiderweg, 2003; Leduc et al., 2003; Pike et al., 2003; Geistlinger et al., 2004; Arnold et al., 2005, 2007; Galande et al., 2005; Wang et al., 2006; Estebanez-Perpina et al., 2007a; Mettu et al., 2007; LaFrate et al., 2008; Parent et al., 2008); these are sometimes referred to as coactivator binding inhibitors. Coactivator binding inhibitors target the receptor at a site spatially distinct from the orthosteric site, leading to modulation of receptor activity. However, unlike allosteric sites defined for other receptor classes, the targeting of the CBS on NHRs has considerable issues with specificity. Specifically, NHRs, as a class, generally form this coactivator binding groove, which has been conserved to interact with LxxLL containing coactivator proteins. Thus, the pocket is highly conserved across NHR subtypes. A number of studies have addressed this issue, demonstrating that one can design selective compounds (Moore et al., 2010), but this will remain a significant challenge if any of these compounds continue toward clinical development.

In addition to targeting the CBS, it is possible to target both nuclear response elements and zinc fingers of the DBD (Moore et al., 2010), which may constitute allosteric sites from the point of view of an orthosteric NHR ligand. Other possible allosteric sites on NHRs potentially available for drug design have recently been observed. For example, the androgen receptor possesses a unique binding surface, termed $\mathrm{BF}-3$, that recognizes small molecules such as 3,3,5-triiodothyroacetic acid to allosterically modulate the binding of coactivators to the adjacent AF-2 region (Estebanez-Perpina et al., 2007b). Most recently, a novel allosteric ligand binding site was identified on PPAR $\gamma$ that, when bound by small molecules, engendered a unique pharmacological profile of regulation of the receptor (Hughes et al., 2014). This suggests that the design of allosteric ligands for NHRs may be primed to develop as a field, akin to other classes of receptor modulators over the past decade.

\section{Receptor Tyrosine Kinases}

Receptor tyrosine kinases (RTKs) are a subset of the larger family of protein tyrosine kinases with a similar molecular architecture. RTKs consist of ligand binding domains in the extracellular region, a single transmembrane helix, and a cytoplasmic region that contains the protein tyrosine kinase (TK) domain with regulatory regions in the C-terminal and juxtamembrane domains. The topology of RTKs and their mechanism of activation are highly conserved, although there are substantial differences on how a cognate ligand leads to their activation. In fact, recent structural studies of RTKs have revealed a great diversity in the extracellular orthosteric ligand-binding site and thus in the mechanisms of their activation by growth factor ligands (Lemmon and Schlessinger, 2010).

1. The Tyrosine Kinase Domain. A vital component of the RTK is represented by the TK domain, a bilobed structure with an N-terminal lobe consisting mainly of $\beta$-sheets and a C-terminal domain comprising $\alpha$-helices (Fabbro and Garcia-Echeverria, 2002; Bardelli et al., 2003; Levitzki, 2003; Vieth et al., 2004, 2005; Cowan-Jacob, 2006; Taylor and Kornev, 2011). The hinge region that lines the ATP-binding site, which is the target of the majority of small molecular weight kinase inhibitors (KIs), connects these two lobes. The N-terminal lobe of the catalytic domain contains the "G-rich" loop, a stretch of glycine residues that is crucial for ATP binding and phosphoryl transfer, and helix $\mathrm{C}$, the sole helical structure in the $\mathrm{N}$-terminal lobe. In contrast, the C-terminal lobe of the kinase domain is involved in substrate binding (ATP and protein substrate) and contains a conserved aspartic acid that is important for the catalytic activity and the A-loop (activation loop) with its N-terminal DFG motif (Fabbro and Garcia-Echeverria, 2002; Bardelli et al., 2003; Levitzki, 2003; Vieth et al., 2004, 2005; Cowan-Jacob, 2006; Taylor and Kornev, 2011).

2. Structural Regulation of the Tyrosine Kinase Domain. The helix C, the G-loop, and the A-loop play important regulatory roles in the dynamics of the protein kinase domain. In particular, the A-loop with its N-terminal DFG motif, provides docking sites for the protein/peptide substrates. The TK domain oscillates between two major conformations: an "on state" with maximal kinase activity (active kinase) and an "off state" with minimal activity. The shift in the equilibrium between active and inactive conformations (conformational bias) is a key determinant in the TK domain regulation and can be brought about by many factors, including ligand binding, post-translational modifications, regulatory proteins, and binding of a ligand (Cowan-Jacob, 2006; Kornev et al., 2006; Zhang et al., 2009; Taylor and Kornev, 2011). Thus far, comprehensive structural, biophysical, and biochemical information revealing the various transitions from the fully inactive to the fully activated state of a kinase are available only for a few TK domains (Morgan, 1996; Hubbard, 1997). Not all protein kinases undergo this cycle of activation/deactivation: some, such as CK2, are always in the "on state" and only the location of the kinase determines its substrate selectivity (Niefind et al., 2009). 
In the context of RTKs, although structural information exists on extracellular hormone-binding and intracellular TK domains, no structure has been solved to date of the complete membrane-embedded receptor. However, recent computational studies have been able to reconcile existing structural information with powerful molecular dynamic simulations to propose a mechanism for the intact epidermal growth factor RTK generally consistent with the expectations of the MWC model (Arkhipov et al., 2013). Specifically, it is proposed that the transition between inactive monomers to inactive and then active dimers involves ligand-dependent changes in the extracellular domains that modulate the dimerization of the transmembrane regions at either the $\mathrm{N}$ termini (for active state) or $\mathrm{C}$ termini (inactive state). This, in turn, is transmitted via the associated juxtamembrane segments to the TK domains to form either asymmetric active or symmetric inactive TK dimers (Fig. 7A).

3. Small Molecule Kinase Inhibitors. To date, numerous small molecule KIs have been described, most of which act in the kinase regions of the protein. Accordingly, most of the information and principles associated with allostery at these proteins have been derived from studies of the kinase domains themselves. In this regard, the most common classification of KIs that target kinases is based on their binding modes relative to the ATP substrate site of the kinase domain (Li et al., 2004). In the minimalistic view, the ATP-site binders are considered to interact with the primary (or canonical) site in a competitive manner to ATP, whereas the non-ATP-site binders are considered to be allosteric and not to compete with ATP. In this context, the RTKs represent a special
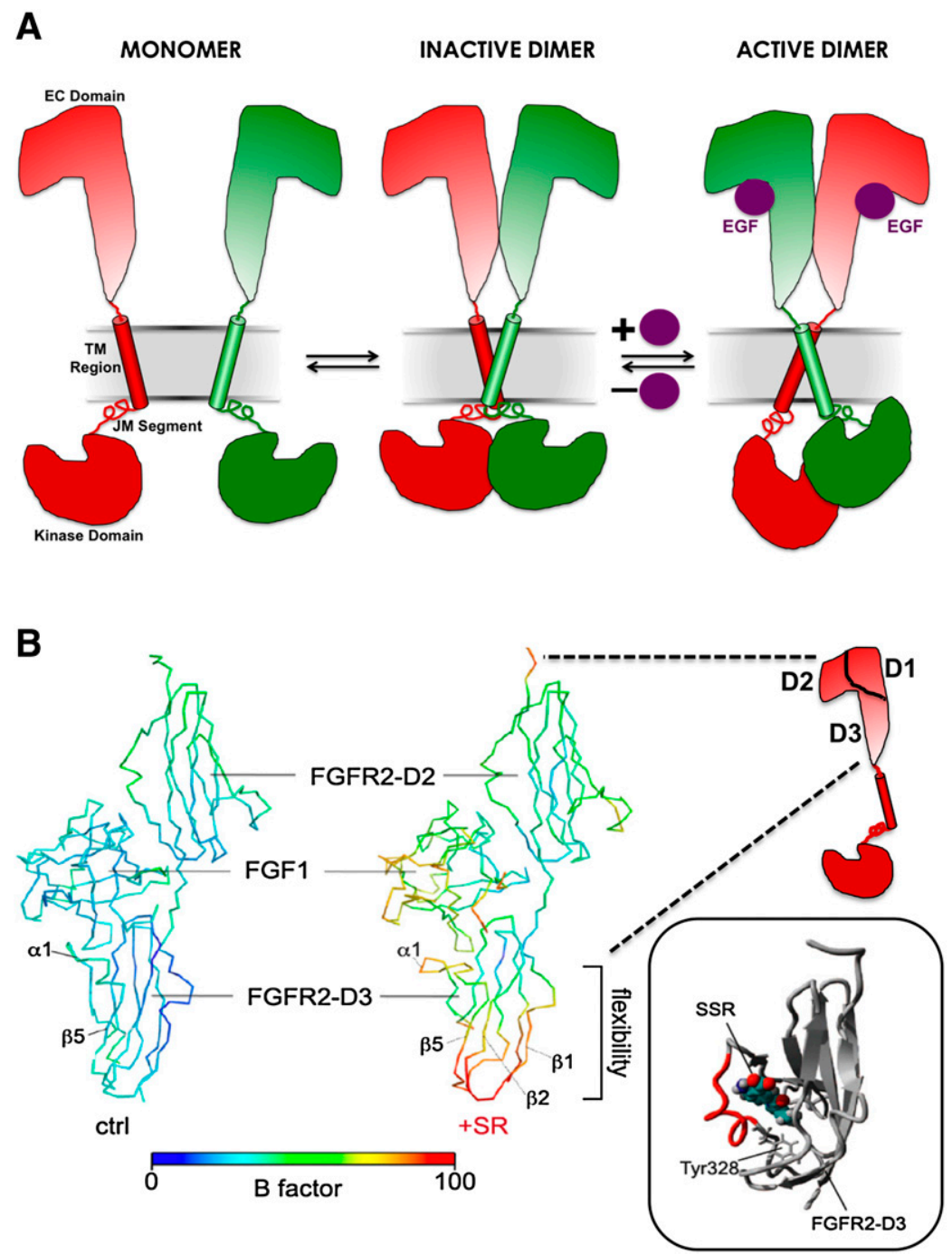

Fig. 7. (A) Schematic representation of the allosteric transition mechanism proposed for intact epidermal growth factor receptor activation based on long timescale molecular dynamics simulations. EC, extracellular; JM, juxtramembrane. Transition from inactive to active states involves liganddependent reorientation of the C- versus N-terminal ends of the TM region. (B) Three-dimensional representation of the 4.2-Å crystal structure of the FGF receptor 2 (FGFR2) extracellular D2-D3 region in complex with FGF1 in the absence (left) or presence (right) of the allosteric modulator SSR1281129E (SSR). Although the molecule could not be resolved at this resolution, the change in B factors (which quantify changes in the vibrational motions of different parts of a structure) suggests an increase in the flexibility of the D3 region. The inset shows a predicted binding mode for the modulator in the D3 region based on free energy calculations and in silico docking. Reproduced, with permission, from Herbert et al. (2013). 
case, as they contain an extracellular orthosteric site for agonist and an intracellular TK domain with the canonical ATP site. This differentiates the RTKs from other receptor superfamilies, like GPCRs, where the orthosteric ligand-binding domain is the locus used for canonical ligand classification.

The KIs (or kinase ligands in general) can be classified into three types, with "Type 1" and "Type 2" being ATPsite competitive, whereas "Type 3 " represents truly allosteric inhibitors (non-ATP-site binders). Type $1 \mathrm{KIs}$ are defined as inhibitors that occupy the ATP site but do not require a DFG-out conformation, whereas the Type 2 KIs target a DFG-out conformation in which a hydrophobic moiety fills the space vacated by the Phe of the DFG motif, and a crucial donor-acceptor motif interacts with the Asp of DFG and/or catalytic Lys and/or Glu of helix $\mathrm{C}$. The Type 1 definition has also been extended to the intermediate "Type 1.5," essentially a Type $2 \mathrm{KI}$ with a smaller back pocket moiety binding to a DFG-in and helix C-out conformation (Zuccotto et al., 2010). In addition to the DFG-in and DFG-out conformations mentioned above, analysis of multiple structures of protein kinases show that combinations of different conformational states of helix C, the DFG motif, the A-, and/or the P-loop can generate various inactive conformations of the TK domain (Lemmon and Schlessinger 2010). Moreover, elements outside the kinase domain, like the juxtamembrane region or other N-terminal elements, the C-terminal tails, and linkers and/or other regulatory domains required for protein-protein interactions, are all important elements in the regulation of the catalytic domain (Cowan-Jacob, 2006). Therefore, each individual kinase has a preferred inactive conformation, depending on its phosphorylation state and regulatory mechanisms involving structures outside the kinase domain. The unique combinations of all these elements create a structural diversity that can be used to design selective inhibitors. Inhibitors binding to the DFG-out and other inactive conformations may have several advantages over regular ATP-site inhibitors, including better selectivity and slower off-rates that increase the residence time of the inhibitor bound to the kinase (Wood et al., 2004; Tummino and Copeland, 2008). However, the paucity of available structures for the inactive, unliganded protein kinases (apo-form) represents a major hurdle in designing inhibitors targeting the inactive conformations. Methods have been developed recently that use active structures as a basis for developing models of the DFG-out conformation that are useful for ligand screening, ligand docking, and ligand activity profiling studies (Kufareva and Abagyan, 2008).

The "Type 3" KIs are classified as KIs (or tyrosine kinase inhibitors [TKIs]) that bind outside of the canonical ATP binding pocket. It should be noted that lack of ATP-competition is not necessarily indicative of allosteric binding. Therefore it needs to be emphasized that only structural determination of the TK domain unambiguously reveals an allosteric KI as occupying a pocket outside of the ATP site (Vanderpool et al., 2009; Fabbro et al., 2012). Type $3 \mathrm{KI}$, like the mitogenactivated protein kinase kinase 1/2 (Ohren et al., 2004) and ABL myristate pocket binders (Zhang et al., 2009; Fabbro et al., 2010), are truly non-ATP competitive. In contrast, the mixed-competition checkpoint kinase 1 inhibitors that, according to structure, also would classify as Type 3, reminds us that "competition" in binding and functional inhibition are not identical (Vanderpool et al., 2009); high negative cooperativity via an allosteric interaction is virtually indistinguishable from competition. The allosteric myr-pocket inhibitors assemble the inactive conformation of $\mathrm{Abl}$ or BcrAbl by promoting the docking of the SH3 and $\mathrm{SH} 2$ domains onto the Abl kinase domain, which seems to work also for the first generation TKI resistant $\mathrm{T}^{315} \mathrm{I}$ mutant (Zhang et al., 2006, 2009; Fabbro et al., 2010). The allosteric (Type 3) inhibitors that display no contact to the hinge show the highest degree of selectivity by exploiting binding sites and regulatory mechanisms that are unique to a particular kinase (Nolen et al., 2004; Cowan-Jacob, 2006; Liu and Gray, 2006; Zhang et al., 2009). In this respect, rapamycin can be cited as the most selective TKI, because it allosterically inhibits the kinase function of only the TORC1 complex (Inoki et al., 2005).

The structurally resolved allosteric KIs known thus far include compounds that inhibit mitogen-activated protein kinase kinase, protein kinase B (AKT), or insulinlike growth factor 1 receptor by occupying a pocket adjacent to the ATP binding site ("allosteric back-pocket") (Ohren et al., 2004; Barnett et al., 2005; Lindsley et al., 2005) or bind to more remote sites, like the myristate binding site (Adrian et al., 2006; Zhang et al., 2009, 2010), the rapamycin binding site of mTOR (Choi et al., 1996; Wang and Sun, 2009; Yang et al., 2013), or the peptide binding site recently discovered in checkpoint kinase 1 (Converso et al., 2009). In addition, targeting the allosteric sites on protein kinases may provide means to identify activators rather than inhibitors that could be useful for therapeutic intervention (Grimsby et al., 2003; Guertin and Grimsby, 2006; Sanders et al., 2007; Hindie et al., 2009).

4. Extracellular Allosteric Modulation of Receptor Tyrosine Kinases. The preceding discussion focused on the phenomenon of allostery within kinase domains. As highlighted above, traditional classification of kinase inhibitors is made by reference of the location of their binding site to the canonical ATP binding site (Type 1, 2, or 3). Clearly there are many potential topographically distinct binding sites on kinases between which allosteric interactions can occur; the point from which the interaction is viewed drives classification of interacting ligands. For example, in this scheme, an inhibitor such as SSR128129E [sodium 2-amino-5-(1-methoxy-2methylindolizine-3-carbonyl)benzoate], which binds extracellularly to allosterically modulate fibroblast growth factor (FGF) signaling, is a special case of a Type 3 small 
molecular weight KI, because it acts outside the canonical ATP binding site (Bono et al., 2013). This is the first well documented example of a small molecule allosteric modulator acting in the extracellular domain of an RTK. The compound SSR128129E binds to multiple subtypes of the FGF receptor family to inhibit FGF signaling with many of the characteristic hallmarks associated with allostery, including a lack of appreciable effect on FGF binding, a limit (ceiling level) to the degree of antagonism, and a bias toward greater inhibition of some signaling pathways relative to others (Bono et al., 2013). Structural studies (Herbert et al., 2013) suggest that the small molecule attains its selectivity by targeting an extracellular domain that is present only in the D2D3 region of FGF receptor (Fig. 7B). In addition to this small molecule example, there is evidence that the extracellular domains of RTKs can be allosterically targeted by peptide-mimetics, "peptoids," and antibodies (Fleishman et al., 2002; Udugamasooriya et al., 2008; Cazorla et al., 2010; Jura et al., 2011).

5. Antibody Modulation of Receptor Tyrosine Kinase Activity. The recent upsurge in interest in monoclonal antibodies that target RTKs and their associated signaling pathways is uncovering new mechanisms of allostery that involve different interaction domains on the receptor and even the cognate ligand. For example, Genentech's (San Francisco, CA) trastuzumab (Herceptin) and pertuzumab, or 2C4 (Perjeta), have both found clinical utility in cancer as anti-HER2/neu receptor-targeting agents, but they act at different domains. Specifically, trastuzumab binds to domain IV of the extracellular segment of the HER2/ neu receptor (Cho et al., 2003), leading to downregulation of HER2/neu and disruption of ligand-independent HER2 signaling through the downstream phosphoinositide 3-kinase cascade (Kute et al., 2004). In addition, trastuzumab inhibits HER2/neu extracellular domain cleavage in breast cancer cells, a process that contributes to the unregulated growth observed in this cancer (Albanell et al., 2003), and also mediates antibody-dependent cell cytotoxicity. By contrast, pertuzumab binds to subdomain II of the HER2/ neu receptor and blocks ligand-dependent HER2 heterodimerization with HER1, HER3, and HER4, while also mediating antibody-dependent cell toxicity (Hynes and Lane, 2005; Hsieh and Moasser, 2007). Importantly, by targeting different domains on the HER2 receptor, pertuzumab and trastuzumab can be administered in combination to provide a more comprehensive blockade of HER2-driven signaling pathways (Scheuer et al., 2009). It should be emphasized that both subdomains II and IV of HER2 do not constitute the orthosteric site, indicating that the two antibodies bind allosterically to HER2, preventing HER2 dimerizing with HER1, HER3, and HER4. As a matter of fact, HER2 resembles HER1 after activation of epidermal growth factor, where the HER2 orthosteric site remains unoccupied by ligand binding, resulting in a constitutive activation of HER2 (Hynes and Lane 2005).
Another interesting example that increases the diversity and complexity of receptor allosterism involves the anti-interleukin- $1 \beta$ (IL-1 $\beta$ ) monoclonal antibody gevokizumab, which was recently shown to exert its highly specific and context-dependent inhibitory effects via a classic allosteric ternary complex mechanism (Roell et al., 2010; Issafras et al., 2014). However, rather than interacting with an allosteric site on the IL- $1 \beta$ receptor, gevokizumab acts on the orthosteric agonist (IL- $1 \beta$ ) itself, changing its subsequent interactive properties with the orthosteric site on the receptor. Importantly, the binding of the receptor to the agonist has the same effect on the antibody, thus demonstrating thermodynamic reciprocity (Issafras et al., 2014). Thus, in this instance, the interaction is allosteric, although the site of action is different. This has necessitated a new designation for this type of antibody, namely "allosteric ligand-modifying antibody," and may represent the first of a new class of allosteric molecules. Indeed, this "ligand-modifying" mechanism was previously reported for RTKs, for instance, the Met receptor, whereby peptide activators have been identified that bind to the orthosteric ligand HGF and change its interaction with Met via an allosteric mechanism transmitted through the ligand to the receptor (Landgraf et al., 2010).

Thus, it can be seen that the RTKs represent a particularly complex case study of allostery, especially with regards to nomenclature, because they possess two different loci that have served historically as a basis for either receptor classification (the orthosteric ligand binding site) or ligand classification (the canonical ATP binding site on the TK domain). It is not the intent of this document to modify the classification of kinase ligands based on ATP binding site locus but to reiterate that any classification involving allosteric modulators must provide context as to the basis of the classification. By their very nature, allosteric interactions must always be considered from the point of view of two spatially distinct but interacting domains.

\section{Recommendations for Allosteric Ligand Classification}

Allosteric modulators have now been identified for every major family of receptor. Allosteric receptor phenomena can arise from a variety of mechanisms, involve multiple spatially distinct binding sites on a receptor macromolecule, and manifest in different ways depending on the nature of the interacting ligands and the experimental conditions used to detect the interaction. Although classifications based on molecular mechanisms would be the most desirable, these remain difficult due to the current lack of robust and readily applicable methods for quantifying the kinetic constants governing allosteric ligand-mediated conformational changes at most receptor types. Furthermore, classification based on ligand-binding locus can be restrictive and not readily transferable between receptor families (e.g., see section IV.D). At this point in time, generic classification of 
allosteric receptor phenomena can generally be managed operationally by ascribing a minimal set of properties expressed by allosteric ligands to each allosteric interaction under study at a given receptor. In each instance, the allosteric interaction must be expressed relative to the effects of the modulator on a reference probe ligand. Typically, the reference probe will be an orthosteric ligand (e.g., the endogenous agonist) or activator (e.g., voltage, $\mathrm{pH}$, etc.) but can also be another ligand acting at a different site.

There are up to three operational properties expressed by allosteric ligands, as follows:

a. Allosteric modulation of reference probe affinity.

b. Allosteric modulation of reference probe efficacy.

Note that the term "efficacy" here is used in relation to the concept and numerical term introduced by Stephenson (Stephenson, 1956) to express the degree to which different agonists produce varying responses when occupying the same proportion of receptors. The term is not being used to infer "maximal agonist effect" nor in the broader sense of in vivo/clinical efficacy.

c. Allosteric agonism/inverse agonism.

It is thus recommended that:

1. Each of the three key properties outlined above be used, where applicable, when describing the actions of an allosteric ligand and that the reference probe and the type of assay used to determine allosteric ligand pharmacology should be stated.

2. Although not preferable, if the properties of an allosteric ligand are described without mention of a reference probe, it will be assumed by default that the description relates to the interaction with the endogenous orthosteric ligand or activator for a given receptor. If there is more than one endogenous orthosteric agonist or activator, however, this is inappropriate, and the relevant reference probe must be indicated.

Although this approach may appear cumbersome, it is necessary to ensure rigor and avoid ambiguity in the classification of allosteric modulators and their effects. Some examples of how known ligands fit into this framework of definitions are shown in Table 2.

Note 10: The classification of an allosteric ligand as a "modulator" is conditional on the nature of the reference ligand that is being used to probe receptor function (Kenakin, 2005). The use of the terms "positive," "negative," or "neutral" must be placed within the context of the interacting ligand against which the allosteric ligand is being tested (e.g., agonist versus antagonist; different chemical structures, etc.) and the experimental conditions; the same allosteric modulator may be positive, negative, or neutral depending on the orthosteric probe or assay conditions. For example, LY2033298 is a neutral allosteric ligand of acetylcholine signaling efficacy, a PAM of oxotremorine-M signaling efficacy, but a NAM of xanomeline signaling efficacy at the $\mathrm{M}_{2}$ muscarinic receptor (Valant et al., 2012a). Thus, all-encompassing standalone descriptions, such as "Compound $X$ is a positive (or negative) allosteric modulator (i.e., PAM or NAM)," or "Compound $Y$ is an ago-allosteric modulator" should be avoided, because they do not explicitly address the context in which the allosteric behavior has been determined. At the very least, if a shorthand term is to be used, then the modulator activity of the ligand must be described first, as well as the interacting orthosteric ligand and, ideally, the assay or pathway involved. For example, "LY2033298 is a PAM-agonist at $\mathrm{M}_{2}$ muscarinic receptor-mediated extracellular signal-regulated kinase 1/2 phosphorylation when tested against oxotremorine-M, but a NAM-agonist when tested against xanomeline" (Valant et al., 2012a).

Note 11: The allosteric effect need not be restricted to modulation of orthosteric ligand affinity or efficacy but can encompass both and, moreover, be different in magnitude and direction. For example, Org27569 [5-chloro-3-ethyl- $N$-(4-(piperidin-1-yl) phenethyl)- $1 H$-indole-2-carboxamide] is a positive allosteric modulator of CP55940 (2-[(1R,2R,5R)-5hydroxy-2-(3-hydroxypropyl) cyclohexyl]-5-(2methyloctan-2-yl)phenol) affinity at the $\mathrm{CB}_{1}$ receptor but a negative allosteric modulator of CP55940 efficacy at the same receptor (Price et al., 2005).

Note 12: The direction and magnitude of allosteric modulation can vary with the signal pathway being measured (Leach et al., 2007, 2010) and may be temperature dependent.

Note 13: Where minimal experimental data are available, e.g., simple screens that include only an agonist concentration-response curve in the absence/ presence of a single modulator concentration, it was previously proposed that purely empirical classification schemes can be used. Specifically, the modulator effect on basal activity, agonist potency, and agonist $E_{\max }$ can be described in single letter codes (e.g., $\mathrm{I}=$ increase, $\mathrm{D}=$ decrease, $\mathrm{N}=\mathrm{no}$ effect). This yields quick "picture" of what the modulator does but cannot be used to classify the modulator (Keov et al., 2011).

\section{Classification of Endogenous Allosteric Ligands}

In contrast to receptor orthosteric binding sites, allosteric sites need not be under similar evolutionary pressure to accommodate endogenous ligands, and it is likely many of the sites targeted by novel small molecule allosteric modulators represent accessory domains normally serving structural roles. However, there are a number 
TABLE 2

Examples of proposed allosteric modulator classifications

\begin{tabular}{|c|c|c|c|}
\hline Target Class & Target & Ligand & Proposed Ligand Descriptors \\
\hline GPCR & Cannabinoid $\mathrm{CB}_{1}$ receptor & Org27569 & $\begin{array}{l}\text { Org27569 is a PAM of CP55940 affinity but a NAM of } \\
\text { CP55940 efficacy for mediating inhibition of cAMP } \\
\text { accumulation. }\end{array}$ \\
\hline GPCR & mGlu1 receptor & CPCCOEt & $\begin{array}{l}\text { CPCCOEt is a NAL with respect to glutamate affinity } \\
\text { but a NAM of glutamate efficacy in mediating } \\
\text { intracellular calcium mobilization }\end{array}$ \\
\hline GPCR & mGlu5 receptor & M-5MPEP & $\begin{array}{l}\text { M-5MPEP is a NAL with respect to glutamate affinity } \\
\text { and NAM of glutamate efficacy for stimulation of } \\
\text { intracellular calcium mobilization and inositol } \\
\text { phosphate accumulation }\end{array}$ \\
\hline GPCR & CCR5 & Aplaviroc & $\begin{array}{l}\text { Aplaviroc is a NAM of CCL3 affinity and a NAL with } \\
\text { respect to CCL5 affinity; it is also a NAM of CCL3 } \\
\text { and CCL5 efficacy to stimulate intracellular calcium } \\
\text { mobilization. }\end{array}$ \\
\hline LGIC & $\begin{array}{l}\text { Benzodiazepine-sensitive } \\
\text { GABA }_{A} \text { receptors }\end{array}$ & Diazepam & $\begin{array}{l}\text { Diazepam is a PAM of GABA affinity and chloride flux } \\
\text { at benzodiazepine-sensitive } \text { GABA }_{\mathrm{A}} \text { receptors. }\end{array}$ \\
\hline LGIC & $\mathrm{GABA}_{\mathrm{A}}$ receptor & Flumazenil & $\begin{array}{l}\text { Flumazenil is a NAL with respect to GABA affinity and } \\
\text { chloride flux at (most) } \mathrm{GABA}_{\mathrm{A}} \text { receptor subtypes. }\end{array}$ \\
\hline LGIC & $\mathrm{GABA}_{\mathrm{A}}$ receptor & Pentobarbital & $\begin{array}{l}\text { Pentobarbital is a PAM of GABA affinity and chloride } \\
\text { flux and an allosteric agonist with respect to } \text { GABA }_{A} \\
\text { receptor gating. }\end{array}$ \\
\hline LGIC & nAChR & Lidocaine & $\begin{array}{l}\text { Lidocaine is a PAM of acetylcholine affinity but a NAM } \\
\text { of acetylcholine-mediated cation flux at the nAChR. }\end{array}$ \\
\hline LGIC & NMDA (GluN1/GluN2A) & TCN-201 & $\begin{array}{l}\text { TCN-201 is a NAM of glycine affinity and efficacy but } \\
\text { a NAL of glutamate activity at the NMDA receptor. }\end{array}$ \\
\hline VGIC & $\mathrm{Ca}_{\mathrm{V} 1}$ & BayK8644 & $\begin{array}{l}\text { BayK } 8644 \text { is an allosteric agonist at } \mathrm{Ca}_{\mathrm{V} 1} \text { channels, } \\
\text { a competitive antagonist of other dihydropyridines, } \\
\text { a PAM with respect to diltiazem, and a NAM with } \\
\text { respect to verapamil. }\end{array}$ \\
\hline RTK & FGFR1 & SSR128129E & $\begin{array}{l}\text { SSR128129E is NAL with respect to FGF } 2 \text { affinity but } \\
\text { a NAM of FGF2 efficacy to mediate phosphorylation } \\
\text { of FRS } 2 \text { and ERK1/2. It is a Type } 3 \text { tyrosine kinase } \\
\text { inhibitor with respect to the ATP binding site. }\end{array}$ \\
\hline
\end{tabular}

BayK8644, methyl 2,6-dimethyl-5-nitro-4-[2-(trifluoromethyl)phenyl]-1,4-dihydropyridine-3-carboxylate; ERK1/2, extracellular signal-regulated kinase 1/2; FGFR1, FGF receptor 1; FRS2, fibroblast growth factor receptor substrate 2; M-5MPEP, 2-[(3-methoxyphenyl)ethynyl]-5-methylpyridine; NAL, neutral allosteric ligand (see also Note 10).

of reported endogenous allosteric modulators for a variety of receptors, and it is likely more may be discovered. For instance, the $G$ protein-binding domain on GPCRs is an obvious example of an evolutionarily conserved allosteric site that plays an obligate role in signal transduction. More specific examples include neuroactive steroids acting at the $\mathrm{GABA}_{\mathrm{A}}$ receptor (Olsen and Sapp, 1995), L-amino acids acting at the extracellular calcium-sensing receptor (Conigrave et al., 2000), and others (Christopoulos, 2002; May et al., 2007). Furthermore, membrane lipids may modify nicotinic receptors allosterically, changing the effects of other allosteric agents (daCosta et al., 2009). Moreover, there are a number of pathophysiological conditions that may be mediated by endogenous substances acting allosterically at some receptors (May et al., 2007). In general, however, the field of endogenous allosteric receptor modulators has not been thoroughly explored to date and is beyond the scope of this article. Nonetheless, consideration needs to be given to terminology applied to such ligands, and it is thus recommended that, where possible, the same criteria applied to exogenous allosteric ligands be applied to endogenous allosteric ligands, with some obvious caveats. Specifically, if an endogenous substance is shown to modulate the function of an orthosteric agonist at a receptor macromolecule, it can be classified as an endogenous allosteric modulator. However, if the same substance is also shown to mediate agonism or inverse agonism in its own right, consideration should be given to reclassifying this substance as an orthosteric agonist/inverse agonist. There is no reason why multiple orthosteric ligands cannot interact allosterically at a given receptor macromolecule as would occur, for instance, in an oligomeric receptor complex with multiple orthosteric sites (e.g., see section IV.A). In this instance, the ligands are classified as orthosteric, but the interaction is classified as allosteric.

\section{Experimental Approaches for Validating an Allosteric Interaction}

Numerous experimental paradigms have been used to ascertain whether a ligand interacts with a receptor by an allosteric mechanism. High-resolution structure determination with bound allosteric modulators is obviously the most direct approach. The remaining approaches are more indirect and rely on pharmacological methods. A key question in this regard is whether classic pharmacology can be robust enough in the face of substantial complexity. This challenge is perhaps best exemplified by numerous studies of allostery at ion channels, where the multiple ion channel subunits, accessory proteins, and gating mechanisms are daunting, although structural knowledge is being published rapidly (Catterall et al., 2005a,b; Bocquet et al., 2009; Collingridge et al., 
2009; Olsen and Sieghart, 2009; Wu et al., 2010b; Payandeh et al., 2011, 2012; Corringer et al., 2012; Tan et al., 2013). However, classic pharmacological principles remain very powerful in that they are designed to evaluate the effects of drugs by cancelling out systemdependent variables using null methods. Approaches such as Schild or resultant analyses are still highly relevant in evaluating allosteric mechanisms (Arunlakshana and Schild, 1959; Spedding, 1985b; Black et al., 1986; Colquhoun, 2007). For example, VGICs have multiple allosteric sites that interact to different extents, allowing tissue selectivity and facilitating discovery of multiple therapeutic agents. Initially these drugs were difficult to evaluate because of rapid channel kinetics overriding the drug effects. However, as many of the drugs had high affinity for the inactivated state, the use of simple potassium-depolarization switched $\sim 70 \%$ of the channels into the inactivated state and allowed competitive interactions between drugs acting as positive or negative allosteric modulators at a common site, which was subsequently defined via the use of resultant analysis (Spedding, 1985b). The availability of radioligands for each of these sites confirmed the functional interactions (Ferry and Glossmann, 1982; Janis et al., 1984). Consequently, it was possible to pharmacologically define up to five interlinked allosteric sites in calcium channels, for example, each site having distinct structure-activity relationships, distinct effects on channel kinetics, distinct effects on channel mode distribution, and selectivity for different channel subtypes, tissues, and eventually, therapeutic utilities (Spedding and Paoletti, 1992).

Key variables affecting the functional and binding properties of drugs at ion channels (and many other drug targets) include membrane composition, surface charge, and membrane potential, media composition, and temperature. This does render screening difficult at times. For example, exquisitely potent compounds acting at one site may appear to have no effect when assessed on a different allosteric, or an orthosteric, site, because the apparent zero effect is a result of negative and positive allosteric effects that are revealed by changing temperature and other experimental variables (Spedding and Mir, 1987); hence the need to define the experimental conditions when quantifying and classifying allosteric compounds. In general, two useful themes in the pharmacological approach to demonstrating allostery are 1) the ability to identify saturability of effect and 2) the ability to demonstrate probe dependence. Thus, the testing of as high a concentration of putative modulator as possible against more than one orthosteric probe ligand is a good practical approach to identifying allostery (Fig. 8). The following guidelines represent ideal criteria with which to build a case for classifying a ligand as allosteric.

\section{A. Structure Determination}

A definitive proof of an allosteric mechanism of action of a ligand is to show by protein crystallography or a similar high-resolution approach that its binding site is spatially distinct and nonoverlapping from that of the orthosteric site(s), ideally by solving the ternary complex or, more likely, as two separate costructure determinations. Such evidence has been provided in the field of enzymology, where allosteric ligand binding sites have been identified on HIV-1 reverse transcriptase, p38 MAP kinase, and glucokinase by crystallography (Hardy and Wells, 2004) and, more recently, for LGICs (Nury et al., 2011; Sauguet et al., 2013) and for GPCRs (Kruse et al., 2013), as described above (sections IV.A, IV.B, and IV.D).

\section{B. Equilibrium Ligand Binding}

One of the most common methods for testing compounds is to determine their effect(s) on the equilibrium binding of a known, labeled orthosteric ligand; most often this is done using a fluorophore or radioactive labeled ligand. The most robust method for such experiments is to study the effect of multiple concentrations of test compound on a saturation isotherm for a labeled ligand. Curve-shifts that reach a saturation point and clearly deviate from a simple competitive interaction in the absence of other confounding factors (such as nonequilibrium situations) are indicative of allostery. However, there are a number of limitations with this method. First, only compounds that modulate the affinity of the labeled orthosteric ligand in question will be detected; if a compound is neutral with respect to affinity, but an allosteric modulator of efficacy, then it will have no effect in the binding assay. For example, the mGluR1 negative allosteric modulator CPCCOEt has no effect on the equilibrium binding of $\left[{ }^{3} \mathrm{H}\right]$ glutamate (Litschig et al., 1999). Second, running multiple saturation curves with a radioligand or fluorescently labeled ligand is rarely practical. In most cases, researchers will construct a "titration" curve to the test compound against a single concentration of labeled orthosteric probe. A positive modulator of affinity would be expected to increase binding in a concentration-dependent manner; conversely, a negative allosteric modulator would decrease binding. Negative modulators of affinity will be unable to inhibit fully the specific binding of an orthosteric ligand if the cooperativity is limited, but for modulators with high degrees of negative cooperativity with respect to the orthosteric probe, full inhibition of specific binding can be observed and thus appear indistinguishable from orthosteric competition. To unmask the allosteric effect, it may be necessary to repeat the experiment at multiple, higher concentrations of orthosteric ligand.

Finally, the range of labeled orthosteric probes generally limits traditional ligand binding assays; such ligands generally need to be high-affinity probes. This is not always useful where the allosteric interaction to be examined is with the endogenous agonist. It is possible to conduct three-way ligand binding studies (with labeled orthosteric probe, a second test orthosteric 

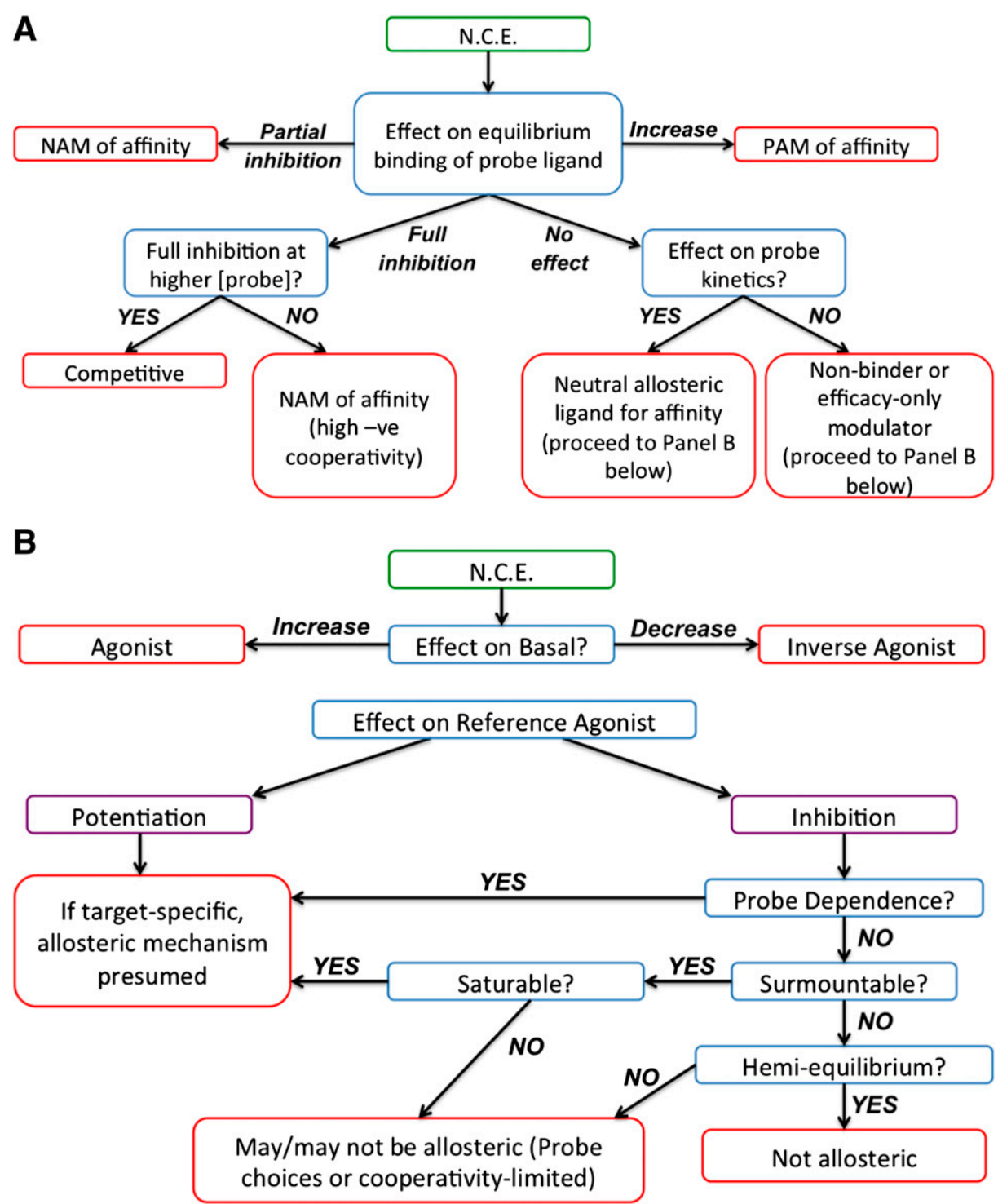

Fig. 8. Work-flow charts to investigate a possible allosteric mechanism of action for a new chemical entity (N.C.E.) using binding (A) or functional (B) assays. Note, the reference probe ligand would typically be an orthosteric ligand (e.g., endogenous agonist) but can also be a well characterized allosteric ligand.

ligand, and a putative allosteric ligand), but the resultant analysis can be complex (Lanzafame et al., 2006). Nonetheless, there are increasing examples where a minimal curve design can be used in radioligand binding assays to derive useful allosteric model parameters (e.g., Lanzafame et al., 2006; Nawaratne et al., 2010; Valant et al., 2012a). Biophysical techniques such as surface plasmon resonance or NMR obviate the need for a labeled orthosteric probe and permit the use of any orthosteric ligand, but require soluble protein and have therefore been rarely available to study membrane bound receptor proteins.

\section{Ligand Binding Kinetics}

One of the most commonly used techniques to unmask an allosteric mechanism of action is to determine the effect of a test ligand on the kinetics of binding of an orthosteric ligand. Any net effect to alter the affinity of an orthosteric ligand must be achieved through conformational modulation of either association or dissociation rate constants or both. The most common approach is to monitor the effects of a test compound on the dissociation rate of a prebound, labeled orthosteric ligand; the only way that the dissociation rate constant can be altered is by the concomitant binding of an allosteric modulator to a topographically distinct site. Such an approach is not limited to radioligand or fluorophorelabeled ligand binding; biophysical techniques such as biointeraction chromatography have been shown to unmask allosteric mechanisms (by quantifying the rate of elution of a ligand from a protein immobilized on affinity chromatography columns; Chen and Hage, 2004). Moreover, although not necessarily as direct, association and dissociation rates can also be determined from the 
concentration dependency of the onset of potentiation or inhibition for modulators at ion channels (Hansen and Traynelis, 2011).

A kinetic approach has the advantage of being able to detect that subset of neutral allosteric ligands that achieve a lack of net effect on equilibrium affinity by modulating both orthosteric ligand association and dissociation rate constants to the same degree (Kostenis and Mohr, 1996; Leach et al., 2010). However, many "efficacy-only" modulators do not share this mechanism and are thus unlikely to be detected using this approach. Furthermore, highly negatively cooperative modulators tend to exert only small effects on ligand dissociation (due to their consequent low affinity for the orthosteric ligand-occupied receptor); this can often be beyond the solubility limit of the compounds involved. A flow chart of binding studies to investigate an allosteric mechanism of action is shown in Fig. 8A.

\section{Functional Assays}

The primary assay format that is used for the discovery or evaluation of allosteric ligands is the cell-based functional assay. This is primarily due to the shift away from radioligand binding assays within high-throughput screening groups in the 1990s. The clear advantage of using a functional assay is that it is not limited to detecting allosteric modulation of affinity; effects that alter agonist efficacy, as well as the phenomenon of allosteric agonism, can readily be detected. Compounds that have no effect in equilibrium or kinetic radioligand binding assays may be neutral ligands with respect to agonist affinity but modulators of agonist efficacy; a functional assay is the only assay format in which such a compound would be detected. However, the same attributes that make functional assays highly suitable for the detection of allosteric ligands render them challenging in understanding and classifying their mechanism. This is because it can be difficult to determine whether a putative allosteric ligand is modulating agonist affinity and/or efficacy using a functional assay alone. As with ligand binding studies, the most robust method for validating an allosteric interaction is to study the effect of multiple concentrations of test compound on a concentrationresponse curve to an orthosteric agonist (usually the endogenous agonist). Orthosteric agonist potency shifts that reach a saturation point and clearly deviate from a simple competitive interaction in the absence of other confounding factors (such as nonequilibrium situations) are indicative of allostery. Saturable, parallel shifts of an agonist concentration-response curve by a test ligand have often been taken as presumptive evidence of allosteric modulation of agonist affinity (which translates into a change in agonist potency). Furthermore, changes in agonist efficacy would be expected to manifest as changes in the maximal agonist response, as well as the $\mathrm{EC}_{50}$. However, in assay systems where there is a high level of receptor expression and/or very efficient coupling between the receptor and functional endpoint being measured, this simple classification may not apply. In a lowexpressing, poorly coupled system where the maximal agonist response is well below the maximal system response, a positive modulator of agonist efficacy will potentiate the maximal agonist response. However, in an assay system with high levels of receptor expression, the maximal agonist response may have already reached the maximal system response such that it cannot be increased further. Therefore the same positive modulator of efficacy will actually produce a leftward shift in the agonist concentration-response curve. Similarly, a negative allosteric modulator of efficacy would be expected to elicit a decrease in the maximal agonist response, but in a highly-coupled system (with spare receptors or receptor reserve) the resultant stimulus may still be sufficient to produce a maximal agonist response that is close to the maximal system response; the result would be a rightward shift in the agonist concentration-response curve. These observations could easily be assumed to be due to effects on agonist affinity, which would be incorrect. It should also be noted that a decrease in maximal agonist response cannot always be attributable to negative allosteric modulation of efficacy; these effects could simply be due to irreversible or slowly dissociating orthosteric antagonists. The effect of the latter can often be confirmed by using an assay that allows receptor, agonist, and test ligand to reach equilibrium or by simultaneous addition of both agonist and test ligand in the case of transient read assay systems.

Given these caveats, it is important to take care when drawing conclusions from functional datasets. Allosteric effects may encompass any combination of allosteric modulation of affinity, efficacy, and allosteric agonism in any direction. There are models available to analyze such functional datasets (Kostenis and Mohr, 1996; Ehlert, 2005; Kenakin, 2005; Price et al., 2005; Leach et al., 2007; May et al., 2007; Hansen et al., 2012), but even in their simplest forms they are necessarily complex to describe the range of potential allosteric phenotypes. The best approach to interpreting such datasets is to have data from independent experiments using ligand-binding methodologies that directly estimate any allosteric modulation of affinity. Integrating ligand binding data in combination with functional datasets is a powerful approach for determining the mechanism of action of an allosteric ligand (Langmead, 2011). As with the ligand binding approaches described above, it is commonplace to test ligands in a titration-curve format in the presence of a single (e.g., $\mathrm{EC}_{20}$ or $\mathrm{EC}_{80}$ ) concentration of orthosteric agonist (whether looking for a positive or negative modulator, respectively). For modulators with weak positive cooperativity (whether mediated by changed affinity or efficacy), such an assay design results in titration curves whose maximal asymptote is lower than that seen with the orthosteric agonist alone. As a result, such allosteric modulators are often incorrectly 
referred to as "partial agonists." Similarly, for negative allosteric modulators with weak negative cooperativity, the resultant titration curves often fail to fully inhibit the agonist response down to basal levels. This profile has led to their description as "partial antagonists." These phenomenological terms should be avoided as they can be misinterpreted; such compounds should be described as positive or negative allosteric modulators with limited cooperativity, respectively. A flow chart of functional studies that can be used to investigate a potential allosteric mechanism of action is shown in Fig. 8B.

\section{E. Allosteric Agonists}

The ability of an allosteric ligand to exhibit positive (or inverse) agonism in the absence of an orthosteric agonist is an increasingly recognized phenomenon (Leach et al., 2010; Gill et al., 2011). Indeed, as predicted by the simplest version of the MWC model, all ligands, be they orthosteric or allosteric, should display some degree of agonism (positive or inverse) depending on which receptor state they preferentially stabilize (Canals et al., 2011). This is routinely accepted for orthosteric ligands, because the orthosteric site has likely evolved as the most efficient means by which receptor activation can be achieved. However, this is not often appreciated for allosteric ligands. The energy barriers for stabilizing active or inactive states via an allosteric site can be higher, and thus allosteric agonism/inverse agonism may not be detected because of assay thresholds, e.g., low and/or physiologic receptor expression, poor coupling efficiency, etc. Nonetheless, at the molecular level such mechanisms are manifest, and the subsequent cobinding of an orthosteric ligand would thus overcome the energy barrier more efficiently than in the absence of the modulator (if the interaction is positive) or less efficiently (if the interaction is negative). If the same interaction were monitored under conditions of higher receptor expression and or more efficient stimulus-response coupling, then any inherent allosteric agonism may be directly observed (Keov et al., 2011).

When such agonism is observed, the process for classifying an agonist as allosteric is thus essentially by meeting the same criteria as described above to show that the (allosteric) agonist binds to a topographically distinct binding site from that of the endogenous ligand(s) on the receptor. Typically this can be determined using the ligand binding approaches but also by looking at the functional interaction between the test and orthosteric agonists or the test agonist and a prototypical orthosteric antagonist. If these interactions produce behavior that is not consistent with a steric interaction, then the test ligand may be allosteric.

\section{F. Mutational Analysis}

The assessment of compound activity at receptors with various mutations in key regions is a useful approach but not usually sufficient in its own right to provide definitive evidence of an allosteric mechanism or site of action. It is possible that sensitivity of test ligand's activity to a point mutation in a manner that is different from a reference orthosteric agonist is presented as evidence that the ligand is allosteric. Although site-directed mutagenesis is often important to understanding the structure-function relationships for an allosteric ligand, defining a ligand as binding to an allosteric site solely based on a loss of binding and/or function at a mutant receptor is not definitive except in clear-cut cases (e.g., Class C GPCRs, where the entire transmembrane domain can be targeted allosterically, whereas the $\mathrm{N}$-terminal domain binds orthosteric ligands, multimeric channel complexes where orthosteric and allosteric sites are known to be located on distinctly different interfaces). Sensitivity of binding or function to a mutation outside of the orthosteric site does not imply the location of a ligand binding site; the mutation could affect binding indirectly or have an effect on downstream function/signaling (Colquhoun, 1998). Therefore it is important to combine mutagenesis studies with the criteria and guidelines highlighted above when classifying ligands as allosteric.

\section{Authorship Contributions}

Wrote or contributed to the writing of the manuscript: Christopoulos, Changeux, Catterall, Fabbro, Burris, Cidlowski, Olsen, Peters, Neubig, Pin, Sexton, Kenakin, Ehlert, Spedding, Langmead.

\section{References}

Acker TM, Yuan H, Hansen KB, Vance KM, Ogden KK, Jensen HS, Burger PB, Mullasseril P, Snyder JP, and Liotta DC, et al. (2011) Mechanism for noncompetitive inhibition by novel GluN2C/D N-methyl-D-aspartate receptor subunitselective modulators. Mol Pharmacol 80:782-795.

Adrián FJ, Ding Q, Sim T, Velentza A, Sloan C, Liu Y, Zhang G, Hur W, Ding S, and Manley P, et al. (2006) Allosteric inhibitors of Bcr-abl-dependent cell proliferation. Nat Chem Biol 2:95-102.

Albanell J, Codony J, Rovira A, Mellado B, and Gascón P (2003) Mechanism of action of anti-HER2 monoclonal antibodies: scientific update on trastuzumab and $2 \mathrm{C} 4$. Adv Exp Med Biol 532:253-268.

Allegretti M, Bertini R, Bizzarri C, Beccari A, Mantovani A, and Locati M (2008) Allosteric inhibitors of chemoattractant receptors: opportunities and pitfalls. Trends Pharmacol Sci 29:280-286.

Antony J, Kellershohn K, Mohr-Andrä M, Kebig A, Prilla S, Muth M, Heller E, Disingrini T, Dallanoce C, and Bertoni S, et al. (2009) Dualsteric GPCR targeting: a novel route to binding and signaling pathway selectivity. FASEB $J$ 23:442-450. Arkhipov A, Shan Y, Das R, Endres NF, Eastwood MP, Wemmer DE, Kuriyan J, and Shaw DE (2013) Architecture and membrane interactions of the EGF receptor. Cell 152:557-569.

Armstrong CM (1974) Ionic pores, gates, and gating currents. Q Rev Biophys 7:179-210. Armstrong CM (1981) Sodium channels and gating currents. Physiol Rev 61:644-683. Arnold LA, Estébanez-Perpiñá E, Togashi M, Jouravel N, Shelat A, McReynolds AC, Mar E, Nguyen P, Baxter JD, and Fletterick RJ, et al. (2005) Discovery of small molecule inhibitors of the interaction of the thyroid hormone receptor with transcriptional coregulators. J Biol Chem 280:43048-43055.

Arnold LA, Kosinski A, Estébanez-Perpiñá E, Fletterick RJ, and Guy RK (2007) Inhibitors of the interaction of a thyroid hormone receptor and coactivators: preliminary structure-activity relationships. J Med Chem 50:5269-5280.

Arunlakshana O and Schild HO (1959) Some quantitative uses of drug antagonists. Br Pharmacol Chemother 14:48-58.

Bardelli A, Parsons DW, Silliman N, Ptak J, Szabo S, Saha S, Markowitz S, Willson JK, Parmigiani G, and Kinzler KW, et al. (2003) Mutational analysis of the tyrosine kinome in colorectal cancers. Science 300:949.

Barnard EA, Skolnick P, Olsen RW, Mohler H, Sieghart W, Biggio G, Braestrup C, Bateson AN, and Langer SZ (1998) International Union of Pharmacology. XV. Subtypes of gamma-aminobutyric acidA receptors: classification on the basis of subunit structure and receptor function. Pharmacol Rev 50:291-313.

Barnett SF, Defeo-Jones D, Fu S, Hancock PJ, Haskell KM, Jones RE, Kahana JA Kral AM, Leander K, and Lee LL, et al. (2005) Identification and characterization of pleckstrin-homology-domain-dependent and isoenzyme-specific Akt inhibitors. Biochem J 385:399-408.

Bautista DM, Siemens J, Glazer JM, Tsuruda PR, Basbaum AI, Stucky CL, Jordt SE, and Julius D (2007) The menthol receptor TRPM8 is the principal detector of environmental cold. Nature 448:204-208. 
Bertrand D and Gopalakrishnan M (2007) Allosteric modulation of nicotinic acetylcholine receptors. Biochem Pharmacol 74:1155-1163.

Black J (1989) Drugs from emasculated hormones: the principle of syntopic antagonism. Science 245:486-493.

Black JW, Gerskowitch VP, Leff P, and Shankley NP (1986) Analysis of competitive antagonism when this property occurs as part of a pharmacological resultant. $\mathrm{Br} J$ Pharmacol 89:547-555.

Bocquet N, Nury H, Baaden M, Le Poupon C, Changeux JP, Delarue M, and Corringer PJ (2009) X-ray structure of a pentameric ligand-gated ion channel in an apparently open conformation. Nature 457:111-114.

Bono F, De Smet F, Herbert C, De Bock K, Georgiadou M, Fons P, Tjwa M, Alcouffe C, Ny A, and Bianciotto M, et al. (2013) Inhibition of tumor angiogenesis and growth by a small-molecule multi-FGF receptor blocker with allosteric properties. Cancer Cell 23:477-488.

Bourinet E, Soong TW, Sutton K, Slaymaker S, Mathews E, Monteil A, Zamponi GW, Nargeot J, and Snutch TP (1999) Splicing of alpha 1A subunit gene generates phenotypic variants of P- and Q-type calcium channels. Nat Neurosci 2:407-415.

Bruning JB, Parent AA, Gil G, Zhao M, Nowak J, Pace MC, Smith CL, Afonine PV, Adams PD, and Katzenellenbogen JA, et al. (2010) Coupling of receptor conformation and ligand orientation determine graded activity. Nat Chem Biol 6 837-843.

Bruns RF and Fergus JH (1990) Allosteric enhancement of adenosine A1 receptor binding and function by 2-amino-3-benzoylthiophenes. Mol Pharmacol 38:939-949.

Brzozowski AM, Pike AC, Dauter Z, Hubbard RE, Bonn T, Engström O, Ohman L, Greene GL, Gustafsson JA, and Carlquist M (1997) Molecular basis of agonism and antagonism in the oestrogen receptor. Nature 389:753-758.

Burris TP, Solt LA, Wang Y, Crumbley C, Banerjee S, Griffett K, Lundasen T, Hughes T, and Kojetin DJ (2013) Nuclear receptors and their selective pharmacologic modulators. Pharmacol Rev 65:710-778.

Canals M, Lane JR, Wen A, Scammells PJ, Sexton PM, and Christopoulos A (2012) A Monod-Wyman-Changeux mechanism can explain G protein-coupled receptor (GPCR) allosteric modulation. J Biol Chem 287:650-659.

Canals M, Sexton PM, and Christopoulos A (2011) Allostery in GPCRs: 'MWC' revisited. Trends Biochem Sci 36:663-672.

Cao E, Liao M, Cheng Y, and Julius D (2013) TRPV1 structures in distinct conformations reveal activation mechanisms. Nature 504:113-118.

Catterall WA (1980) Neurotoxins that act on voltage-sensitive sodium channels in excitable membranes. Annu Rev Pharmacol Toxicol 20:15-43.

Catterall WA (2010) Ion channel voltage sensors: structure, function, and pathophysiology. Neuron 67:915-928.

Catterall WA, Cestèle S, Yarov-Yarovoy V, Yu FH, Konoki K, and Scheuer T (2007) Voltage-gated ion channels and gating modifier toxins. Toxicon 49:124-141.

Catterall WA, Goldin AL, and Waxman SG (2005a) International Union of Pharmacology. XLVII. Nomenclature and structure-function relationships of voltagegated sodium channels. Pharmacol Rev 57:397-409.

Catterall WA, Perez-Reyes E, Snutch TP, and Striessnig J (2005b) International Union of Pharmacology. XLVIII. Nomenclature and structure-function relationships of voltage-gated calcium channels. Pharmacol Rev 57:411-425.

Cazorla M, Jouvenceau A, Rose C, Guilloux JP, Pilon C, Dranovsky A, and Prémont J (2010) Cyclotraxin-B, the first highly potent and selective TrkB inhibitor, has anxiolytic properties in mice. PLoS ONE 5:e9777.

Cestèle S and Catterall WA (2000) Molecular mechanisms of neurotoxin action on voltage-gated sodium channels. Biochimie 82:883-892.

Chan WY, McKinzie DL, Bose S, Mitchell SN, Witkin JM, Thompson RC, Christopoulos A, Lazareno S, Birdsall NJ, and Bymaster FP, et al. (2008) Allosteric modulation of the muscarinic M4 receptor as an approach to treating schizophrenia. Proc Natl Acad Sci USA 105:10978-10983.

Chandra V, Huang P, Hamuro Y, Raghuram S, Wang Y, Burris TP, and Rastinejad F (2008) Structure of the intact PPAR-gamma-RXR- nuclear receptor complex on DNA. Nature 456:350-356

Chandra V, Huang P, Potluri N, Wu D, Kim Y, and Rastinejad F (2013) Multidomain integration in the structure of the HNF-4 $\alpha$ nuclear receptor complex. Nature 495 394-398.

Chang Cy, Norris JD, Grøn H, Paige LA, Hamilton PT, Kenan DJ, Fowlkes D, and McDonnell DP (1999) Dissection of the LXXLL nuclear receptor-coactivator interaction motif using combinatorial peptide libraries: discovery of peptide antagonists of estrogen receptors alpha and beta. Mol Cell Biol 19:8226-8239.

Chang CY, Abdo J, Hartney T, and McDonnell DP (2005) Development of peptide antagonists for the androgen receptor using combinatorial peptide phage display. Mol Endocrinol 19:2478-2490.

Changeux JP (1961) The feedback control mechanisms of biosynthetic L-threonine deaminase by L-isoleucine. Cold Spring Harb Symp Quant Biol 26:313-318.

Changeux JP (2010) Allosteric receptors: from electric organ to cognition. Annu Rev Pharmacol Toxicol 50:1-38.

Changeux JP (2012) Allostery and the Monod-Wyman-Changeux model after 50 years. Annu Rev Biophys 41:103-133.

Changeux JP (2013a) 50 years of allosteric interactions: the twists and turns of the models. Nat Rev Mol Cell Biol 14:819-829.

Changeux JP (2013b) The concept of allosteric modulation: an overview. Drug Discov Today Technol 10:e223-e228.

Changeux JP and Edelstein SJ (1998) Allosteric receptors after 30 years. Neuron 21: 959-980

Changeux JP and Edelstein SJ (2005) Allosteric mechanisms of signal transduction. Science 308:1424-1428.

Changeux JP, Thiéry J, Tung Y, and Kittel C (1967) On the cooperativity of biological membranes. Proc Natl Acad Sci USA 57:335-341.

Chen J and Hage DS (2004) Quantitative analysis of allosteric drug-protein binding by biointeraction chromatography. Nat Biotechnol 22:1445-1448.

Chiara DC, Jayakar SS, Zhou X, Zhang X, Savechenkov PY, Bruzik KS, Miller KW, and Cohen JB (2013) Specificity of intersubunit general anesthetic-binding sites in the transmembrane domain of the human $\alpha 1 \beta 3 \gamma 2 \gamma$-aminobutyric acid type A $\left(\mathrm{GABA}_{\mathrm{A}}\right)$ receptor. $J$ Biol Chem 288:19343-19357.

Chiara DC, Gill JF, Chen Q, Tillman T, Dailey WP, Eckenhoff RG, Xu Y, Tang P, and Cohen JB (2014) Photoaffinity labeling the propofol binding site in GLIC. Biochemistry 53:135-142.

Cho HS, Mason K, Ramyar KX, Stanley AM, Gabelli SB, Denney DW Jr, and Leahy DJ (2003) Structure of the extracellular region of HER2 alone and in complex with the Herceptin Fab. Nature 421:756-760.

Choi J, Chen J, Schreiber SL, and Clardy J (1996) Structure of the FKBP12rapamycin complex interacting with the binding domain of human FRAP. Science 273:239-242.

Christopoulos A (2002) Allosteric binding sites on cell-surface receptors: novel targets for drug discovery. Nat Rev Drug Discov 1:198-210.

Christopoulos A and Kenakin T (2002) G protein-coupled receptor allosterism and complexing. Pharmacol Rev 54:323-374.

Clark AL and Mitchelson F (1976) The inhibitory effect of gallamine on muscarinic receptors. Br J Pharmacol 58:323-331.

Collingridge GL, Olsen R, Peters JA, and Spedding M (2009) Ligand gated ion channels. Neuropharmacology $56: 1$.

Colquhoun D (1973) The relation between classical and cooperative models for drug action, in Drug Receptors (Rang HP ed) pp 149-182, Macmillan Press, London.

Colquhoun D (1998) Binding, gating, affinity and efficacy: the interpretation of structure-activity relationships for agonists and of the effects of mutating receptors. Br J Pharmacol 125:924-947.

Colquhoun D (2007) Why the Schild method is better than Schild realised. Trends Pharmacol Sci 28:608-614.

Colquhoun D and Lape R (2012) Perspectives on: conformational coupling in ion channels: allosteric coupling in ligand-gated ion channels. J Gen Physiol 140: 599-612.

Conigrave AD, Quinn SJ, and Brown EM (2000) L-amino acid sensing by the extracellular Ca2+-sensing receptor. Proc Natl Acad Sci USA 97:4814-4819.

Conn PJ, Christopoulos A, and Lindsley CW (2009) Allosteric modulators of GPCRs: a novel approach for the treatment of CNS disorders. Nat Rev Drug Discov 8:41-54.

Converso A Hartingh T, Garbaccio RM, Tasber E, Rickert K, Fraley ME, Yan Y, Kreatsoulas C, Stirdivant S, and Drakas B, et al. (2009) Development of thioquinazolinones, allosteric Chk1 kinase inhibitors. Bioorg Med Chem Lett 19: 1240-1244.

Corringer PJ, Poitevin F, Prevost MS, Sauguet L, Delarue M, and Changeux JP (2012) Structure and pharmacology of pentameric receptor channels: from bacteria to brain. Structure 20:941-956.

Costa T and Herz A (1989) Antagonists with negative intrinsic activity at delta opioid receptors coupled to GTP-binding proteins. Proc Natl Acad Sci USA 86:7321-7325.

Cowan-Jacob SW (2006) Structural biology of protein tyrosine kinases. Cell Mol Life Sci 63:2608-2625.

Cuatrecasas P (1974) Membrane receptors. Annu Rev Biochem 43:169-214.

Cui Q and Karplus M (2008) Allostery and cooperativity revisited. Protein Sci 17: $1295-1307$

daCosta CJ, Medaglia SA, Lavigne N, Wang S, Carswell CL, and Baenziger JE (2009) Anionic lipids allosterically modulate multiple nicotinic acetylcholine receptor conformational equilibria. J Biol Chem 284:33841-33849.

de Kruijf P, Lim HD, Roumen L, Renjaän VA, Zhao J, Webb ML, Auld DS, Wijkmans JC, Zaman GJ, and Smit MJ, et al. (2011) Identification of a novel allosteric binding site in the CXCR2 chemokine receptor. Mol Pharmacol 80:1108-1118.

Del Castillo J and Katz B (1957) Interaction at end-plate receptors between different choline derivatives. Proc $R$ Soc Lond B Biol Sci 146:369-381.

De Lean A, Stadel JM, and Lefkowitz RJ (1980) A ternary complex model explains the agonist-specific binding properties of the adenylate cyclase-coupled betaadrenergic receptor. J Biol Chem 255:7108-7117.

Dong M, Cox RF, and Miller LJ (2009) Juxtamembranous region of the amino terminus of the family B G protein-coupled calcitonin receptor plays a critical role in small-molecule agonist action. J Biol Chem 284:21839-21847.

Dorr P, Westby M, Dobbs S, Griffin P, Irvine B, Macartney M, Mori J, Rickett G, Smith-Burchnell C, and Napier C, et al. (2005) Maraviroc (UK-427,857), a potent, orally bioavailable, and selective small-molecule inhibitor of chemokine receptor CCR5 with broad-spectrum anti-human immunodeficiency virus type 1 activity. Antimicrob Agents Chemother 49:4721-4732.

Downing SS, Lee YT, Farb DH, and Gibbs TT (2005) Benzodiazepine modulation of partial agonist efficacy and spontaneously active GABA(A) receptors supports an allosteric model of modulation. Br J Pharmacol 145:894-906.

Dror RO, Green HF, Valant C, Borhani DW, Valcourt JR, Pan AC, Arlow DH, Canals M, Lane JR, and Rahmani R, et al. (2013) Structural basis for modulation of a G-protein-coupled receptor by allosteric drugs. Nature 503:295-299.

Ehlert FJ (1985) The relationship between muscarinic receptor occupancy and adenylate cyclase inhibition in the rabbit myocardium. Mol Pharmacol 28:410-421.

Ehlert FJ (1988) Estimation of the affinities of allosteric ligands using radioligand binding and pharmacological null methods. Mol Pharmacol 33:187-194.

Ehlert FJ (2005) Analysis of allosterism in functional assays. J Pharmacol Exp Ther 315:740-754

Estébanez-Perpiñá E, Arnold LA, Jouravel N, Togashi M, Blethrow J, Mar E, Nguyen P, Phillips KJ, Baxter JD, and Webb P, et al. (2007a) Structural insight into the mode of action of a direct inhibitor of coregulator binding to the thyroid hormone receptor. Mol Endocrinol 21:2919-2928.

Estébanez-Perpiñá E, Arnold LA, Nguyen P, Rodrigues ED, Mar E, Bateman R, Pallai P, Shokat KM, Baxter JD, and Guy RK, et al. (2007b) A surface on the androgen receptor that allosterically regulates coactivator binding. Proc Natl Acad Sci USA 104:16074-16079.

Fabbro D, Cowan-Jacob SW, Möbitz H, and Martiny-Baron G (2012) Targeting cancer with small-molecular-weight kinase inhibitors. Methods Mol Biol 795:1-34.

Fabbro D and García-Echeverría C (2002) Targeting protein kinases in cancer therapy. Curr Opin Drug Discov Devel 5:701-712. 
Fabbro D, Manley PW, Jahnke W, Liebetanz J, Szyttenholm A, Fendrich G, Strauss A, Zhang J, Gray NS, and Adrian F, et al. (2010) Inhibitors of the Abl kinase directed at either the ATP- or myristate-binding site. Biochim Biophys Acta 1804 454-462.

Fenalti G, Giguere PM, Katritch V, Huang XP, Thompson AA, Cherezov V, Roth BL, and Stevens RC (2014) Molecular control of $\delta$-opioid receptor signalling. Nature 506:191-196.

Fenton AW (2008) Allostery: an illustrated definition for the 'second secret of life' Trends Biochem Sci 33:420-425.

Ferry DR and Glossmann H (1982) Evidence of multiple receptor sites within the putative calcium channel. Naunyn Schmiedebergs Arch Pharmacol 321:80-83.

Fleishman SJ, Schlessinger J, and Ben-Tal N (2002) A putative molecular-activation switch in the transmembrane domain of erbB2. Proc Natl Acad Sci USA 99 15937-15940.

Flynn GE, Black KD, Islas LD, Sankaran B, and Zagotta WN (2007) Structure and rearrangements in the carboxy-terminal region of $\mathrm{SpIH}$ channels. Structure $\mathbf{1 5}$ $671-682$.

Fredholm BB, IJzerman AP, Jacobson KA, Linden J, and Müller CE (2011) International Union of Basic and Clinical Pharmacology. LXXXI. Nomenclature and classification of adenosine receptors-an update. Pharmacol Rev 63:1-34.

Galande AK, Bramlett KS, Trent JO, Burris TP, Wittliff JL, and Spatola AF (2005) Potent inhibitors of LXXLL-based protein-protein interactions. ChemBioChem 6: 1991-1998

Galzi JL, Bertrand S, Corringer PJ, Changeux JP, and Bertrand D (1996) Identification of calcium binding sites that regulate potentiation of a neuronal nicotinic acetylcholine receptor. EMBO J 15:5824-5832.

Galzi JL and Changeux JP (1994) Neurotransmitter-gated ion channels as unconventional allosteric proteins. Curr Opin Struct Biol 4:554-565.

Gao F, Sexton PM, Christopoulos A, and Miller LJ (2008) Benzodiazepine ligands can act as allosteric modulators of the Type 1 cholecystokinin receptor. Bioorg Med Chem Lett 18:4401-4404.

Geistlinger TR, McReynolds AC, and Guy RK (2004) Ligand-selective inhibition of the interaction of steroid receptor coactivators and estrogen receptor isoforms. Chem Biol 11:273-281.

Gerhart JC and Pardee AB (1962) The enzymology of control by feedback inhibition. J Biol Chem 237:891-896.

Gill JK, Savolainen M, Young GT, Zwart R, Sher E, and Millar NS (2011) Agonist activation of alpha7 nicotinic acetylcholine receptors via an allosteric transmembrane site. Proc Natl Acad Sci USA 108:5867-5872.

Gilman AG (1987) G proteins: transducers of receptor-generated signals. Annu Rev Biochem 56:615-649.

Grimm C, Aneiros E, and de Groot M (2011) Dissecting TRPV1: lessons to be learned? Channels (Austin) 5:201-204.

Grimsby J, Sarabu R, Corbett WL, Haynes NE, Bizzarro FT, Coffey JW, Guertin KR, Hilliard DW, Kester RF, and Mahaney PE, et al. (2003) Allosteric activators of glucokinase: potential role in diabetes therapy. Science 301:370-373.

Guertin KR and Grimsby J (2006) Small molecule glucokinase activators as glucose lowering agents: a new paradigm for diabetes therapy. Curr Med Chem 13:1839-1843.

Hall DA (2000) Modeling the functional effects of allosteric modulators at pharmacological receptors: an extension of the two-state model of receptor activation. $M o$ Pharmacol 58:1412-1423.

Hall JM, Chang CY, and McDonnell DP (2000) Development of peptide antagonists that target estrogen receptor beta-coactivator interactions. Mol Endocrinol 14: 2010-2023.

Hamm HE (1998) The many faces of G protein signaling. J Biol Chem 273:669-672.

Hamouda AK, Kimm T, and Cohen JB (2013) Physostigmine and galanthamine bind in the presence of agonist at the canonical and noncanonical subunit interfaces of a nicotinic acetylcholine receptor. $J$ Neurosci 33:485-494.

Hanchar HJ, Chutsrinopkun P, Meera P, Supavilai P, Sieghart W, Wallner M, and Olsen RW (2006) Ethanol potently and competitively inhibits binding of the alcohol antagonist Ro15-4513 to alpha4/6beta3delta GABAA receptors. Proc Nat Acad Sci USA 103:8546-8551.

Hansen SB and Taylor P (2007) Galanthamine and non-competitive inhibitor binding to ACh-binding protein: evidence for a binding site on non-alpha-subunit interfaces of heteromeric neuronal nicotinic receptors. J Mol Biol 369:895-901.

Hansen KB and Traynelis SF (2011) Structural and mechanistic determinants of a novel site for noncompetitive inhibition of GluN2D-containing NMDA receptors. $J$ Neurosci 31:3650-3661.

Hansen KB, Ogden KK, and Traynelis SF (2012) Subunit-selective allosteric inhibition of glycine binding to NMDA receptors. J Neurosci 32:6197-6208.

Hardy JA and Wells JA (2004) Searching for new allosteric sites in enzymes. Curr Opin Struct Biol 14:706-715.

Heery DM, Kalkhoven E, Hoare S, and Parker MG (1997) A signature motif in transcriptional co-activators mediates binding to nuclear receptors. Nature 387: 733-736.

Herbert C, Schieborr U, Saxena K, Juraszek J, De Smet F, Alcouffe C, Bianciotto M, Saladino G, Sibrac D, and Kudlinzki D, et al. (2013) Molecular mechanism of SSR128129E, an extracellularly acting, small-molecule, allosteric inhibitor of FGF receptor signaling. Cancer Cell 23:489-501.

Hess P, Lansman JB, and Tsien RW (1984) Different modes of Ca channel gating behaviour favoured by dihydropyridine Ca agonists and antagonists. Nature 311: 538-544.

Hibbs RE and Gouaux E (2011) Principles of activation and permeation in an anionselective Cys-loop receptor. Nature 474:54-60.

Hille B (2001) Ionic channels of excitable membranes, Sinauer Associates Inc., Sunderland, MA.

Hindie V, Stroba A, Zhang H, Lopez-Garcia LA, Idrissova L, Zeuzem S, Hirschberg D, Schaeffer F, Jørgensen TJ, and Engel M, et al. (2009) Structure and allosteric effects of low-molecular-weight activators on the protein kinase PDK1. Nat Chem Biol 5:758-764.
Hoare SR, Fleck BA, Gross RS, Crowe PD, Williams JP, and Grigoriadis DE (2008) Allosteric ligands for the corticotropin releasing factor type 1 receptor modulate conformational states involved in receptor activation. Mol Pharmacol 73:1371-1380. Hockerman GH, Johnson BD, Abbott MR, Scheuer T, and Catterall WA (1997a) Molecular determinants of high affinity phenylalkylamine block of L-type calcium channels in transmembrane segment IIIS6 and the pore region of the alpha1 subunit. $J$ Biol Chem 272:18759-18765.

Hockerman GH, Peterson BZ, Sharp E, Tanada TN, Scheuer T, and Catterall WA (1997b) Construction of a high-affinity receptor site for dihydropyridine agonists and antagonists by single amino acid substitutions in a non-L-type Ca2+ channel. Proc Natl Acad Sci USA 94:14906-14911.

Hogg RC, Buisson B, and Bertrand D (2005) Allosteric modulation of ligand-gated ion channels. Biochem Pharmacol 70:1267-1276.

Hollenstein K, Kean J, Bortolato A, Cheng RK, Doré AS, Jazayeri A, Cooke RM, Weir M, and Marshall FH (2013) Structure of class B GPCR corticotropin-releasing factor receptor 1. Nature 499:438-443.

Hsieh AC and Moasser MM (2007) Targeting HER proteins in cancer therapy and the role of the non-target HER3. Br J Cancer 97:453-457.

Hubbard SR (1997) Crystal structure of the activated insulin receptor tyrosine kinase in complex with peptide substrate and ATP analog. EMBO $J$ 16:5572-5581.

Hughes TS, Giri PK, de Vera IM, Marciano DP, Kuruvilla DS, Shin Y, Blayo AL, Kamenecka TM, Burris TP, and Griffin PR, et al. (2014) An alternate binding site for PPAR $y$ ligands. Nat Commun 5:3571 DOI: 10.1038/ncomms4571.

Hynes NE and Lane HA (2005) ERBB receptors and cancer: the complexity of targeted inhibitors. Nat Rev Cancer 5:341-354.

Inoki K, Corradetti MN, and Guan KL (2005) Dysregulation of the TSC-mTOR pathway in human disease. Nat Genet 37:19-24.

Issafras H, Corbin JA, Goldfine ID, and Roell MK (2014) Detailed mechanistic analysis of gevokizumab, an allosteric anti-IL-1 $\beta$ antibody with differential receptor-modulating properties. J Pharmacol Exp Ther 348:202-215.

Ito H, Klugbauer N, and Hofmann F (1997) Transfer of the high affinity dihydropyridine sensitivity from L-type To non-L-type calcium channel. Mol Pharmacol 52:735-740.

Jackson MB (1984) Spontaneous openings of the acetylcholine receptor channel. Proc Natl Acad Sci USA 81:3901-3904.

Jacobson KA and Gao ZG (2006) Adenosine receptors as therapeutic targets. Nat Rev Drug Discov 5:247-264

Janis RA, Sarmiento JG, Maurer SC, Bolger GT, and Triggle DJ (1984) Characteristics of the binding of $[3 \mathrm{H}]$ nitrendipine to rabbit ventricular membranes: modification by other $\mathrm{Ca}++$ channel antagonists and by the $\mathrm{Ca}++$ channel agonist Bay K 8644. J Pharmacol Exp Ther 231:8-15.

Jenkinson DH, Barnard EA, Hoyer D, Humphrey PP, Leff P, and Shankley NP (1995) International Union of Pharmacology Committee on Receptor Nomenclature and Drug Classification. IX. Recommendations on terms and symbols in quantitative pharmacology. Pharmacol Rev 47:255-266.

Jura N, Zhang X, Endres NF, Seeliger MA, Schindler T, and Kuriyan J (2011) Catalytic control in the EGF receptor and its connection to general kinase regulatory mechanisms. Mol Cell 42:9-22.

Karlin A (1967) On the application of "a plausible model" of allosteric proteins to the receptor for acetylcholine. J Theor Biol 16:306-320.

Katz B and Thesleff S (1957) A study of the desensitization produced by acetylcholine at the motor end-plate. J Physiol 138:63-80.

Kenakin T (2005) New concepts in drug discovery: collateral efficacy and permissive antagonism. Nat Rev Drug Discov 4:919-927.

Kenakin T (2009) Interrogating 7TM receptors: does texture in the question yield greater texture in the answer? J Recept Signal Transduct Res 29:132-139.

Kenakin T and Christopoulos A (2013) Signalling bias in new drug discovery: detection, quantification and therapeutic impact. Nat Rev Drug Discov 12:205-216.

Kenakin T and Miller LJ (2010) Seven transmembrane receptors as shapeshifting proteins: the impact of allosteric modulation and functional selectivity on new drug discovery. Pharmacol Rev 62:265-304.

Keov P, Sexton PM, and Christopoulos A (2011) Allosteric modulation of G proteincoupled receptors: a pharmacological perspective. Neuropharmacology 60:24-35.

Kern D and Zuiderweg ER (2003) The role of dynamics in allosteric regulation. Curr Opin Struct Biol 13:748-757.

Kjelsberg MA, Cotecchia S, Ostrowski J, Caron MG, and Lefkowitz RJ (1992) Constitutive activation of the alpha $1 \mathrm{~B}$-adrenergic receptor by all amino acid substitutions at a single site. Evidence for a region which constrains receptor activation. J Biol Chem 267:1430-1433.

Knudsen LB, Kiel D, Teng M, Behrens C, Bhumralkar D, Kodra JT, Holst JJ, Jeppesen CB, Johnson MD, and de Jong JC, et al. (2007) Small-molecule agonists for the glucagon-like peptide 1 receptor. Proc Natl Acad Sci USA 104:937-942.

Kojetin DJ and Burris TP (2014) REV-ERB and ROR nuclear receptors as drug targets. Nat Rev Drug Discov 13:197-216.

Kornev AP, Haste NM, Taylor SS, and Eyck LF (2006) Surface comparison of active and inactive protein kinases identifies a conserved activation mechanism. Proc Natl Acad Sci USA 103:17783-17788.

Koshland DE Jr, Némethy G, and Filmer D (1966) Comparison of experimental binding data and theoretical models in proteins containing subunits. Biochemistry 5:365-385.

Kostenis E and Mohr K (1996) Two-point kinetic experiments to quantify allosteric effects on radioligand dissociation. Trends Pharmacol Sci 17:280-283.

Krause RM, Buisson B, Bertrand S, Corringer PJ, Galzi JL, Changeux JP and Bertrand D (1998) Ivermectin: a positive allosteric effector of the alpha7 neuronal nicotinic acetylcholine receptor. Mol Pharmacol 53:283-294.

Kruse AC, Ring AM, Manglik A, Hu J, Hu K, Eitel K, Hübner H, Pardon E, Valant C, and Sexton PM, et al. (2013) Activation and allosteric modulation of a muscarinic acetylcholine receptor. Nature 504:101-106.

Kufareva I and Abagyan R (2008) Type-II kinase inhibitor docking, screening, and profiling using modified structures of active kinase states. J Med Chem 51: $7921-7932$ 
Kute T, Lack CM, Willingham M, Bishwokama B, Williams H, Barrett K, Mitchell T, and Vaughn JP (2004) Development of Herceptin resistance in breast cancer cells. Cytometry A 57:86-93.

LaFrate AL, Gunther JR, Carlson KE, and Katzenellenbogen JA (2008) Synthesis and biological evaluation of guanylhydrazone coactivator binding inhibitors for the estrogen receptor. Bioorg Med Chem 16:10075-10084.

Landgraf KE, Santell L, Billeci KL, Quan C, Young JC, Maun HR, Kirchhofer D, and Lazarus RA (2010) Allosteric peptide activators of pro-hepatocyte growth factor stimulate Met signaling. J Biol Chem 285:40362-40372.

Lane JR, Sexton PM, and Christopoulos A (2013) Bridging the gap: bitopic ligands of G-protein-coupled receptors. Trends Pharmacol Sci 34:59-66.

Langmead CJ (2011) Determining allosteric modulator mechanism of action: integration of radioligand binding and functional assay data. Methods Mol Biol 746: 195-209.

Langmead CJ and Christopoulos A (2014) Functional and structural perspectives on allosteric modulation of GPCRs. Curr Opin Cell Biol 27:94-101.

Lanzafame AA, Sexton PM, and Christopoulos A (2006) Interaction studies of multiple binding sites on 4 muscarinic acetylcholine receptors. Mol Pharmacol 70: $736-746$.

Lazareno S, Dolezal V, Popham A, and Birdsall NJ (2004) Thiochrome enhances acetylcholine affinity at muscarinic M4 receptors: receptor subtype selectivity via cooperativity rather than affinity. Mol Pharmacol 65:257-266.

Lazareno S, Popham A, and Birdsall NJ (2002) Analogs of WIN 62,577 define a second allosteric site on muscarinic receptors. Mol Pharmacol 62:1492-1505.

Leach K, Loiacono RE, Felder CC, McKinzie DL, Mogg A, Shaw DB, Sexton PM, and Christopoulos A (2010) Molecular mechanisms of action and in vivo validation of an M4 muscarinic acetylcholine receptor allosteric modulator with potentia antipsychotic properties. Neuropsychopharmacology 35:855-869.

Leach K, Sexton PM, and Christopoulos A (2007) Allosteric GPCR modulators: tak ing advantage of permissive receptor pharmacology. Trends Pharmacol Sci 28 $382-389$.

Leach K, Wen A, Cook AE, Sexton PM, Conigrave AD, and Christopoulos A (2013) Impact of clinically relevant mutations on the pharmacoregulation and signaling bias of the calcium-sensing receptor by positive and negative allosteric modulators. Endocrinology 154:1105-1116.

Leduc AM, Trent JO, Wittliff JL, Bramlett KS, Briggs SL, Chirgadze NY, Wang Y, Burris TP, and Spatola AF (2003) Helix-stabilized cyclic peptides as selective inhibitors of steroid receptor-coactivator interactions. Proc Natl Acad Sci USA 100: 11273-11278.

Lemmon MA and Schlessinger J (2010) Cell signaling by receptor tyrosine kinases. Cell 141:1117-1134.

Le Novère N, Grutter T, and Changeux JP (2002) Models of the extracellular domain of the nicotinic receptors and of agonist- and Ca2+-binding sites. Proc Natl Acad Sci USA 99:3210-3215

Lewis M (2005) The lac repressor. C R Biol 328:521-548.

Lewis M, Chang G, Horton NC, Kercher MA, Pace HC, Schumacher MA, Brennan RG, and Lu P (1996) Crystal structure of the lactose operon repressor and its complexes with DNA and inducer. Science 271:1247-1254.

Levitzki A (2003) Protein kinase inhibitors as a therapeutic modality. Acc Chem Res 36:462-469.

Li B, Liu Y, Uno T, and Gray N (2004) Creating chemical diversity to target protein kinases. Comb Chem High Throughput Screen 7:453-472.

Li GD, Chiara DC, Cohen JB, and Olsen RW (2010) Numerous classes of general anesthetics inhibit etomidate binding to gamma-aminobutyric acid type $\mathrm{A}\left(\mathrm{GABA}_{\mathrm{A}}\right)$ receptors. J Biol Chem 285:8615-8620.

Li GD, Chiara DC, Sawyer GW, Husain SS, Olsen RW, and Cohen JB (2006) Identification of a $\mathrm{GABA}_{\mathrm{A}}$ receptor anesthetic binding site at subunit interfaces by photolabeling with an etomidate analog. J Neurosci 26:11599-11605.

Li-Smerin Y and Swartz KJ (1998) Gating modifier toxins reveal a conserved structural motif in voltage-gated $\mathrm{Ca} 2+$ and $\mathrm{K}+$ channels. Proc Natl Acad Sci USA 95:8585-8589.

Liao M, Cao E, Julius D, and Cheng Y (2013) Structure of the TRPV1 ion channel determined by electron cryo-microscopy. Nature 504:107-112

Lindberg JS, Culleton B, Wong G, Borah MF, Clark RV, Shapiro WB, Roger SD, Husserl FE, Klassen PS, and Guo MD, et al. (2005) Cinacalcet HCl, an oral calcimimetic agent for the treatment of secondary hyperparathyroidism in hemodialysis and peritoneal dialysis: a randomized, double-blind, multicenter study. J Am Soc Nephrol 16:800-807.

Lindsley CW, Zhao Z, Leister WH, Robinson RG, Barnett SF, Defeo-Jones D, Jones RE, Hartman GD, Huff JR, and Huber HE, et al (2005) Allosteric Akt (PKB) inhibitors: discovery and SAR of isozyme selective inhibitors. Bioorg Med Chem Lett 15:761-764.

Litschig S, Gasparini F, Rueegg D, Stoehr N, Flor PJ, Vranesic I, Prézeau L, Pin JP Thomsen C, and Kuhn R (1999) CPCCOEt, a noncompetitive metabotropic glutamate receptor 1 antagonist, inhibits receptor signaling without affecting glutamate binding. Mol Pharmacol 55:453-461.

Liu W, Chun E, Thompson AA, Chubukov P, Xu F, Katritch V, Han GW, Roth CB, Heitman LH, and IJzerman AP, et al. (2012) Structural basis for allosteric regulation of GPCRs by sodium ions. Science 337:232-236.

Liu Y and Gray NS (2006) Rational design of inhibitors that bind to inactive kinase conformations. Nat Chem Biol 2:358-364.

Long SB, Tao X, Campbell EB, and MacKinnon R (2007) Atomic structure of a voltagedependent $\mathrm{K}+$ channel in a lipid membrane-like environment. Nature 450 $376-382$

Lou X, Toresson G, Benod C, Suh JH, Philips KJ, Webb P, and Gustafsson JA (2014) Structure of the retinoid X receptor $\alpha$-liver X receptor $\beta(\mathrm{RXR} \alpha$-LXR $\beta)$ heterodimer on DNA. Nat Struct Mol Biol 21:277-281.

Lüllmann H, Ohnesorge FK, Schauwecker GC, and Wassermann O (1969) Inhibition of the actions of carbachol and DFP on guinea pig isolated atria by alkane-bisammonium compounds. Eur J Pharmacol 6:241-247.
MacKinnon R and Miller C (1989) Mutant potassium channels with altered binding of charybdotoxin, a pore-blocking peptide inhibitor. Science 245:1382-1385.

Matulef K and Zagotta WN (2003) Cyclic nucleotide-gated ion channels. Annu Rev Cell Dev Biol 19:23-44.

May LT, Leach K, Sexton PM, and Christopoulos A (2007) Allosteric modulation of G protein-coupled receptors. Annu Rev Pharmacol Toxicol 47:1-51.

Melancon BJ, Hopkins CR, Wood MR, Emmitte KA, Niswender CM, Christopoulos A Conn PJ, and Lindsley CW (2012) Allosteric modulation of seven transmembrane spanning receptors: theory, practice, and opportunities for central nervous system drug discovery. $J$ Med Chem 55:1445-1464.

Mettu NB, Stanley TB, Dwyer MA, Jansen MS, Allen JE, Hall JM, and McDonnell DP (2007) The nuclear receptor-coactivator interaction surface as a target for peptide antagonists of the peroxisome proliferator-activated receptors. Mol Endocrinol 21:2361-2377.

Mohr K, Schmitz J, Schrage R, Tränkle C, and Holzgrabe U (2013) Molecular alliance-from orthosteric and allosteric ligands to dualsteric/bitopic agonists at G protein coupled receptors. Angew Chem Int Ed Engl 52:508-516.

Monod J, Changeux JP, and Jacob F (1963) Allosteric proteins and cellular control systems. J Mol Biol 6:306-329.

Monod J and Jacob F (1961) Teleonomic mechanisms in cellular metabolism, growth, and differentiation. Cold Spring Harb Symp Quant Biol 26:389-401.

Monod J, Wyman J, and Changeux JP (1965) On the nature of allosteric transitions: a plausible model. J Mol Biol 12:88-118.

Moore TW, Mayne CG, and Katzenellenbogen JA (2010) Minireview: Not picking pockets: nuclear receptor alternate-site modulators (NRAMs). Mol Endocrinol 24:683-695.

Moras D and Gronemeyer H (1998) The nuclear receptor ligand-binding domain: structure and function. Curr Opin Cell Biol 10:384-391.

Morgan DO (1996) The dynamics of cyclin dependent kinase structure. Curr Opin Cell Biol 8:767-772.

Mulle C, Léna C, and Changeux JP (1992) Potentiation of nicotinic receptor response by external calcium in rat central neurons. Neuron 8:937-945.

Nawaratne V, Leach K, Felder CC, Sexton PM, and Christopoulos A (2010) Structural determinants of allosteric agonism and modulation at the M4 muscarinic acetylcholine receptor: identification of ligand-specific and global activation mechanisms. J Biol Chem 285:19012-19021.

Nemecz A and Taylor P (2011) Creating an $\alpha 7$ nicotinic acetylcholine recognition domain from the acetylcholine-binding protein: crystallographic and ligand selectivity analyses. J Biol Chem 286:42555-42565.

Neubig RR, Spedding M, Kenakin T, and Christopoulos A; International Union of Pharmacology Committee on Receptor Nomenclature and Drug Classification (2003) International Union of Pharmacology Committee on Receptor Nomenclature and Drug Classification. XXXVIII. Update on terms and symbols in quantitative pharmacology. Pharmacol Rev 55:597-606.

Nguyen NH, Apriletti JW, Cunha Lima ST, Webb P, Baxter JD, and Scanlan TS (2002) Rational design and synthesis of a novel thyroid hormone antagonist that blocks coactivator recruitment. J Med Chem 45:3310-3320.

Nicholls DJ, Tomkinson NP, Wiley KE, Brammall A, Bowers L, Grahames C, Gaw A Meghani P, Shelton P, and Wright TJ, et al. (2008) Identification of a putative intracellular allosteric antagonist binding-site in the CXC chemokine receptors 1 and 2. Mol Pharmacol 74:1193-1202.

Niefind K, Raaf J, and Issinger OG (2009) Protein kinase CK2 in health and disease: Protein kinase CK2: from structures to insights. Cell Mol Life Sci 66:1800-1816.

Nilius B, Talavera K, Owsianik G, Prenen J, Droogmans G, and Voets T (2005) Gating of TRP channels: a voltage connection? J Physiol 567:35-44.

Noetzel MJ, Gregory KJ, Vinson PN, Manka JT, Stauffer SR, Lindsley CW, Niswender CM, Xiang Z, and Conn PJ (2013) A novel metabotropic glutamate receptor 5 positive allosteric modulator acts at a unique site and confers stimulus bias to mGlu5 signaling. Mol Pharmacol 83:835-847.

Nolen B, Taylor S, and Ghosh G (2004) Regulation of protein kinases; controlling activity through activation segment conformation. Mol Cell 15:661-675.

Norris JD, Paige LA, Christensen DJ, Chang CY, Huacani MR, Fan D, Hamilton PT, Fowlkes DM, and McDonnell DP (1999) Peptide antagonists of the human estrogen receptor. Science 285:744-746.

Nowycky MC, Fox AP, and Tsien RW (1985) Three types of neuronal calcium channel with different calcium agonist sensitivity. Nature 316:440-443.

Nury H, Van Renterghem C, Weng Y, Tran A, Baaden M, Dufresne V, Changeux JP, Sonner JM, Delarue M, and Corringer PJ (2011) X-ray structures of general anaesthetics bound to a pentameric ligand-gated ion channel. Nature 469:428-431. Ohren JF, Chen H, Pavlovsky A, Whitehead C, Zhang E, Kuffa P, Yan C, McConnell P, Spessard C, and Banotai C, et al (2004) Structures of human MAP kinase kinase 1 (MEK1) and MEK2 describe novel noncompetitive kinase inhibition. Nat Struct Mol Biol 11:1192-1197.

Olivera BM, Miljanich GP, Ramachandran J, and Adams ME (1994) Calcium channe diversity and neurotransmitter release: the omega-conotoxins and omega-agatoxins. Annu Rev Biochem 63:823-867.

Olsen RW, Chang CS, Li G, Hanchar HJ, and Wallner M (2004) Fishing for allosteric sites on GABA(A) receptors. Biochem Pharmacol 68:1675-1684

Olsen RW, Li GD, Wallner M, Trudell JR, Bertaccini EJ, Lindahl E, Miller KW, Alkana RL, and Davies DL (2014) Structural models of ligand-gated ion channels: sites of action for anesthetics and ethanol. Alcohol Clin Exp Res 38:595-603.

Olsen RW and Sapp DW (1995) Neuroactive steroid modulation of GABAA receptors. Adv Biochem Psychopharmacol 48:57-74.

Olsen RW and Sieghart W (2009) GABA A receptors: subtypes provide diversity of function and pharmacology. Neuropharmacology 56:141-148.

Orlov I, Rochel N, Moras D, and Klaholz BP (2012) Structure of the full human RXR/ VDR nuclear receptor heterodimer complex with its DR3 target DNA. EMBO $J \mathbf{3 1}$ 291-300.

Pan J, Chen Q, Willenbring D, Mowrey D, Kong XP, Cohen A, Divito CB, Xu Y, and Tang $\mathrm{P}$ (2012) Structure of the pentameric ligand-gated ion channel GLIC bound with anesthetic ketamine. Structure 20:1463-1469. 
Pantazis A and Olcese R (2012) Relative transmembrane segment rearrangements during BK channel activation resolved by structurally assigned fluorophorequencher pairing. J Gen Physiol 140:207-218.

Parent AA, Gunther JR, and Katzenellenbogen JA (2008) Blocking estrogen signaling after the hormone: pyrimidine-core inhibitors of estrogen receptor-coactivator binding. J Med Chem 51:6512-6530.

Payandeh J, Gamal El-Din TM, Scheuer T, Zheng N, and Catterall WA (2012) Crystal structure of a voltage-gated sodium channel in two potentially inactivated states. Nature 486:135-139.

Payandeh J, Scheuer T, Zheng N, and Catterall WA (2011) The crystal structure of a voltage-gated sodium channel. Nature 475:353-358.

Perkins DI, Trudell JR, Crawford DK, Asatryan L, Alkana RL, and Davies DL (2009) Loop 2 structure in glycine and GABA(A) receptors plays a key role in determining ethanol sensitivity. J Biol Chem 284:27304-27314.

Peters JA, Cooper MA, Carland JE, Livesey MR, Hales TG, and Lambert JJ (2010) Novel structural determinants of single channel conductance and ion selectivity in 5-hydroxytryptamine type 3 and nicotinic acetylcholine receptors. J Physiol 588: 587-596.

Pike JW, Pathrose P, Barmina O, Chang CY, McDonnell DP, Yamamoto H, and Shevde NK (2003) Synthetic LXXLL peptide antagonize 1,25-dihydroxyvitamin D3-dependent transcription. J Cell Biochem 88:252-258.

Pin JP, Neubig R, Bouvier M, Devi L, Filizola M, Javitch JA, Lohse MJ, Milligan G, Palczewski K, and Parmentier M, et al. (2007) International Union of Basic and Clinical Pharmacology. LXVII. Recommendations for the recognition and nomenclature of G protein-coupled receptor heteromultimers. Pharmacol Rev 59:5-13.

Pin JP and Prézeau L (2007) Allosteric modulators of GABA(B) receptors: mechanism of action and therapeutic perspective. Curr Neuropharmacol 5:195-201.

Poon G (2005) Cinacalcet hydrochloride (Sensipar). Proc (Bayl Univ Med Cent) 18 $181-184$

Popovych N, Tzeng SR, Tonelli M, Ebright RH, and Kalodimos CG (2009) Structural basis for cAMP-mediated allosteric control of the catabolite activator protein. Proc Natl Acad Sci USA 106:6927-6932.

Price MR, Baillie GL, Thomas A, Stevenson LA, Easson M, Goodwin R, McLean A, McIntosh L, Goodwin G, and Walker G, et al. (2005) Allosteric modulation of the cannabinoid CB1 receptor. Mol Pharmacol 68:1484-1495.

Proska J and Tucek S (1994) Mechanisms of steric and cooperative actions of alcuronium on cardiac muscarinic acetylcholine receptors. Mol Pharmacol 45:709-717.

Ragsdale DS, McPhee JC, Scheuer T, and Catterall WA (1994) Molecular determinants of state-dependent block of $\mathrm{Na}+$ channels by local anesthetics. Science $\mathbf{2 6 5}$ $1724-1728$

Rasmussen SG, DeVree BT, Zou Y, Kruse AC, Chung KY, Kobilka TS, Thian FS, Chae PS, Pardon E, and Calinski D, et al. (2011) Crystal structure of the adrenergic receptor-Gs protein complex. Nature 477:549-555.

Renaud JP, Rochel N, Ruff M, Vivat V, Chambon P, Gronemeyer H, and Moras D (1995) Crystal structure of the RAR-gamma ligand-binding domain bound to alltrans retinoic acid. Nature 378:681-689.

Revah F, Bertrand D, Galzi JL, Devillers-Thiéry A, Mulle C, Hussy N, Bertrand S, Ballivet M, and Changeux JP (1991) Mutations in the channel domain alter desensitization of a neuronal nicotinic receptor. Nature 353:846-849.

Roell MK, Issafras H, Bauer RJ, Michelson KS, Mendoza N, Vanegas SI, Gross LM, Larsen PD, Bedinger DH, and Bohmann DJ, et al. (2010) Kinetic approach to pathway attenuation using XOMA 052 , a regulatory therapeutic antibody that modulates interleukin-1beta activity. $J$ Biol Chem 285:20607-20614.

Rogers CJ, Twyman RE, and Macdonald RL (1994) Benzodiazepine and betacarboline regulation of single GABAA receptor channels of mouse spinal neurones in culture. J Physiol 475:69-82.

Rubin MM and Changeux JP (1966) On the nature of allosteric transitions: implications of non-exclusive ligand binding. J Mol Biol 21:265-274.

Sanders MJ, Ali ZS, Hegarty BD, Heath R, Snowden MA, and Carling D (2007) Defining the mechanism of activation of AMP-activated protein kinase by the small molecule A-769662, a member of the thienopyridone family. $J$ Biol Chem 282:32539-32548.

Sauguet L, Howard RJ, Malherbe L, Lee US, Corringer PJ, Harris RA, and Delarue M (2013) Structural basis for potentiation by alcohols and anaesthetics in a ligandgated ion channel. Nat Commun 4:1697.

Sauguet L, Shahsavar A, Poitevin F, Huon C, Menny A, Nemecz À, Haouz A Changeux JP, Corringer PJ, and Delarue M (2014) Crystal structures of a pen tameric ligand-gated ion channel provide a mechanism for activation. Proc Natl Acad Sci USA 111:966-971.

Savkur RS and Burris TP (2004) The coactivator LXXLL nuclear receptor recognition motif. J Pept Res 63:207-212.

Sawyer GW, Chiara DC, Olsen RW, and Cohen JB (2002) Identification of the bovine gamma-aminobutyric acid type A receptor alpha subunit residues photolabeled by the imidazobenzodiazepine [3H]Ro15-4513. J Biol Chem 277:50036-50045.

Scheuer W, Friess T, Burtscher H, Bossenmaier B, Endl J, and Hasmann M (2009) Strongly enhanced antitumor activity of trastuzumab and pertuzumab combination treatment on HER2-positive human xenograft tumor models. Cancer Res 69 9330-9336.

Schmalhofer WA, Calhoun J, Burrows R, Bailey T, Kohler MG, Weinglass AB, Kaczorowski G.J, Garcia ML, Koltzenburg M, and Priest BT (2008) ProTx-II, a selective inhibitor of NaV1.7 sodium channels, blocks action potential propagation in nociceptors. Mol Pharmacol 74:1476-1484.

Scholten DJ, Canals M, Maussang D, Roumen L, Smit MJ, Wijtmans M, de Graaf C, Vischer HF, and Leurs R (2012) Pharmacological modulation of chemokine receptor function. Br J Pharmacol 165:1617-1643.

Sinnegger MJ, Wang Z, Grabner M, Hering S, Striessnig J, Glossmann H, and Mitterdorfer J (1997) Nine L-type amino acid residues confer full 1,4-dihydropyridine sensitivity to the neuronal calcium channel alpha1A subunit. Role of L-type Met1188. J Biol Chem 272:27686-27693.

Smith GB and Olsen RW (1995) Functional domains of GABAA receptors. Trends Pharmacol Sci 16:162-168.
Smith GB and Olsen RW (2000) Deduction of amino acid residues in the GABA(A) receptor alpha subunits photoaffinity labeled with the benzodiazepine flunitrazepam. Neuropharmacology 39:55-64.

Sokolov S, Kraus RL, Scheuer T, and Catterall WA (2008) Inhibition of sodium channel gating by trapping the domain II voltage sensor with protoxin II. Mol Pharmacol 73:1020-1028.

Srinivasan S, Nwachukwu JC, Parent AA, Cavett V, Nowak J, Hughes TS, Kojetin DJ, Katzenellenbogen JA, and Nettles KW (2013) Ligand-binding dynamics rewire cellular signaling via estrogen receptor- $\alpha$. Nat Chem Biol 9:326-332.

Spedding M (1985a) Activators and inactivators of Ca++ channels: new perspectives. J Pharmacol 16:319-343.

Spedding M (1985b) Competitive interactions between Bay K 8644 and nifedipine in $\mathrm{K}+$ depolarized smooth muscle: a passive role for $\mathrm{Ca}+$ ? Naunyn Schmiedebergs Arch Pharmacol 328:464-466.

Spedding M, Kenny B, and Chatelain P (1995) New drug binding sites in Ca2+ channels. Trends Pharmacol Sci 16:139-142.

Spedding M and Mir AK (1987) Direct activation of Ca2+ channels by palmitoyl carnitine, a putative endogenous ligand. $\mathrm{Br}$ J Pharmacol 92:457-468.

Spedding M and Paoletti R (1992) Classification of calcium channels and the sites of action of drugs modifying channel function. Pharmacol Rev 44:363-376.

Steinfeld T, Mammen M, Smith JA, Wilson RD, and Jasper JR (2007) A novel multivalent ligand that bridges the allosteric and orthosteric binding sites of the M2 muscarinic receptor. Mol Pharmacol 72:291-302.

Stephenson RP (1956) A modification of receptor theory. Br Pharmacol Chemother 11:379-393.

Stockton JM, Birdsall NJ, Burgen AS, and Hulme EC (1983) Modification of the binding properties of muscarinic receptors by gallamine. Mol Pharmacol 23:551-557.

Striessnig J (1999) Pharmacology, structure and function of cardiac L-type $\mathrm{Ca}(2+)$ channels. Cell Physiol Biochem 9:242-269.

Study RE and Barker JL (1981) Diazepam and (-)-pentobarbital: fluctuation analysis reveals different mechanisms for potentiation of gamma-aminobutyric acid responses in cultured central neurons. Proc Natl Acad Sci USA 78 $7180-7184$

Taly A, Corringer PJ, Grutter T, Prado de Carvalho L, Karplus M, and Changeux JP (2006) Implications of the quaternary twist allosteric model for the physiology and pathology of nicotinic acetylcholine receptors. Proc Natl Acad Sci USA 103: 16965-16970.

Taly A, Corringer PJ, Guedin D, Lestage P, and Changeux JP (2009) Nicotinic receptors: allosteric transitions and therapeutic targets in the nervous system. Nat Rev Drug Discov 8:733-750.

Tan Q, Zhu Y, Li J, Chen Z, Han GW, Kufareva I, Li T, Ma L, Fenalti G, and Li J, et al. (2013) Structure of the CCR5 chemokine receptor-HIV entry inhibitor maraviroc complex. Science 341:1387-1390.

Tao YX (2008) Constitutive activation of G protein-coupled receptors and diseases: insights into mechanisms of activation and therapeutics. Pharmacol Ther 120: 129-148.

Taylor SS and Kornev AP (2011) Protein kinases: evolution of dynamic regulatory proteins. Trends Biochem Sci 36:65-77.

Thron CD (1973) On the analysis of pharmacological experiments in terms of an allosteric receptor model. Mol Pharmacol 9:1-9.

Tikhonov DB and Zhorov BS (2012) Architecture and pore block of eukaryotic voltage-gated sodium channels in view of NavAb bacterial sodium channel structure. Mol Pharmacol 82:97-104.

Torchia J, Rose DW, Inostroza J, Kamei Y, Westin S, Glass CK, and Rosenfeld MG (1997) The transcriptional co-activator p/CIP binds CBP and mediates nuclearreceptor function. Nature 387:677-684.

Traynelis SF, Wollmuth LP, McBain CJ, Menniti FS, Vance KM, Ogden KK, Hansen KB, Yuan H, Myers SJ, and Dingledine R (2010) Glutamate receptor ion channels: structure, regulation, and function. Pharmacol Rev 62:405-496.

Tummino PJ and Copeland RA (2008) Residence time of receptor-ligand complexes and its effect on biological function. Biochemistry 47:5481-5492.

Udugamasooriya DG, Dineen SP, Brekken RA, and Kodadek T (2008) A peptoid "antibody surrogate" that antagonizes VEGF receptor 2 activity. J Am Chem Soc 130:5744-5752.

Valant C, Felder CC, Sexton PM, and Christopoulos A (2012a) Probe dependence in the allosteric modulation of a $\mathrm{G}$ protein-coupled receptor: implications for detection and validation of allosteric ligand effects. Mol Pharmacol 81:41-52.

Valant C, Gregory KJ, Hall NE, Scammells PJ, Lew MJ, Sexton PM, and Christopoulos A (2008) A novel mechanism of G protein-coupled receptor functional selectivity. Muscarinic partial agonist McN-A-343 as a bitopic orthosteric/allosteric ligand. J Biol Chem 283:29312-29321.

Valant C, Robert Lane J, Sexton PM, and Christopoulos A (2012b) The best of both worlds? Bitopic orthosteric/allosteric ligands of $\mathrm{g}$ protein-coupled receptors. Annu Rev Pharmacol Toxicol 52:153-178.

Vanderpool D, Johnson TO, Ping C, Bergqvist S, Alton G, Phonephaly S, Rui E, Luo C, Deng YL, and Grant S, et al. (2009) Characterization of the CHK1 allosteric inhibitor binding site. Biochemistry 48:9823-9830.

Van Giezen JJJ, Nilsson L, Berntsson P, Wissing B-M, Giordanetto F, Tomlinson W, and Greasley PJ (2009) Ticagrelor binds to human P2Y(12) independently from $\mathrm{ADP}$ but antagonizes $\mathrm{ADP}$-induced receptor signaling and platelet aggregation. $J$ Thromb Haemost 7:1556-1565.

Vargas E, Yarov-Yarovoy V, Khalili-Araghi F, Catterall WA, Klein ML, Tarek M, Lindahl E, Schulten K, Perozo E, and Bezanilla F, et al. (2012) An emerging consensus on voltage-dependent gating from computational modeling and molecular dynamics simulations. J Gen Physiol 140:587-594.

Venkatakrishnan AJ, Deupi X, Lebon G, Tate CG, Schertler GF, and Babu MM (2013) Molecular signatures of G-protein-coupled receptors. Nature 494:185-194.

Vernino S, Amador M, Luetje CW, Patrick J, and Dani JA (1992) Calcium modulation and high calcium permeability of neuronal nicotinic acetylcholine receptors. $\mathrm{Neu}$ ron 8:127-134. 
Vieth M, Higgs RE, Robertson DH, Shapiro M, Gragg EA, and Hemmerle H (2004) Kinomics-structural biology and chemogenomics of kinase inhibitors and targets. Biochim Biophys Acta 1697:243-257.

Vieth M, Sutherland JJ, Robertson DH, and Campbell RM (2005) Kinomics: characterizing the therapeutically validated kinase space. Drug Discov Today 10:839-846.

Voegel JJ, Heine MJ, Tini M, Vivat V, Chambon P, and Gronemeyer H (1998) The coactivator TIF2 contains three nuclear receptor-binding motifs and mediates transactivation through CBP binding-dependent and -independent pathways. EMBO J 17:507-519.

Wang X and Sun SY (2009) Enhancing mTOR-targeted cancer therapy. Expert Opin Ther Targets 13:1193-1203.

Wang Y, Chirgadze NY, Briggs SL, Khan S, Jensen EV, and Burris TP (2006) A second binding site for hydroxytamoxifen within the coactivator-binding groove of estrogen receptor beta. Proc Natl Acad Sci USA 103:9908-9911.

Weng Y, Yang L, Corringer PJ, and Sonner JM (2010) Anesthetic sensitivity of the Gloeobacter violaceus proton-gated ion channel. Anesth Analg 110:59-63.

Winterfield JR and Swartz KJ (2000) A hot spot for the interaction of gating modifier toxins with voltage-dependent ion channels. J Gen Physiol 116:637-644.

Wood ER, Truesdale AT, McDonald OB, Yuan D, Hassell A, Dickerson SH, Ellis B, Pennisi C, Horne E, and Lackey K, et al. (2004) A unique structure for epidermal growth factor receptor bound to GW572016 (Lapatinib): relationships among protein conformation, inhibitor off-rate, and receptor activity in tumor cells. Cancer Res 64:6652-6659.

Wootten D, Christopoulos A, and Sexton PM (2013) Emerging paradigms in GPCR allostery: implications for drug discovery. Nat Rev Drug Discov 12:630-644.

Wootten D, Simms J, Koole C, Woodman OL, Summers RJ, Christopoulos A, and Sexton PM (2011) Modulation of the glucagon-like peptide-1 receptor signaling by naturally occurring and synthetic flavonoids. J Pharmacol Exp Ther 336:540-550.

Wu H, Wang C, Gregory KJ, Han GW, Cho HP, Xia Y, Niswender CM, Katritch V, Meiler J, and Cherezov V, et al. (2014) Structure of a class C GPCR metabotropic glutamate receptor 1 bound to an allosteric modulator. Science 344:58-64.

Wu LJ, Sweet TB, and Clapham DE (2010a) International Union of Basic and Clinical Pharmacology. LXXVI. Current progress in the mammalian TRP ion channel family. Pharmacol Rev 62:381-404.
Wu Y, Yang Y, Ye S, and Jiang Y (2010b) Structure of the gating ring from the human large-conductance $\mathrm{Ca}(2+)$-gated $\mathrm{K}(+)$ channel. Nature 466:393-397.

Yang H, Rudge DG, Koos JD, Vaidialingam B, Yang HJ, and Pavletich NP (2013) mTOR kinase structure, mechanism and regulation. Nature 497:217-223.

Yarov-Yarovoy V, DeCaen PG, Westenbroek RE, Pan CY, Scheuer T, Baker D, and Catterall WA (2012) Structural basis for gating charge movement in the voltage sensor of a sodium channel. Proc Natl Acad Sci USA 109:E93-E102.

Yu FH and Catterall WA (2004) The VGL-chanome: a protein superfamily specialized for electrical signaling and ionic homeostasis. Sci STKE 2004:re15.

Yu Z, Klaasse E, Heitman LH, and Ijzerman AP (2014) Allosteric modulators of the hERG K(+) channel: radioligand binding assays reveal allosteric characteristics of dofetilide analogs. Toxicol Appl Pharmacol 274:78-86.

Yuan P, Leonetti MD, Pico AR, Hsiung Y, and MacKinnon R (2010) Structure of the human BK channel Ca2+-activation apparatus at 3.0 A resolution. Science $\mathbf{3 2 9}$ 182-186.

Zhang J, Adrián FJ, Jahnke W, Cowan-Jacob SW, Li AG, Iacob RE, Sim T, Powers J, Dierks C, and Sun F, et al. (2010) Targeting Bcr-Abl by combining allosteric with ATP-binding-site inhibitors. Nature 463:501-506.

Zhang J, Yang PL, and Gray NS (2009) Targeting cancer with small molecule kinase inhibitors. Nat Rev Cancer 9:28-39.

Zhang X, Gureasko J, Shen K, Cole PA, and Kuriyan J (2006) An allosteric mechanism for activation of the kinase domain of epidermal growth factor receptor. Cell 125:1137-1149.

Zhang X, Ren W, DeCaen P, Yan C, Tao X, Tang L, Wang J, Hasegawa K, Kumasaka $\mathrm{T}$, and $\mathrm{He} \mathrm{J}$, et al. (2012) Crystal structure of an orthologue of the $\mathrm{NaChBac}$ voltage-gated sodium channel. Nature 486:130-134.

Zimmermann I, Marabelli A, Bertozzi C, Sivilotti LG, and Dutzler R (2012) Inhibition of the prokaryotic pentameric ligand-gated ion channel ELIC by divalent cations. PLoS Biol 10:e1001429.

Zuccotto F, Ardini E, Casale E, and Angiolini M (2010) Through the "gatekeeper door": exploiting the active kinase conformation. J Med Chem 53:2681-2694.

Zweemer AJ, Nederpelt I, Vrieling H, Hafith S, Doornbos ML, de Vries H, Abt J Gross R, Stamos D, and Saunders J, et al. (2013) Multiple binding sites for smallmolecule antagonists at the CC chemokine receptor 2. Mol Pharmacol 84:551-561. 